\title{
Siv Skarstein
}

\section{Frequent use of over-the-counter analgesics}

\author{
among adolescents - a warning sign of troubled
}

\section{lives}

DISSERTATION FROM THE UNIVERSITY OF OSLO - 2018

\section{$\mathrm{UiO}$ : Faculty of Medicine}

University of Oslo

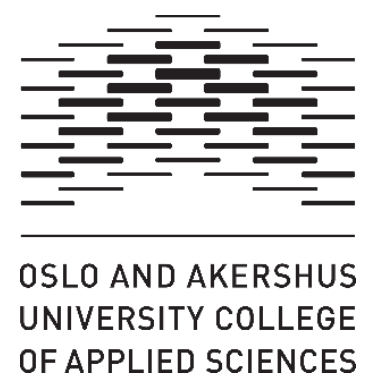


(C) Siv Skarstein, 2018

Series of dissertations submitted to the Faculty of Medicine, University of Oslo

\section{ISBN 978-82-8377-166-4}

All rights reserved. No part of this publication may be reproduced or transmitted, in any form or by any means, without permission.

Cover: Hanne Baadsgaard Utigard.

Print production: Reprosentralen, University of Oslo. 


\section{Abstrakt (norsk)}

Vi ønsket økt kunnskapen om ungdom som hyppig bruker reseptfrie smertestillende medisiner. Tre studier inngår, en kvantitativ studie og to kvalitative studier. I den kvantitative studien (studie 1) undersøkte vi 367 ungdommer mellom fjorten og femten år fra seks ungdomskoler De som brukte reseptfrie smertestillende daglig til ukentlig, høyforbrukerne, ble sammenlignet med de som brukte slik medisin sjeldnere eller aldri. Det viste seg at høyforbrukerne hadde mer smerter fra ulike deler av kroppen, sov mindre, hadde høyere skolefravær, inntok mer koffeinholdige drikker, hadde flere episoder med fyll, arbeidet mer i fritiden, hadde lavere ambisjoner for fremtidig utdanning og lavere selvtillit enn de andre ungdommene. For å få dypere innsikt i ungdommenes livsopplevelser ble det gjennomført kvalitative intervjuer. I den første studien (studie 2) intervjuet vi nitten høyforbrukende ungdommer mellom 14 og 16 år.Gjennom samtalene kom det frem at smerte reduserte ungdommenes evne til å håndtere dagliglivets utfordringer. Ungdommene følte seg ikke fornøyde med seg selv, sitt utseende eller egne prestasjoner. De strevde med å tilpasse seg for å oppnå tilhørighet og føle seg verdsatt. For å få ytterligere kunnskap intervjuet vi så åtte mødre til ungdommer som hadde deltatt i studie 2. Vi analyserte intervjuene som dyader bestående av mor og barn (studie 3). Stressende barndom og oppvekst med mangel på forutsigbarhet, langvarige familiekonflikter, hyppig skifte av bosted og alvorlige helse- eller rusproblemer i nær familie var fremtredende. Savnet etter et trygt og god vennskap sto sentralt, det samme var utryggheten ved konfliktsituasjoner mellom foreldrene. Mor syntes å være den primære omsorgspersonen, ofte uten støtte fra far eller øvrig familie. Ungdommene syntes å være psykososialt avhengige av sine mødre. Mødre hadde også betydelig innflytelse på ungdommenes daglige aktiviteter, vurdering av smerte, smertemestring herunder bruk av reseptfrie smertestillende medisiner. 


\section{Abstract (english)}

We aimed for better knowledge about adolescents who frequently use over-the-counter analgesics. Three studies, one quantitative study and two qualitative studies are conducted. In the quantitative study (study 1) we examined 367 fourteen and fifteen year olds from six junior high schools (study 1). Those who used over-the-counter analgesics daily to weekly, high consumers, were compared to those who used the medicine less often or never. It turned out that high consumers had more pain from different parts of the body, slept less, had higher school absenteeism, consumed more caffeinated drinks, had more episodes of binge drinking, worked more in their spare time, had lower ambitions for future education and also lower selfesteem, compared to those who rarely or never used non-prescription painkillers. In order to attain better knowledge of life experiences to high consuming adolescents we conducted qualitative interviews. Nineteen adolescents between the ages of 14 and 16 who used overthe-counter analgesics daily or several times a week were included (study 2). Analyzing the interviews revealed that pain reduced the young peoples’ ability to cope with everyday challenges. The adolescents did not feel satisfied with themselves, neither with their own appearance or their own achievements. They strived to adapt in order to be accepted among peers and to feel appreciated by others. To further gain a deeper insight into life experiences and development of identity in adolescents with high consumption of OTCA, we also interviewed eight of the mothers of youngsters who participated in study 2. We analyzed the interviews as dyads, consisting of mother and child. A stressful childhood and upbringing with lack of predictability, long-term family conflicts, frequent change of residence and serious health or drug problems in close family seem to have hampered development of a good quality of life in during adolescence. Missing a safe and good friendship was prominent, The mother seemed to be the primary caregiver, often without support from the father or other 
family members. Mothers had a significant influence on the youths' daily activities, assessment of pain, pain relief including the use of painkillers. 



\section{Forord}

Innledningsvis vil jeg takke ungdommene og mødrene som har bidratt i dette forskningsarbeidet. Dere har tatt delt erfaringer og refleksjoner som har gitt en utvidet forståelse og innsikt. På sikt kan nettopp deres bidrag føre til at fagfolk blir bedre rustet til å samarbeide med ungdom som sliter med smerter og som forsøker å mestre hverdagen ved å bruke reseptfrie smertestillende medisiner. Takk også til helsesøstre, rektorer og lærere som har tilrettelagt for forskingsprosjektet og rekruttering av deltagere.

Takk til Høgskolen i Oslo og Akershus som gav meg doktorgradstipend og dermed mulighet til å fordype meg i et forskningsfelt og en tematikk som jeg lenge har vært og er opptatt av.

Takk til medisinsk fakultet ved Universitetet i Oslo som tilrettela et lærerikt og spennende doktorgradsprogram og sørget for praktisk hjelp til gjennomføringen.

Tusen takk til mine veiledere; Sølvi Helseth, Per Lagerløv og Lisbeth Gravdal Kvarme. Dere har på hver deres enestående måte veiledet, støttet og trøstet meg gjennom arbeidet med doktorgraden. En spesiell takk til Sølvi som har vært hovedveileder. Du har delt av din kunnskap og dine erfaringer, du har utfordret meg faglig og samtidig støttet meg når veien har opplevdes bratt. Du har også innlemmet meg i andre forskningsprosjekter og forskningsformidling som har bidratt til min faglige vekst og personlige utvikling. Tusen takk kjære Per for raske tilbakemeldinger med presise og gode kommentarer. Takk for tålmodig undervisning og veiledning i bruk av statistisk metode. Takk for en «åpen dør», gode samtaler og oppmuntrende kort når det har røynet på. Det har jeg satt stor pris på. Takk til deg Lisbeth for din åpenhet og ydmykhet, for dine innsiktsfulle refleksjoner og faglige innspill. Takk til 
dere alle tre for at dere er faglig engasjerte og gjennom tiår har arbeidet for at barn og unge skal få det bedre.

Takk til gode kollegaer som bidrar med klokskap, kunnskap og humør. Takk til Tanja Holager, Elin Olaug Rosvold og Milada C. Småstuen for faglig innspill, råd og hjelp. Tusen takk til Marit Leegaard som er en målrettet motivator for videre forskningsaktiviteter og som tar seg tid til en god prat over en kaffekopp. Takk til ansatte ved Videreutdanningen og masterprogrammet i psykisk helse. Daglig gir dere meg ny kunnskap, utfordringer og inspirasjon. En spesiell takk til Torunn Erichsen som er og har vært en god venn, en diskusjonspartner og en kollegial støttespiller gjennom mange år. En stor takk også til Vidar Frigstad som jeg har hatt gleden av å samarbeide med først i regi av Norsk sykepleieforbund, deretter i forbindelse med utvikling av et undervisningsopplegg om barn og unges psykiske helse, samt et bidrag til en lærebok for lærerutdanningen om samme tematikk.

Avslutningsvis vil jeg takke mine barn Sara og Anders, min ektemann Steinar, øvrig familie og gode venner for kjærlighet, trygghet og samhold.

Oslo, 12 desember 2017

Siv Skarstein 


\section{Contents}

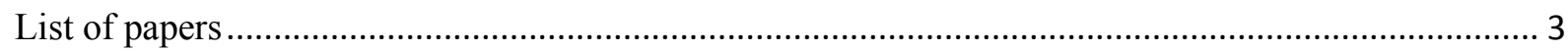

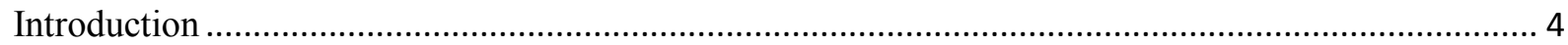

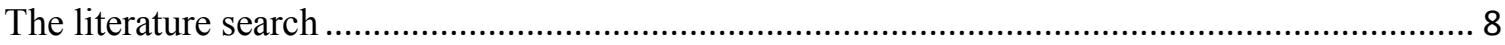

Aim

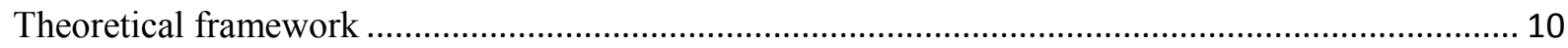

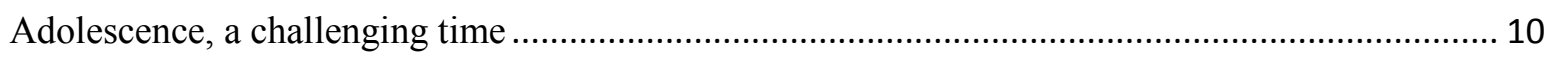

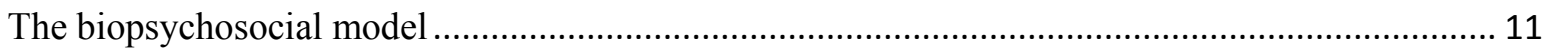

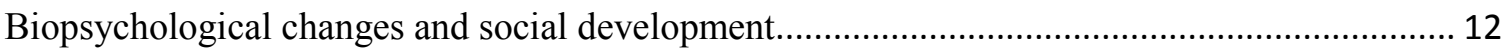

Pain

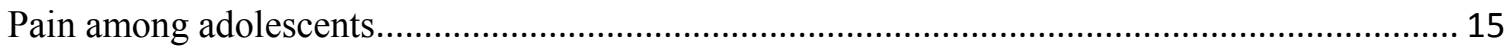

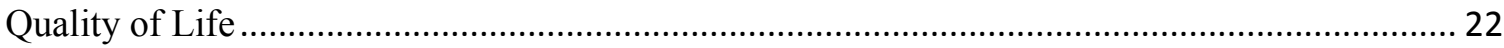

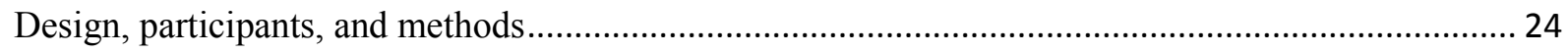

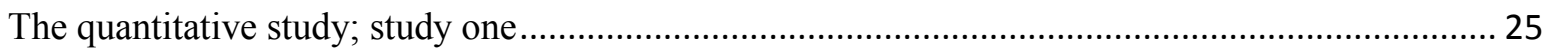

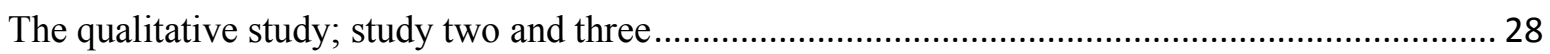

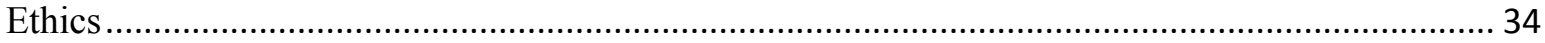

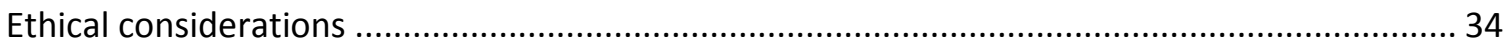

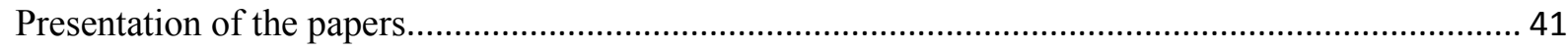

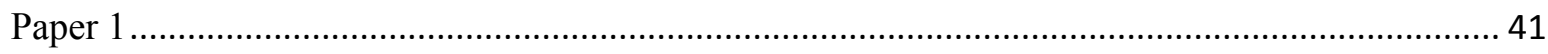

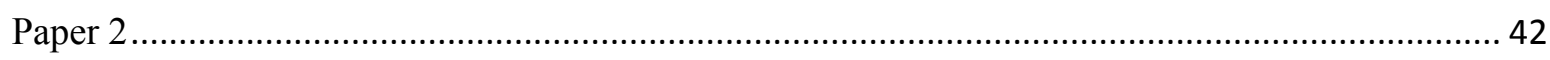

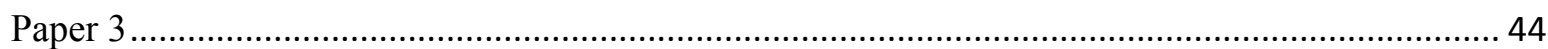

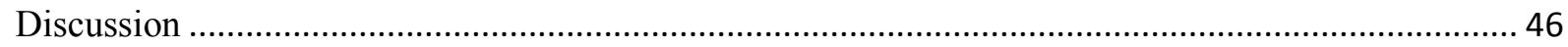


Methodological issues 46

Quality in quantitative research. 46

Quality in the qualitative research 51

Discussion of results. 59

Ethical experiences and reflections 77

Conclusion. 80

References 82

Appendix 1: The questionnaire for the quantitative cross-sectional study (study 1)

Appendix 2: The thematic interview guide for adolescents (study 2 and 3)

Appendix 3: The thematic interview guide for parents (study 3)

Appendix 4: The consents form for the quantitative study (study 1)

Appendix 5: The consent form for the qualitative study (study 2 and 3) 


\section{List of papers}

Skarstein, S., Rosvold, E. O., Helseth, S., Kvarme, L. G., Holager, T., Småstuen, M. C., Lagerløv, P. (). High-frequency use of over-the-counter analgesics among adolescents: reflections of an emerging difficult life, a cross-sectional study. Scandinavian journal of caring sciences, 2014. 28(1), 49-56.

Skarstein, S., Lagerløv P., Kvarme L.G., Helseth S. High use of over-the-counter analgesic; possible warnings of reduced quality of life in adolescents- a qualitative study. BMC nursing. 2016 Mar 3;15(1):1.

Skarstein, S., Lagerløv, P., Kvarme, L. G., Helseth, S. Pain management and development of identity in adolescents who frequently use of over-the-counter analgesics: a qualitative study. 2017. Under review: August 2018 


\section{Introduction}

Adolescence as a period of transition in human life, is filled with both excitement and challenges for the adolescents themselves as well as their caregivers. The changes that occur are biological, psychological, and social [1]. Development of identity is a major concern, and relationships with family and peers are important [2]. Psychosocial processes are involved in navigating increasingly complex and intimate relationships, which continue to develop throughout this stage of life. External stress might interact with increasing executive functions and heightened social sensitivity to influence some adolescent behaviours [1,3-5]. Childhood and adolescence as life phases have great significance for future health [6, 7]. A biopsychosocial understanding of human development and health is the fundament for the choice of theory in this thesis [8]. Three papers, representing three part studies, will be presented on the interaction between adolescents and non-prescriptive pain medication. The results will be discussed from a biopsychosocial perspective while considering theories of attachment, identity, social learning, stress, and Quality of Life [2, 9-12]. With the help of this rather extensive theoretical foundation, I hope to acquire new knowledge and deeper insight into the lives of adolescents with a frequent use of Over-The-Counter Analgesics (OTCAs).

OTCAs are analgesics sold to consumers without a prescription from healthcare professionals (generally medical doctors) as opposed to prescription drugs, sold only to consumers possessing a valid prescription. Many countries, Norway among them, regulate the sale of OTCAs through a national regulatory medicine agency to ensure that the ingredients are safe and effective when used without a physician's care [13]. Indications for use shall be recognisable by the consumer and the medication is intended for use over a limited duration. OTCAs were released for sale outside pharmacies in Norway in 2003, when a change in regulation allowed for the establishment of private pharmacies and sale of certain OTCAs in 
retail stores and gas stations [14]. This deregulation gave consumers in Norway easier access to OTCAs. Paracetamol (acetaminophen) and ibuprofen are now the most frequently used analgesics among children and adolescents [15]. Increased access to OTCAs, mainly paracetamol (acetaminophen) and ibuprofen, was expected to provide new opportunities for self-care. Concurrent with the deregulation, the use of OTCAs increased markedly. In Norway, in just six years, the proportion of daily and weekly users of OTCAs among 15 to 16 year olds increased from 5\% among boys and 14\% among girls to $26 \%$ for both genders [14, 16]. The same tendencies were found in Denmark and Sweden [17, 18]. Many adolescents consume large quantities of OTCAs. In Norway, one out of ten adolescents uses OTCAs daily, while $26 \%$ use the medication weekly [14]. If this consumption pattern is representative for Norwegian adolescents from 13 to 19 years of age, this indicates that about 45000 adolescents in Norway use OTCAs daily, while about 116000 use the medication on a daily to weekly basis $[14,19]$.

Self-administration of OTCAs starts early among adolescents [20], and most adolescents have access to OTCAs at home [20,21]. Adolescents use a wide array of medications and non-drug approaches to self-treat their pain, starting at the age of eleven [22]. A Swedish study found that young girls used twice as much medicine for pain and psychological problems compared to young boys [23]. Maternal self-medication with OTCAs influences the use of OTCAs among children [24]. However, many adolescents use analgesics without discussing the need and usage with an adult, and parents are often unaware of the quantities of OTCAs consumed by their adolescents [25]. Adolescents who report a frequent intake of OTCAs describe such medication as 'necessary, essential', and the majority of adolescents $(94.6 \%)$ are convinced that using analgesics is socially acceptable [26]. Most teenagers have a reasonable approach to the use of OTCAs, but some have attitudes that may be characterised as careless [27]. The 
latter group experiments with the dosage and has a habit of taking more tablets than recommended to maximise the effect or 'just to be sure'. Further, they combine different types of analgesic drugs and do not seem worried about any side effects; these behaviors cement a casual view of drug use [27]. Adolescents seem to be familiar with over-the-counter product names, but have limited knowledge of actual use of analgesics, such as the dosage, whether and how they should be combined with other drugs, and when such use may become hazardous [27]. Both parents and peers influence the adolescent's attitude to and use of OTCAs [21, 27]. Research revealed knowledge gaps among adolescents regarding the use of over-the-counter medicines [27]. Many teenagers may be poorly informed about type and content of medicine in the package and its effects on the body. However, the adolescents themselves consider their knowledge about OTCAs to be satisfactory [22, 27]. Moreover, according to the adolescents, they are the ones best suited to judge their own use of OTCAs $[22,27]$

It is evident that the use of OTCAs is associated with the experience of pain in adolescents, and in general, pain is the main indication for using OTCAs [17]. A study by Lagerløv et al. (2016) described different patterns of use among the adolescents in pain. The adolescents were grouped with respect to similarities in attitudes and management strategies to pain. The four following groups were described: 'pain is manageable', 'pain is communicable', 'pain is inevitable' and 'pain is all over'. The participants within each group differed in how they engaged their parents in pain; how they perceived, communicated and managed pain; and how they involved emotions and used OTCAs. There were some differences between the four groups in their use of OTCAs; however, the groups shared common attitudes to the medicines. Particular views on the low risks of using OTCAs could not be ascribed to any specific group [28]. Some adolescents frequently used OTCAs to alleviate stress and common 
health complaints; such frequent use may be a preferred way for some adolescents to deal with health problems [29]. These findings indicate that there may be good reasons for challenging the effect of OTCAs, such as paracetamol, for different kinds of pain [30].

Medication overuse, and subsequent medication-overuse headaches, are a growing problem worldwide; epidemiological data suggest that up to $4 \%$ of the population overuse analgesics and other drugs for the treatment of pain conditions such as migraines [31]. A continuous high consumption of OTCAs may give rise to health problems such as headaches and liver damage caused by medication overuse [31,32]. Long-term use of OTCAs can also lead to a worsening of headaches and cause a spiral of analgesic use and rebound headaches [33]. Overuse of analgesics strongly predicts chronic pain and specifically chronic pain associated with analgesic overuse 11 years later, especially among those with chronic migraines [34].

In a long-term perspective, the use of OTCAs early in life to alleviate pain and stress may prevent the users from developing better, healthier ways of coping with challenges, and may lead to a life-long use or abuse of medicine [35].

Adolescence is also known as a period in life suitable for interventions and where one is given opportunities to mitigate negative consequences of earlier developmental insults [36]. If greater effort is directed at improving life situations perceived by adolescents as painful and uncomfortable, the future need for OTCAs may be reduced [16]. However, current knowledge about adolescence and pain management does not give an explanation as to why some adolescents are using OTCAs to such a high extent. Based on this knowledge gap, the following two questions emerged: 
- Are there some identifiable characteristics in adolescents who use OTCAs to a high extent?

- What life experiences characterise adolescents with a frequent use of OTCAs?

\section{The literature search}

To increase knowledge about adolescents' use of OTCAs and to design the research studies, a structured literature search for information was conducted. The search for information was done several times; first while planning the study in 2011, then frequently throughout the period of the study, and lastly in February 2016. The first and last searches were done with support from a senior librarian. The searches were done through The Norwegian Electronic Health Library, a publicly funded online knowledge service for healthcare professionals and students in Norway. The search combinations included the search words (MeSH Terms): Adolescent and Non-Prescription (ed); added were also: 13-18 years. The searches revealed possible relevant and peer-reviewed papers about adolescents and their use of OTCAs. Some of the results from the different databases overlapped. After reading the titles, 45 possible relevant abstracts were identified. If an abstract was deemed relevant per the aim of this study, the whole article was read. Relevant articles were identified through this process, and they helped underpin the background and discussing the findings and results in this thesis.

The results from the literature searches showed that there was little research in this field, and what had been done was limited. We did not find research that clearly provided information on how to identify adolescents who used OTCAs on a daily to weekly basis (high-frequency users). In addition, no literature was available that dealt directly with life experiences of 
adolescents with a high consumption of OTCAs. Developing such knowledge is useful in identifying and supporting adolescents at risk for development of future health problems.

\section{Aim}

The overall aim of the study was to increase knowledge about adolescents with frequent use of OTCAs. To achieve this, a quantitative study (study 1) and two qualitative studies (studies 2 and 3) with the following main objectives were conducted:

1. To identify differences between adolescents who used OTCAs daily to weekly (highfrequency users), as compared to those who used less or no analgesics (low-frequency users), and to analyse the differences in pain experience, lifestyle, self-esteem, school attendance, and educational ambition.

2. To increase knowledge about life experiences of adolescents, from 14 to 16 years old, with a high consumption of OTCAs.

3. To achieve insight into pain management and development of identity in adolescents with frequent use of OTCAs, through the dyadic perspectives of adolescents and their mothers. 


\section{Theoretical framework}

In this section, physical, psychological, and social perspectives in adolescence will be highlighted through the biopsychosocial model [8] and the biobehavioural model of paediatric pain [12]. In this section, physical, psychological, and social perspectives in adolescence will be highlighted through the biopsychosocial model [8] and the biobehavioural model of paediatric pain [12]. Elements from theories and research on adolescence, pain, attachment, identity, social learning, stress and Quality of Life will be used to broaden our insight and understanding.

\section{Adolescence, a challenging time}

Adolescence is a period of great changes in life, and children are faced with potentially challenging physical, psychological, and social developments [37]. This stage in life is characterised by an increased need to regulate affect and behaviour in accordance with longterm goals and consequences, often at some distance from the adults who provided regulatory structure and guidance during childhood [3]. As the developing brain and behavioural and cognitive systems mature at different rates and under the control of biological processes, this period is often one of increased vulnerability and adjustment $[3,11]$. Normal development in adolescence requires coordination of emotional, intellectual, and behavioural proclivities and capabilities. Psychopathology in adolescence may reflect difficulties in this coordination process [3]. During adolescence, developmental effects related to puberty and brain development lead to new sets of behaviours and capacities, which enable transitions in family, peer, and educational domains, as well as in health behaviours [6]. Health in adolescence is the result of interactions between prenatal and early childhood development, the specific biological and social role changes that accompany puberty, shaped by social determinants and risk, and protective factors that affect health-related behaviours [6]. 
Gaps between emotion, cognition, and behaviour have important implications for our understanding of many aspects of both normal and atypical development during this period of life $[37,38]$. The physical changes that signal the start of adolescence occur alongside psychological and social changes, making this period a critical stage in becoming an adult $[2$, $4,39,40]$. Several models or theories identify adolescence as one of the periods of human development from birth to death. Most of these models are "stage" models, with each stage completed before the individual moves on to the next. Each model identifies a different set of "tasks" that define adolescence: Freud sees adolescence as a recapitulation of the development of sexual awareness in infancy [40]; Piaget sees the development of abstract thinking as enabling the transition to independent adult functioning [41, 42]; and Erikson [2, 4] identifies the tensions around the development of personal identity as central to the notion of adolescence. All of these models aim to give a broader understanding of human development, but mainly have a psychosocial focus. To expand our theoretical perspective, this thesis will try to understand high consumption of OTCAs among adolescents from a biopsychosocial basis [8]. The biopsychosocial model, including the biobehavioural model of paediatric pain, and perspectives on pain, attachment, identity, social learning, stress, and Health-Related Quality of Life (HRQOL) are used in the theoretical foundation. Erikson's theory of social learning is used in this thesis, as this theory postulates the ability to heal development impairments from earlier stages of life in later life and emphasises the importance of therapeutic intervention [2, 4].

\section{The biopsychosocial model}

For a broader perspective, the biopsychosocial model, especially as it has been developed further into the biopsychosocial approach, might be useful. [8]. The biopsychosocial model 
focuses on both disease and illness, with illness being viewed as the complex interaction of biological, psychological, and social factors [43, 44]. The model acknowledges that adolescence has biological (puberty and sexual development), as well as psychological and social, elements $[3,8]$. Both the model and the approach include adolescence as a part of a "system." The person's position in the system is determined by his or her relationships with different parts of the system and mediated by either external and internal demands or tasks. Internal physical and psychological changes interact with the external or social changes. The successful achievement and negotiation of the different tasks are thus interdependent, and each of them relies on the others taking place at the appropriate time. When these challenges intersect with health or illness, they might produce unique communication and management challenges, particularly around risk-taking behaviours and adherence to medical advice or regimens $[3,8]$.

\section{Biopsychological changes and social development}

Normal pubertal development is characterised by major physical alterations: sexual maturation, changes in body composition, and rapid skeletal growth [45]. Breast development is the first manifestation of puberty in approximately $85 \%$ of girls; the normal age for initial breast development is 8 to 13 years, and menarche generally occurs within 2 years of the onset of breast development, with a mean age of 12.8 years. In boys, the first manifestation of puberty is testicular enlargement; the normal age for initial signs of puberty is 9 to 14 years in males, and pubic hair in boys generally appears 18 to 24 months after the onset of testicular growth and is often conceived as the initial marker of sexual maturation in male adolescents $[45,46]$. Skeletal growth is one of the most striking characteristics of puberty, and lean body mass, which primarily reflects muscle mass, begins to increase during early puberty in both boys and girls [46]. Fat mass increases during the late stages of puberty in girls [46]. Sex 
differences in adolescent growth spurt produce the characteristic sexual dimorphism in shape and proportions seen in young adults [45-47].

Adolescence is a developmental stage of particular interest, with substantial neurostructural changes occurring, paralleled by environmental and biological changes that increase teenagers' exposure to social situations $[1,48]$. From an environmental perspective, social maturation is a function of increasing personal independence and peer-group interaction, as well as the heightened importance of friendships and relationships. Concurrently, the brain undergoes marked changes in areas that have been shown to underlie social cognition [49]. The physical changes are visible to both the adolescent and to the environment, and this might lead to new expectations and different demands. The physical growth may not correspond to the growth in personality, and gaining further knowledge about the psychosocial development may be of use.

In early adolescence, young people gradually begin to develop abstract thinking, which is the ability to use internal symbols or images to represent reality. This contrasts with the child's more concrete thinking, where objects represent "things" or "ideas" for solving problems [3]. Abstract thinking enables us to think hypothetically about the future and assess multiple outcomes. It is important to recognise the interactions of psychological development with puberty, particularly in the context of a developing sense of sexuality and body image. Body image and self-esteem are vulnerable to differences in the timing of puberty among peers and to the physical effects of chronic illnesses [3, 10, 50-53]. Adolescence is also described as an important period in the development of identity, in which independence is achieved [4]. Throughout adolescence, there is a change in the balance of independence and dependence with other parts of the adolescent's environment, including parents, peers, community, and 
teachers; even health professionals may play an important role [5]. The timing of these changes depends on the different social and cultural expectations from the environment in which the adolescents live [3-5]. As adolescents start to redefine themselves in relation to others, they begin to move into a position where they define other people in relation to themselves. This way of thinking about oneself may entail difficulties with understanding the impact of one's behaviour on others. Knowledge that has been "handed down" by adults is awarded little value and adolescents may strongly believe that no other person can have a clear understanding of a young person's feelings [3].

\section{Pain}

Gaining a common understanding and perception of pain as a concept is difficult, and arriving at an agreed-upon definition of pain has proved to be a challenge. What one individual considers painful may be rated as mild discomfort by another. The International Association for the Study of Pain (IASP) Task Force on Taxonomy [54] defined pain as: "an unpleasant sensory and emotional experience associated with actual or potential tissue damage or described in terms of such damage". They further stated, "Pain is always subjective. Each individual learns the application of the word through experiences related to injury in early life" [54 p. 209-14]. The first part of this definition clearly associates pain with tissue damage, implying a negative health outcome related to the pain. The latter part of the definition, however, alludes to sociocultural learning, thus acknowledging important sociocultural influences on the concept of pain. According to ISAP, pain unquestionably refers to a sensation in a part or parts of the body, but it is always unpleasant and therefore an emotional experience [54 p. 209-14]. Per ISAP`s definition, everybody is an expert on his or her pain, by virtue of biological preparedness and personal experience. This is supported by McCaffery's definition, which states that pain is what a person experiences and says is pain, and this 
should be accepted as pain [55]. One important point is that both definitions avoid tying pain to the stimulus. This means that psychological, social, cultural, and existential factors and past events may influence the experience of pain. Experiences, expectations, and coping strategies also influence sensitivity to pain; this underpins that a biopsychosocial understanding might be useful to gain a deeper understanding of adolescents with a frequent use of OTCAs [56].

\section{Pain among adolescents}

The literature shows that as much as $15 \%$ to $25 \%$ of adolescents suffer from recurrent or chronic pain conditions, and this is regarded as a significant public health problem [57-60]. Differences in pain prevalence may be caused by differences between studies according to age groups, recall periods, participation rates, or methodology [57]. Experiences of pain are also increasing among adolescents and are highly prevalent with significant increases in intensity related to levels of physical activity, number of pain sites, and gender [58,61]. Both national and international studies indicate that self-reported pain in children and adolescents increases with age $[57,58,61]$. The most common chronic pain conditions are those relating to the head, the stomach, or the musculoskeletal system $[57,59,61]$. In Norway, $60 \%$ of children and adolescents reported pain within the previous 3 months, and pain increased with age, with girls aged 16-18 years reporting the most pain [57]. The effect of pain on the adolescents' daily activities, such as school attendance, participation in hobbies, maintenance of social contacts, and sleep, is significant $[22,57,59]$. The costs of chronic pain among adolescents are found to be huge in terms of direct medical costs and productivity loss [62].

Pain problems can persist into adulthood and develop into chronic or persistent pain [63]. Children with recurrent headaches, abdominal pain, and other symptoms are at increased risk of developing chronic musculoskeletal pain in adulthood [64]. Pain in childhood can also 
result in short- and long-term physical and emotional problems for the children and their families, and is associated with social and psychological problems such as psychological distress, psychological vulnerability, and anxiety $[60,65]$. Family structures influence the relationship, indicating that family pain models and shared environmental factors are important to the origin of chronic pain [66]. However, studies on the level of agreement between children and their parents in rating pain have shown that parents often underestimate or overestimate pain in their children [67-69]. Explanations may include a lack of communication between children and their parents, reducing the parents' knowledge of and insight into their children's lives and experiences of pain $[57,70]$.

Sawyer (2005) presented a biobehavioural model for understanding paediatric pain. This model offers a broader understanding of the complexity of pain and how pain influences Health Related Quality of Life (HRQOL) [12]. Following this model, there are several reasons for experiencing pain and different aspects that intervene with an experience of pain.

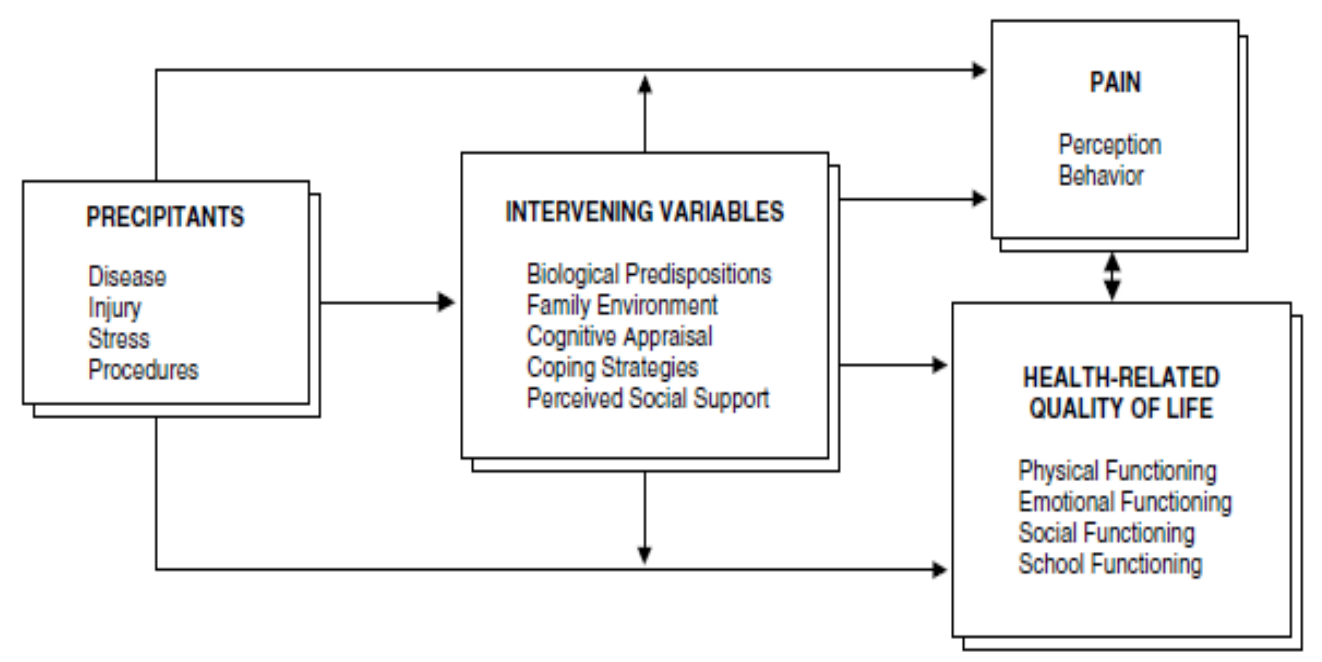

Biobehavioural model of paediatric pain, Sawyer et al 2005 [12]. 
According to this model, biological, psychological, and social experiences all play a role in the experience of pain [12]. This is also underpinned by other researchers $[56,71,72]$. To gain deeper and broader biopsychosocial understanding of the development of perception and behaviour in relation to pain, it might be of interest to investigate the development of some of the intervening variables, applying elements from the theories of attachment, identity, social learning and stress. Furthermore, it would be useful to gain insight into the aspects that might affect adolescents' experience of Quality of Life.

\section{Attachment}

Attachment theory is the work of John Bowlby and Mary Ainsworth [79, 80]. Bowlby revolutionised our thinking about the child's ties to its mother and the disruption of these ties through separation, deprivation, and bereavement [79]. Bowlby's major conclusion, grounded in the available empirical evidence, was that to grow mentally healthy, "the infant and young child should experience a warm, intimate, and continuous relationship with his or her mother (or permanent mother substitute) in which both find satisfaction and enjoyment" [80 p.13]. Bowlby also emphasises the role of social networks on economic as well as health factors in the development of well-functioning mother-child relationships [79]. Mary Ainsworth's methodology made it possible to test some of Bowlby's ideas empirically and expand the theory [79]. Ainsworth contributed the concept of the attachment figure as a secure base from which an infant can explore the world. She formulated the concept of maternal sensitivity to infant signals and its role in the development of infant-mother attachment patterns [79]. According to attachment theory, the first years of life might be of great importance to a human being's socialisation and experiences of being safe and valued. Through attachment, children learn how to adapt to be included and accepted. Mary Ainsworth [9] applied the term 
'socialisation' to describe the process through which a child becomes as social being. She pointed out that the development of the attachment relationship between an infant and its mother in the first year of life has a strong influence on the socialising of an individual in a lifetime perspective. This implies that a child is not initially a social being, but only gradually becomes so [9]. Attachment in adolescence has a broad and substantial connection to adolescents' functioning in several major social relationships beyond the mother-child relationship, and to the development of symptoms of psychosocial dysfunction during early adolescence. Security in adolescence has been conceptualised as integrally tied to the capacity to maintain a sense of relatedness while pursuing autonomy negotiations with important others and to develop emotion regulation capabilities to support this process [81]. Attachment insecurity in childhood is found to be linked to higher levels of depressive symptoms during adolescence, to a trend toward higher externalising symptoms at age 13, and to a significant pattern of increasing levels of externalised symptoms during early adolescence, as well as to multiple patterns of dysfunctions [82]. Attachment security reflects the individual's fundamental orientation toward the cognitive and affective processing of highly emotionally charged situations and toward emotion regulation capacities in general [83]. Furthermore, it is linked not simply to relational markers, but also to long-term patterns of psychological function and dysfunction. In might be that by adolescence, such insecurity has sufficiently distorted an increasing number of critical relationships so that clear links to psychopathology begin to emerge [84].

\section{Identity}

Erik H. Erikson $[2,4,85,86]$ claims that a person's fidelity and identity are shaped during adolescence, and questioning of the self, such as "Who am I", "How do I fit in", and "Where am I going in my life?", become important issues. Identity can be defined as a concept that 
includes self-esteem, self-worth, and self-respect $[10,87]$. Self-esteem in adolescence is multidimensional in structure, influenced by a complex, interdependent array of individual and contextual factors, and linked bidirectionally to adjustment outcomes in ways that can both promote and hinder overall development [88]. Identity formation is the main psychosocial task of adolescence and evolves from an intertwining of individual, societal, cultural, and historical experiences $[2,89]$. Identity grows from the resolution of earlier psychosocial stages, and provides a basis for psychosocial development in adulthood $[2,4,85$, 86]. An individual who successfully advances in the task of identity formation anticipates likely future roles the self may adopt. Furthermore, such an individual perceives the self's sameness and continuity in time and space. It has knowledge that the self's sameness and continuity is recognised by others. This individual also perceives that this self is recognised and valued by the social environment $[2,4,89]$. Erikson believed that the parents' influence was important for this development and pointed out that if parents let the child explore, the child would conclude its own identity. If the parents continually pushed the adolescent to confirm the parents' own views, the adolescent might go into "identity confusion". Erikson also claimed that personality is shaped over the entire life span, which implies that experiences later in life can heal or ameliorate problems in early childhood. On the other hand, he also pointed out that early life experiences might cause stress later in life. James Marcia's research on identity statuses of adolescents applies to Erikson's framework of identity crises in adolescents [90, 91]. Marcia characterised Erikson's ego identity statuses by the following four terms: the identity diffusion status, the identity foreclosure status, the identity moratorium status, and the identity achievement status [5]. In this operationalisation of Erikson's theory, identity formation is argued to occur through two processes of exploration and commitment that yield the four identity statuses. Adolescents that have succeeded in identity achievement are characterised by high exploration and high commitment to an 
identity, whereas moratorium adolescents have also explored but have not made identity commitments $[5,86,91]$. Both foreclosed and diffused adolescents are characterised by low exploration; however, foreclosed individuals have made a commitment to an identity and diffused individuals have not [86]. Throughout adolescence, there is a change in the balance of independence and dependence with other parts of the adolescents' environments.

Furthermore, the adolescents are exploring and trying to commit to important aspects of their identity $[4,91,92]$. Secure attachments to one's parents might buffer emotional distress, facilitate social competence, and enhance self-esteem [87].

\section{Social learning}

Albert Bandura $[10,50,93]$ developed the theory of social learning, later called social cognitive theory. This theory provides a unified theoretical framework for analysing human thought and behaviour. The theory outlines how behaviour is learned and modified by experience, and highlights social behaviour as a continuous interaction among cognitive, behavioural, and environmental factors [10]. Bandura points out that actions and behaviour are influenced by expectations of the outcome, of efficacy, and of interpretation of the consequences of actions. According to social cognitive theory, people exercise control because they expect to gain benefits [10]. Albert Bandura [93] defined self-efficacy as one's belief in one's ability to succeed in specific situations. One's sense of self-efficacy can play a major role in how one approaches goals, tasks, and challenges [50]. Bandura's social cognitive theory emphasises the role of observational learning and social experience in personality development [10]. A high level of self-efficacy is related to positive emotions and effective problem solving [10,93]. Self-efficacy influences cognitive development and psychobiological functioning [50,93]. Furthermore, self-efficacy plays an important role in coping, including coping with pain [51]. People learn coping strategies through observation, 
imitation, and modelling [94]. Coping strategies have been defined by Lazarus and Folkman (1984) as a set of behavioural and cognitive responses that are designed to master, tolerate, or reduce the demands of a stressful situation $[95,96]$. The ability to cope effectively with stress such as pain, pressure, and expectations has been viewed as a crucial component of resilience among children and adolescents, and important in influencing patterns of positive growth and development [97]. According to Badura (1987), self-efficacy has a significant influence on pain experience. Further, having strategies for coping with pain increased pain self-efficacy and gave a feeling of being able to control the painful situation [51]. In an experiment where the participants were told how to react to the electric shocks that would be given, the participants reported much less pain than when they were told that they could do nothing to avoid the pain [98]. Regardless of the conditions, the stronger the perceived self-efficacy to withstand pain was, the longer the subjects could endure mounting pain stimulation. The attenuation of the impact of pain stimulation through cognitive control is mediated by both opioid and non-opioid mechanisms [51].

\section{Stress}

Stress can be defined as a relationship between the person and the environment that is appraised as personally significant and as demanding or exceeding existing resources for coping [95]. Allostasis is a biological response that promotes adaptation to stress by using systemic mediators, such as sympathetic and parasympathetic activity, cortisol, pro- and antiinflammatory cytokine, and metabolic mediators that interact with each other [11]. Allostatic overload is the cumulative wear and tear on the body's systems after prolonged or poorly regulated allostatic responses [99]. Sustained stress, such as a difficult family situation, promotes the release of inflammatory cytokines and induces resistance to cortisol [100]. Cortisol is the main glucocorticoid in humans and is produced in the adrenal cortex. Cortisol 
inhibits the immune system by reducing immunological responses and this is used in the treatment of some illnesses. Inadequate amounts as well as too much cortisol can cause illness [71]. OTCAs work by inhibiting the effects of some cytokines; for instance, they inhibit the production of prostaglandins. In this perspective, OTCAs might influence the feeling of stress. According to the theory of stress and allostatic load, adverse childhood experiences may give bodily symptoms such as pain and increased sensitivity to pain. Furthermore, allostatic load is associated with reduced health later in life [101].

\section{Quality of Life}

The concept of Quality of Life (QOL) is commonly used as an outcome and evaluation criterion in the fields of public health and nursing $[102,103]$. The concept has its academic roots in the disciplines of psychology and sociology. Quality of Life is a subjective phenomenon and a normative concept based on the individual's beliefs, expectations, and goals. Moreover, it is a multidimensional concept which includes physical, psychological, social, and existential dimensions of life [103]. Næss (2001) defines Quality of Life as psychological well-being. Defined as psychological well-being, Quality of Life implies that a person's well-being is sensitive to the effects of life events that are either positive or negative $[104,105]$. This is in line with Ferrans $(2005)$, who uses the term Quality of Life to mean "a person's sense of well-being that stems from satisfaction or dissatisfaction with the areas of life that are important to him/her" [102 p. 15]. Quality of Life is a concept comprised of four domains: health and functioning, social and economic, psychological (spiritual), and family. The degree of satisfaction in these dimensions will constitute a person's subjective experience of Quality of Life [102]. When a broader definition of health was suggested by the World Health Organization (WHO), the healthcare disciplines became interested in the Quality of Life concept [106]. The WHO defines health as "a state of complete physical, mental and 
social well-being, not merely the absence of disease" [107]. A multidimensional healthoriented concept named Health-related Quality of Life (HRQOL) has been implemented as a part of quality of life [102]. Health-related Quality of Life is defined as "a personal, evaluative statement summarising the positivity and negativity of attributes that characterise one`s psychological, physical, social and spiritual well-being at a point in time when health, illness, and treatment conditions are relevant" [108 p. 301]. However, the distinctions between quality of life and Health-related Quality of Life are fluid, as each component in quality of life can be health-related [102, 135]. As mentioned earlier, adolescence involves important changes which can be physical, psychological and/or social, and which might influence overall health-related quality of life. Research has shown that in the general population, adolescents rate their own health-related quality of life lower than younger children [109]. The subjective sense of satisfaction or dissatisfaction with one`s body was an important predictor for health-related quality of life. In addition, pain and being bullied are found to affect health-related quality of life negatively [110]. A study by Merlijn et al. (2006) showed that children with chronic pain experienced significantly poorer quality of life compared with children with no pain [115]. Several other studies have also shown that health issues and pain have a strong impact on quality of life [111-114]. A study on chronic pain among adolescents showed that the greater the intensity and frequency of pain, the lower the self-reported quality of life [114]. An interplay among expectation, adaptation, and self-report of well-being has been demonstrated with pain and overall quality of life [116]. However, neither quality of life nor health-related quality of life should be considered as uniform concepts and one must consider how the various definitions fit the purpose of a research study and how they can be used. 


\section{Design, participants, and methods}

The overall aim of the thesis was to increase knowledge about adolescents with a high consumption of OTCAs. This aim was addressed in the following studies:

\section{The quantitative study (study 1)}

- Paper 1: High-frequency use of over-the-counter analgesics among adolescents: reflections of an emerging difficult life, a cross-sectional study. This paper was based on a cross-sectional questionnaire study. 367 (58.6\%) of 626 registered tenth grade students in a medium sized Norwegian town, 15-16 years of age, were included.

\section{The qualitative study (study 2 and 3)}

- Paper 2: High use of over-the-counter analgesics: possible warnings of reduced quality of life in adolescents - a qualitative study. This paper was based on a qualitative study with individual in-depth interviews. The participants were 19 adolescents, 14 -16 years of age, having used OTCAs on a daily-to-weekly schedule for at least four continuous weeks within the last year.

- Paper 3: Pain management and development of identity in adolescents who frequently use of over-the-counter analgesics: a qualitative study. This paper was based on a qualitative study including eight of the in-depth interviews with adolescents participating in study 2. Further, these adolescents' mothers were interviewed. The eight interviews with adolescents from study 2 were reanalysed according to the aim of study 3. The adolescents' and their mothers' interviews were analysed as dyads. 


\section{The quantitative study; study one}

Study 1 is a cross-sectional questionnaire-based study in which we aimed to identify characteristics of adolescents who used OTCAs on a daily to weekly basis (high-frequency users). We further aimed to uncover possible differences in pain, lifestyle, self-esteem, school attendance, and educational ambition between high and low/no frequency users. A quantitative method with a cross-sectional questionnaire-based study was deemed suitable to achieve our aim.

The questionnaire used in this study was developed through a three-step process. The first step was to gather information about young people and their everyday lives through meetings with resource persons (school nurses, leaders of youth clubs and after-school care, child welfare and crime prevention) in a district in central Oslo . Meetings were held with teachers in ninth and tenth grade from two secondary schools in the same district. Based on these discussions an interview guide was designed to gather first-hand information on the adolescents' experiences. The second step included four focus group interviews with a total of 29 youths in eighth to tenth grade, two groups of boys and two groups of girls [190]. The teachers at the two schools invited the students to participate, and obtained the needed consent from the students and their guardians. The interviews were recorded and analysed using qualitative methodology. Based on this and with literature from other studies, the questionnaire was designed. The third step was to test the questionnaire in a pilot with everyone present in two tenth grade classes at each of the two schools. This resulted in minor adjustments.

The questionnaire (appendix 1) contained 65 questions with sub-questions, with one or more predetermined answer choices to cross out. The questionnaire covered the use of OTCAs, pain 
experience, sociodemographic and lifestyle factors, self-efficacy, school absence, and future educational plans. The Norwegian short version of Rosenberg's Scale of Self-esteem, already used in another Norwegian study, was used to measure the adolescents' self-esteem [117119]. The questionnaire was complemented with a colour picture of the packages of the most commonly used OTCAs.

A study protocol including the questionnaire and the consent form was developed. The Regional Committees for Medical and Health Research Ethics (REC) in Norway approved the study protocol in the beginning of 2007, project number: 2.2006 .2650 . The study was registered with the Norwegian Data Inspectorate.

The Drammen Municipality in southern Norway was chosen as the study location as sales data for analgesics and antipyretics for Buskerud County were close to the national average [120]. The study took place in the ninth and tenth grades in six secondary schools.

Participation was voluntary and required written, informed consent from the students and their guardians. Contact with the six secondary schools in Drammen was established through school nurses at a local meeting. The schools' rectors were informed about the study by an official from Drammen Municipality and later by nurses at the various schools. On behalf of each school, the rector and tenth grade teachers were invited to participate and were consulted regarding practical implementation. All schools agreed to participate. The Buskerud County Physician was informed about the study. Tenth grade teachers assumed responsibility for the distribution and collection of consent forms from students and their guardians. Consent was obtained one month before the survey took place. Teachers collected the signed consent forms. 
The surveys were conducted during two weeks in March 2007, one day at each of the six secondary schools. All classes participated in each school. Two of the project members were present in class with teachers and attended to the distribution and collection of questionnaires. They were also available to students to answer questions about ambiguities. In some classes, assistant teachers were available to students in need of assistance.

At the six secondary schools in Drammen, 367 (58.6\%) of 626 registered tenth grade students participated in the survey. Students absent from school the day in question were not registered. There was no statistical association between response rates at the schools and the percentage of students who had taken painkillers.

My contribution to this study was to analyse the characteristics of adolescents with high consumption of OTCAs, and by logistic regression to identify risk factors associated with high use of OTCAs.

In the analysis we used fitted multiple logistic regression models to control for possible confounders. The dependent (outcome) variable was 'high use' (daily to weekly use during the last 4 weeks) versus 'no or low use' (no use or use less than weekly during the last 4 weeks). The independent variables were gender, perceived family economic state, pain in three or more body parts, sleep, absence from school, paid spare-time work, future educational plans, binge drinking, daily caffeine intake, and self-esteem. Self-esteem was measured using the Norwegian short version of Rosenberg Self-Esteem Scale, which is a 5 items questionnaire measuring global self-esteem on a 4-point Likert scale, ranging from $0=$ strongly disagree to 3 = strongly agree. The sum score in the present study ranged from zero to 30 , a higher sum score indicating higher self-esteem $[117,118]$. The results were 
presented as odds ratios (OR), with $95 \%$ confidence intervals. Data were described as proportions/percentages and crude differences between pairs of categorical variables were assessed with chi-square tests.

Values were missing for $<5 \%$ of all questions, so we did not perform any imputations of missing data. All analyses were conducted using SPSS version 18 (Oslo, Norway). Students absent from school the day in question were not registered.

\section{The qualitative study; study two and three}

The qualitative study includes study 2 and 3 . Through these studies, we aimed to increase knowledge about life experiences of adolescents with high consumption of over-the-counter analgesics.

In study 2, we aimed to increase knowledge about the adolescents life experiences through the adolescents' own perspectives. In study 3 , we aimed to achieve deeper insight into the adolescents life experiences and their development of identity, by comparing the dyadic perspectives of adolescents and their mothers.

A qualitative design, with individual face-to-face, in-depth interviews, was planned and conduced, this in order to provide new knowledge, insights, and representations about adolescents with a high consumption of OTCAs.

Five experienced school nurses were engaged in a resource group supporting the research group with their experiences with supporting adolescents in planning study 2 and 3 . This group had regular meetings with the main author of the three papers (SS) during the planning 
phase. In collaboration, the resource group and the research group developed information material and two thematic interview guides, one for adolescents and one for mothers [appendix 2 and 3].

The interview guides address the adolescents' life history, upbringing and family life, OTCA use, pain, stress, coping, peer relations, eating habits, sleep, activities, and important life events and future educational plans. The adolescents' interview guide also included questions about self-harming and suicidality.

Eligible participants in study 2 were students from 14 to 16 years of age using OTCAs on a daily-to-weekly schedule for at least four continuous weeks within the last year. Three adolescents were excluded, two due to chronic illness that could give rise to a need for OTCAs, one because signed consent from parents was missing.

Both in study 2 and 3, the participants constitute a convenience sample based on participant self-selection. The adolescents themselves recruited their mothers. Those who wanted to participate contacted the researcher. Participants were required to be able to read and understand the Norwegian language. Exclusion criteria for the adolescents were having a medical diagnosis of illness or injury requiring extended use of OTCAs within the last year. Adolescents from five schools, representing three urban and two sub-urban schools were included.

Twenty randomly selected schools in southern Norway, representing urban, sub-urban, and rural areas, were invited by contacting the rectors by phone. Rectors of ten schools, five in urban, three in sub-urban areas and two in rural areas, gave written consent to inform and 
recruit adolescents in their schools. The researchers and author of this thesis (SS) visited the ten schools and gave a 15-minute presentation of the project to all classes in ninth and tenth grades, a total of 52 classes with an average of 25 students in each. Two weeks before the information meetings took place, the school nurses hung up information posters in the classrooms and outside their offices. In information meetings, the adolescents were given written information about the project, including a study information package with a combined bookmark/ruler that contained brief information about the study and the researchers' contact information. This information package also included information to the parents and a request for parents to participate. Adolescents and parents who wanted to participate contacted the researcher (SS) by telephone.

Interviews were carried out from September 2013 to March 2014. Participants were recruited and interviewed until we were confident that no new themes emerged and saturation was achieved [123]. One researcher (SS) conducted the one-on-one interviews, lasting approximately one hour, at an office at the adolescents' schools or at an office at the researcher's work place. The interview guides were used as guidance; however, participants were as far as possible given the opportunity to steer the conversation so that their stories and experiences appeared spontaneously $[121,122]$.

The interviews were recorded and transcribed verbatim. The transcription was done partly by one of the researchers (SS), and partly by a professional. Both audio files and transcripts were saved within the programme NVIVO 10 [124]. This made it possible to read the transcript and listen to the voices at the same time. While reading the transcripts it became clear that both adolescents and their mothers were focused, well prepared, and willing to tell their stories and share their life experiences. 
The research group consisted of a general practice physician, two public health nurses, and a psychiatric nurse working together in the analytical process. Three of the group members were experienced qualitative researchers. Dependent on positions and perspectives, the members of the research group contributed with different viewpoints on raw data, but arrived at a consensus for meaningful units and interpretations.

A hermeneutic approach to analysis was chosen, involving an interpretive circular process of moving back and forth between the stories and the interpretations [125]. In the analytical process, the researcher (SS) listened to audio recordings, and read and reread the transcripts. The analysis was done by using in Kvale`s three contexts: self-understanding, common sense, and theory [126], which are illustrated in the method sections of paper 2 and 3.

In study 2 , in the first context, the transcribed interviews were read by all the researchers and summarised in a condensed form by the main author. The researchers identified broad categories that emerged from the data, such as: family life and childhood, friendship, school life, about myself, pain, health, use of OTCAs, important life events, support from professionals, quality of life, health, self-harming and suicidal tendencies. All interviews were then reread. Meaningful units and categories of interpretations were identified using descriptive terminology, for example: 'family and childhood'. The second step involved interpreting the meaning of these findings by asking questions such as: 'What does this tell us about the adolescent's family life and childhood, the significance of family life and friendships, and the significance of family and childhood to the use of OTCAs?" During the interpretation patterns emerged, and they formed the basis for the presentation of our findings. The findings are presented descriptively and illustrated by quotes both in paper 2 and 3 . 
Study 3 had 16 participants. Eight of the interviews with adolescents from study 2 were reanalysed together with interviews of these adolescents' mothers. In this study we used a dyadic analysis, useful in deriving themes in couple relationships [127]. The interviews with adolescents from study 2 were reanalysed together with interviews with their respective mothers. We focused on the similarities and differences between the coupled interviews, and searched for meaningful units and interpretations in the text on the descriptive and interpretive level [127]. The researchers read and reread the transcripts and organized the quotes, first for each of the participants, then for pairs of mothers and adolescents. The adolescents' quotes were organized into the following categories: about myself, about OTCAs, about pain and health, about my mother, about my father, about healthcare support. The mothers' quotes were organized into the following categories: about my child, about the use of OTCAs, about pain and health, about myself, about the adolescent's father, about healthcare support. The quotes and stories were subsequently analysed as dyads; one dyad included one adolescent and his or her mother. Each of the researchers analysed two or three dyads and presented their findings of meaning and interpretations in the research group. Similarities and differences were then discussed. After analysing the eight dyads, the meaningful units and interpretations were compared to the whole material and discussed. The interpretations evolved through an iterative process, moving back and forth from parts of the text to the text as a whole, then back again [128]. In critical understanding, the researchers used common sense and a critical perspective to interpret and comment upon what the participants expressed. The results are presented descriptively and illustrated as dyadic quotes in paper 3.

In the analysis process consensus among the researchers was usually reached for the majority of the meaningful units and interpretations. When doubt or disagreement arose, the 
researchers returned to the data and reassessed the meaning of the participant's expressions, bringing these into new discussions. Through this repetitive process, a broader and deeper understanding arose.

Both in study 2 and in study 3 the third level of analysis concerned theoretical understanding [129]. On this level, the findings were interpreted and discussed in light of knowledge and theories also presented earlier in this thesis. In study 2, the theoretical perspectives of biopsychosocial understanding [12] including elements from theories on attachment [9), social cognitive theory [10], pain and stress $[7,11]$ and quality of life [12] were used to interpret the results. In study three the theories of identity [8,] attachment [9] and social cognitive theory [10] were used in the analysis on Kvale's level of theoretical understanding [129]. 


\section{Ethics}

A study protocol, including an information package for adolescents and parents, a consent form, and the two interview guides were developed. The Regional Committees for Medical and Health Research Ethics (REK) [192] in Norway, approved the study protocols for study 2 and 3, in autumn 2012, study number: 2012/1460a.

Data and material from the study will be kept in the Department of Nursing, Oslo and Akershus University College of Applied Sciences, Oslo, Norway until 2018. The ethical principles highlighted in the Declaration of Helsinki were followed [191]. Participation was voluntary and required written informed consent. For participants younger than 16 years of age, written informed consent from their guardians (main caregiver) was required.

In each school, the school nurse was informed about the study and was prepared to support adolescents at any health risk. By signing a consent form, the adolescents also agreed to consult the school nurse if the interviewer deemed it necessary. The participants were informed that they were free to withdraw from the project at any time.

\section{Ethical considerations}

"One of the most fundamental ethical principles in research is that of beneficence, which impose a duty on researchers to minimise harm and maximise benefits. Human research should be intended to produce benefits for participants themselves or - a situation that is more common - for other individuals or society as a whole. This principle covers multiple dimensions." (125) 
The Declaration of Helsinki states that a child' s perspective about his or her own life is equally important to an adult's perspective. Their right to participate and influence their lives are stated both in Norwegian law and in the Unites Nation's Convention on the Rights of the Child (UN) [193]. However, involving adolescents in research requires special attention to their vulnerability $[141,193]$. Therefore, our research group thoroughly assessed the necessity for this research and the risks involved. Nontherapeutic research like our studies should not increase the risk that an informant normally encounters in their everyday life. From our findings in the initial quantitative study (study 1), we assumed that adolescents participating in the qualitative study might have reduced self-esteem and be vulnerable. Therefore, the school health nurse at each school had to sign a statement that stated their responsibility for supporting participating adolescents if the researcher detected health-threatening conditions during the interview.

To give all the adolescents who received information about our research opportunity to discuss their own pain problems and use of OTCAs, even if they did not participate, teachers and school health nurses attended the class-based information meetings and offered support. In order to ensure that participating adolescents truly wanted their parents to participate in the qualitative study, the researchers made a recruitment strategy where the adolescents themselves invited their parents to participate. An information packet, including a consent form [appendix 4: The consents form for the quantitative study - study 1), appendix 5: The consent form for the qualitative study (study 2 and 3)], was given to all the adolescents participating in information meetings. According the qualitative study the adolescents who wanted their parents to participate in the study brought the information back home. If the parents wanted to participate, they had to sign the same consent form as the adolescents. Adolescents below the age of 16 needed written, informed consent from their parents. In 
Norway, this type of parental consent is statutory and we also believed this was important to ensure the interests of youth

The researchers were aware that some participants might regret what they had said or even on their participation. Therefore, the participants in our studies were informed both in writing and orally about the right to withdraw without risking any repercussions. This was stated in the signed consent forms. The researchers also made it clear that participants had access to the information that was registered about them and that they could correct any errors in this information. This was also explained instead in the informed consent. None of the participants used any of these options.

Even though the participants were informed both orally and in writing informed that their statements would be used to fulfil the study's aim. The fact that they might not fully grasp the possible consequences of their participation was present. Initially, the research group considered that there was a very low risk that the methods in use could harm the participants. However, since the participants in the qualitative study (study 2 and 3) were interviewed individually, they could potentially risk exposing themselves more than they felt was comfortable. This could happen either consciously or subconsciously. We also considered that this method could lead to adverse effects, for example in terms of integrity violations. For these reasons, the researcher was acutely aware of the responsibility for taking care of the participants.

Qualitative interviews can create an emotional link between the researcher and the research participants. The researcher may expect the informant to be forthcoming and helpful, and the informant may also feel obliged to be helpful. It is also important that the interviewees have 
opportunities to express themselves. There must therefore be an openness for expression as well as an emotional availability during the interviews. We discussed this thoroughly in the research group and agreed that the researcher who conducted the interviews would receive guidance from the main supervisor.

The researcher's interest for the adolescent and his or her pain and pain management can be perceived as positive attention. The interview situation may give the participants an experience of sharing very private issues with an important person who meets them with interest, understanding and acknowledgement.

When participants were given a chance to reflect on the different themes they may have discovered meaningful insights about their situation. However, it could also result in feelings of sadness and sorrow. Therefore, we made every effort to take any reservations they expressed seriously, and not to abuse the trust that had been placed in us as researchers. In the interviews, the researcher focused on signs of discomfort or unease in the informant. If it was observed that a topic was sensitive or distressing, the interviewer avoided pushing so as not to put the informant in a painful situation. At the end of each interview, the researcher questioned the participant about how he or she felt, and if something should be added or done differently.

The researchers considered it important to ensure privacy for the participants. Some of the information shared with the researchers was considered highly private and intimate, and the interviews was therefore anonymised through codes. Privacy was also a large factor in the recruitment of the adolescents. On request from REC, the recruitment procedure in the 
qualitative study (study 2 and 3), was changed. Those who considered participating directly contacted the researchers, instead of being recruited by the school health nurses.

In the qualitative study (study 2 and 3), we used quotes to illustrate our findings. However, we were worried that the participants recognising their own quotes. This was especially apparent in study 3 , because the quotes had to be presented as pairs (adolescents and their mother) to illustrate the findings. For this reason, we did not mark the quotes with the gender of the adolescent presenting the results from study 3 . The research group considered anonymization more important than the need to specify gender, especially because the aim of the study 3 was not to impose specific relationships related to gender identity.

Using quotes to illustrate our points was challenging when the participants spoke Norwegian and the findings were to be presented in English. To get the most accurate translation, we used a seventeen year old Norwegian-English girl to translate the adolescents' quotes, and a Norwegian-English mother to translate the mothers' quotes. In the submitted material, quotes from the interviews are translated into English and published no earlier than two years after the interviews took place. We assumed this would reduce the possibility of the participants recognising what they had said.

When presenting the results from study 2 and 3, quotes are used as illustrations. The quotes represent a participant's individual and unique experiences. At the same time, the quote also focus on a main theme. In the text describing the result, the research group discussed and chose to use words such as many and some, which quantified the material. The research group agreed that individual processes and experiences are subject to subdivisions. Nevertheless, quantifying qualitative material might undermine the uniqueness of the qualitative knowledge. 
We also felt that is was appropriate to describe flows when a theme was mentioned by many or few. We were aware that the way the results are presented should draw attention to individual processes of creating meaning, but at the same time we felt it problematic not to mention whether it was many or few that mentioned the topic. As I see it this is both a research dilemma and an ethical dilemma. The article "The One or the Many: Quantified Subjectivity and Aggregated Uniqueness in Qualitative Rehabilitation Research" both describe and discuss this dilemma more in-depth (194).

\section{Informed consent}

When preparing the consent form for the qualitative project, the statement was based on a layout from Regional Committees for Medical and Health Research Ethics (REC) [192]. We strived for clear and consistent language adapted to adolescents and parents. The resource group considered the text before it was approved by the research group and then submitted to approval by REC [192]. REC requested some minor changes, and the consent statement was revised according to their wishes and then approved [attachment 5].

Due to the consideration of the privacy of other participants, and because the results are a summary of different stories presented in the final result, the research group decided that it was too problematic and complicated to give the individual participant the possibility to comment on the results. This was a dilemma, because it could be very valuable for the researcher to know if the interpretations of the material made sense to the informants or not.

On the other hand, researchers had to emphasise independent interpretation and relied on the summary of the material from interviews. This is also important, as the interpretation of the meaning of content does not necessarily coincide with the participants' self-understanding. The research group considered it central to carry out a qualified assessment of the information 
from the interviews. At the same time, the researchers had to differentiate between the researcher's perspective and the informants' understanding in the presentation of the findings, and could therefore - as well as for confidentiality reasons - not allow participants to give input on the final material. 


\section{Presentation of the papers}

In this section, a summary of the three papers in this thesis will be presented.

\section{Paper 1}

"High-frequency use of over-the-counter analgesics among adolescents: reflections of an emerging difficult life, a cross -sectional study".

In this paper, we aimed to identify differences between those who used OTCAs daily to weekly (high-frequency users) and those who used less or no analgesics (low-frequency users). We also aimed to analyse the differences in pain experience, lifestyle, self-esteem, school attendance, and educational ambition. This was done so we could assess possible associations between selected characteristics of 15 to 16-year-old adolescents and their use of OTCAs.

\section{Findings}

A total of 367 of 626 targeted adolescents (59\%) participated; 186 girls (51\%) and 178 boys (49\%). Overall, 90 of 348 adolescents (26\%) reported that they had used OTCAs daily or weekly during the previous 4 weeks. Twenty-two boys and 13 girls (a total of 10\%) were daily users. Forty boys and 81 girls (a total of 35\%) used OTCAs less than weekly, while 83 boys and 54 girls (a total of 39\%) had not used such medication during the previous 4 weeks. Adolescents who experienced pain in three or more body parts were three times more likely to be high-frequency users of OTCAs than those who did not experience such pain. Highfrequency use of OTCAs was also associated with less than seven hours sleep a night, having paid spare-time work, two or more episodes of binge drinking and daily intake of caffeinated 
drinks. Moreover, high-frequency users were significantly associated with lower self-esteem, less ambitious educational plans, and absence from school over three days or more.

\section{Conclusion}

High-frequency use of OTC analgesics was associated with more widespread pain, unhealthy lifestyles, lower self-esteem, less ambitious educational goals and higher account of absence from school. High-frequency users reported lower self-esteem than low-frequency users. This may indicate reduced capability to handle stress and strain. Continuous stress may induce allostatic overload, which may partly explain why some adolescents frequently experience pain.

\section{Paper 2}

"High use of over-the-counter analgesics: possible warnings of reduced quality of life in adolescents - a qualitative study”.

The aim of paper 2 was to increase knowledge about the life experiences of adolescents between 14 and 16 years old with a high consumption of OTCAs.

Results

The adolescents described daily pain in several parts of their bodies and a daily to weekly consumption of OTCAs over time. In everyday life, they struggled to perform well, be accepted and fit in. Most reported serious family problems throughout childhood. Several had moved several times, some had divorced parents and lived partly with the mother and partly with their father. The majority had experienced bullying or being an outsider among peers and they all tried to avoid conflicts. The adolescents experienced complex interconnected 
problems including moderate-to-severe pain, fatigue, sleeping problems, lack of concentration, feelings of loneliness, stress, worry, sadness, and anxiety. They struggled to succeed in various areas and described high ambitions for themselves. To demonstrate the load of psychosocial problems described, many talked about serious eating problems, more than half had been bullied and almost one third had required support from the Child Welfare Authorities. Some had engaged in self-harming and several had thought about taking their own lives. The adolescents described continuous feelings of not being good enough compared to their own standards of performance and achievements. They all longed for a close friend. The adolescents used OTCAs to deal with the various problems, even though the problems were often beyond the known medical indications for OTCAs, such as social gatherings, exams, and competitions. Most participants had tentative or incomplete medical insights into their pain, leading to uncertainty and rationalisation regarding their need for OTCAs. They also sometimes interpreted their discomfort as an indication for using OTCAs. According to the adolescents, mothers were the prime caregivers throughout their childhood and the mothers engaged naturally in caregiving to alleviate pain and improve their child's health. Several had moved from mother-assisted OTCA use to become more autonomous.

\section{Conclusion}

Childhood experiences influence how adolescents experience pain and use OTCAs. Coping with difficult situations or attempting to mask symptoms with OTCAs can perpetuate and amplify underlying problems. High consumption of OTCAs and frequent pain may be warning signs of adolescents with possible health-threatening conditions and reduced quality of life. 


\section{Paper 3}

"Pain management and development of identity in adolescents who frequently use of overthe-counter analgesics: a qualitative study”.

The aim of this paper was to achieve insight into life experiences related to pain management and development of identity in adolescents from 14 to 16 years of age with high consumption of OTCAs, through the dyadic perspectives of mother and adolescent.

\section{Results}

A total of 16 participants were interviewed: eight adolescents, two boys and six girls aged 14 to 16 , and their eight mothers. Half of the adolescents lived with both parents. The other half lived with their mother as primary caregiver. The mothers said they had the main responsibility for bringing up their child. Among the mothers who lived without a partner, some said they struggled financially. Both mothers and adolescents worried about the adolescents' health complaints. The mothers spent great efforts trying to help their child; several described this as a lonely struggle, without support from the child's father or the extended family. The adolescents' and their mothers' stories described the adolescents' life experiences, pain, use of OTCAs, and treatments with congruence. The descriptions differed, however, regarding the adolescents' strengths and difficulties. The mothers focused on the adolescents' achievements and appearance, and the adolescents' polite behaviour was emphasised. The adolescents worried about whether they were able to manage everyday life, including social gatherings, exams, tests, and competitions. They also feared being rejected by peers. Through the stories, an experience of a very close relationship between mothers and adolescents emerged. The mothers had a great influence on the adolescents' everyday life. The adolescents highly admired their mothers and tried to adjust to and fulfil these 
expectations. Expressing pain resulted in attention and care from the mothers. Mothers and adolescents agreed that the use of OTCAs was an accepted way of getting relief from pain. Several mothers expressed that they felt they had to ignore their own needs to attend to the child's needs. The adolescents and their mothers put different emphasis on the relationship between adolescents and their fathers, the adolescents wanting and hoping for a good relationship with their fathers. Many of the mothers had a confrontational and emotionally oriented relation to the adolescents' fathers, often characterised by bitterness. The adolescents were highly aware of this and it bothered them significantly. The themes that emerged from the analysis were "Vulnerable adolescents", "Mother knows best" and "Pain is a shared project".

\section{Conclusion}

The adolescents tried to adjust and adapt to avoid conflict and to fit in. With few possibilities to explore life challenges by themselves, the adolescents struggled with developing their identity. This may cause identity confusion and dependence on others for a sense of worth. Frequent pain may be the result of a stressful life and the use of analgesics is a learned coping strategy to combat this. Frequent pain and high consumption of OTCAs may signal adolescents in need of professional support, and the adolescents' mothers' influence must be considered when deciding how to support the adolescent professionally. 


\section{Discussion}

In the first section, methodological issues will be discussed; in the second section, the findings from the three studies will be discussed in the light of the presented theory.

\section{Methodological issues}

When discussing credibility, strengths, and application in nursing research, the terms validity and reliability are commonly used in quantitative research $[125,130]$. Other terms have been suggested to describe these aspects within qualitative research. The following five corresponding qualitative terms are suggested by Lincoln and Guba (1985) used to evaluate trustworthiness in qualitative research: credibility, transferability, conformability, dependability, and authenticity [131]. Others think that reflexivity is an important approach for evaluating quality in research [132]. In the following, quality in the quantitative research presented in paper 1 will be discussed in accordance with the terms validity and reliability. Then, the quality in the qualitative studies, presented in paper 2 and 3 , will be discussed in accordance with credibility (including reflexivity), transferability, conformability, dependability, and authenticity [92, 125, 131, 133].

\section{Quality in quantitative research}

Study 1 was a quantitative study with a cross-sectional design, at a single time point of measurement. A cross-sectional design is appropriate when the aim is to describe the status of a phenomenon or relationship at a certain point in time [128]. This precludes finding out what happens to respondents over time, but the main advantage is that this is an economical design, and rather easy to manage. In study 1, a cross-sectional design was chosen in accordance with the aim. However, there are problems with interfering changes and trends over time with such a design [125]. The quantitative study gave a broad overview of the target group: adolescents 
between 15 and 16 years of age with a high consumption of OTCAs. Quantitative research uses several criteria to assess the quality of a study, and reliability and validity are considered the paramount criteria [125]. The researcher needs to carefully evaluate the content of the questionnaire in addition to other properties, such as the validity and reliability, before the final decision is made with regards to which instrument is used in a given study [135].

\section{Reliability}

Reliability refers to the accuracy and consistency of the information obtained in a study [125]. Reliability is defined as the likelihood of obtaining the same results when the researcher measures the same variable more than once, or when more than one person measure the same variable. Reliability therefore relates to the measurement accuracy of the data collection instrument. An instrument can be said to be reliable if its measurement accurately reflects the true scores of the attribute under investigation [125]. We used a self-designed instrument alongside reliability-tested and validated questionnaires such as Rosenberg's scale of selfesteem $[117,118]$. The questionnaire also contained questions from The Nord-Trøndelag Health Study (HUNT) [134]. The results from the HUNT studies are included in a unique database of medical histories, both personal and family histories, collected during three intensive studies. To increase reliability, the questionnaire included pictures of the packets containing OTCAs, so that the adolescents would be able to recognise the medication even if they did not remember the name. Answers were given by checking boxes for predetermined alternatives. The responses to the questionnaire sheets were scanned optically into an electronic database, reducing errors in the transfer. The four-item Norwegian version of Rosenberg's scale of self-esteem which was part of the questionnaire has shown satisfactory internal consistency reliability, and the Cronbach's alpha of 0.88 for this study was close to that of other Norwegian studies [119]. 


\section{Validity}

Validity is a concept that broadly concerns the soundness of the study evidence and the degree of inferential support the evidence yields [125]. Validity refers to whether there is evidence to support the inference, and that the method really measures what it purports to measure. Internal validity asks whether the study investigates what it is intended to, whereas external validity asks in what contexts the findings can be applied, implicitly to what population the results can be generalised [92].

To ensure external validity, the adolescents participating in study 1 were sampled in a Norwegian town where sales data indicated that consumption of OTCAs approximated the average consumption in Norway as a whole. Another study has shown that the use of OTCAs by adolescents living in urban and rural areas is similar [16]. Therefore, we assume that the patterns of use revealed in our study are like those found in other regions of Norway and that the results can be generalised to the whole population of Norwegian adolescents.

The response rate of $59 \%$ is somewhat low. The response rate for each of the schools and the proportion of students who had used OTCAs during last four weeks are described by Lagerløv (2009) [14]. There were no statistical association between the response rate of the schools and the proportion of students who had taken painkillers. This may indicate that the response rate did not influence the recorded frequency of use extensively. The gender distribution in our sample is like the one seen in the general population of adolescents, and the gender-related patterns of use were almost identical throughout all six of the recruited secondary schools, located in different socioeconomic regions in the area. Moreover, the aim of our study was to 
compare high frequency users with low/no frequency users. Thus, we compared data within the total set of data we had gathered.

We assume also that any recall bias related to the four-week sampling period is similar in both high and low/no frequency users. Therefore, we consider our sample to be representative of the targeted population: all 15 to 16-year-old adolescents in Norway.

We collected data by means of a self-designed questionnaire. The item 'How often have you used pain medication during the last 4 weeks?' covered the main outcome. There were four possible response alternatives. Due to the number of responses in each of the possible categories we chose to dichotomise the outcome as high vs low/no frequency users. It is often seen in the literature that outcome variables originating from questionnaires are treated as continuous variables and analysed using linear regression. However, we did not consider this approach valid for our data, as they were not normally distributed.

Logistic regression is a statistical model that relies on fewer assumptions than linear regression regarding the distribution of data, and the resulting ORs are easy to interpret also for non-statisticians. We considered our study as explorative and therefore did not perform any correction for multiple testing; -values $<0.05$ were considered statistically significant and all tests were two-sided. The independent variables were not intercorrelated and thus the total model was presented in our article.

To strengthen the internal validity, two of the project members were present in class with teachers and attended to the distribution and collection of questionnaires; they were also 
available for students to answer questions about ambiguities. Students who may have need of assistance also had assistant teachers available.

Another strength of our study was the rather large number of adolescents we approached and the response rate. Moreover, values were missing from the respondents for only $<5 \%$ of all questions. Therefore, we did not have to perform any imputation.

One limitation of this study is that we have no information about the adolescents who did not participate in the study. Some did not participate because they were absent and some because they did not bring their parents' consent form. Although we have no information on reasons for non-participation, adolescents with high use of OTCAs are more likely to be absent from school than others. Therefore, the absolute proportion of adolescents consuming high amounts of OTCAs on a daily to weekly basis might be even higher than reported in this thesis. Measuring subjective health with single-sample approaches does not produce data representative of average complaints over a period. More than two samples are required when collecting subjective data on health complaints, both when the aim is to reveal changes in health, as in interventions studies, and when the aim is to obtain representative data for the averaging of complaints over time [137]. However, we are aware that we applied the questions on experiences of pain and use of OTCAs only once. In this case, we might have overestimated the pain reported by the participants and frequency of OTCAs used.

Another limitation is that when using questionnaires to cover sensitive topics, it is known that the responders tend to under- or over-report [136]. We were, however, more interested in the differences between users and not in the absolute prevalence. We have no reason to believe 
that high users underreported more on certain items compared to low/no frequency users, therefore we consider our comparisons valid.

\section{Quality in the qualitative research}

To investigate the adolescents' life experiences, we designed two qualitative studies (study 2 and 3). Through this studies we hoped to increase our knowledge about how the adolescents manage their everyday life, how pain affects everyday life, which challenges they faced and how they managed them, and how they reflect upon their pain and the use of OTCAs. In study 2 the theories of stress, social learning and quality of life were used to interpreted our results. In study 3 , we study the adolescents life experiences also through their mothers experiences and interaction with their adolescents. In this study, the theory of identity development $(2,4$, 5) was used to interpreted the results. According to Malterud (2001), qualitative research methods involve: "the systematic collection, organisation, and interpretation of textual material derived from talk or observation. It is used in the exploration of meanings of social phenomena as experienced by individuals themselves, in their natural context" [92 p. 483].

Hermeneutics is a philosophical method for interpreting data, usually text. Interpretations must be ensured a certain degree of inter-subjectivity. This is ensured when the research team has examined, discussed, and agreed upon the interpretations. Nevertheless, the context for interpretations must be clearly defined so that such interpretations may be acknowledged beyond the research team, i.e. by the reader. Findings from a qualitative study are not facts that are applicable to the population as a whole, but should rather be looked upon as descriptions, notions, or theories applicable within a specified setting [92]. The hermeneutic research tradition, which uses lived experience as its basis, may give us a broader understanding of the physiological, psychological, and social contexts in which the use of 
OTCAs occurs. Hermeneutic inquiry focuses on how individuals interpret their world within their given context. This implies that meaning and interpretation are considered and treated as findings [125]. Qualitative research design tends to be flexible and elastic, and it is possible to adjust the design to what is learned during the data collection process. The method gives possibilities for various data collection strategies such as triangulations. Furthermore, it tends to be holistic and strives for an understanding of the whole. It requires the researcher to become involved and requires ongoing analysis of the data to formulate subsequent strategies and to determine when the data collection is done [125].

Trustworthiness in qualitative research encompasses several different dimensions: credibility including reflexivity, transferability, conformability, dependability, and authenticity [92, 125, 133]. Below I will discuss the qualitative studies in relation to these concepts.

\section{Credibility}

Credibility is about the true value of data and interpretations of these [125, 131], and whether the findings or results are congruent with reality [137]. Malterud (2001) points out the importance of reflexivity as part of credibility in qualitative research and says: "the question is neither whether the researcher affects the process, nor whether such an effect can be prevented. This methodological point has been turned into a commitment to reflexivity. The illusion of denying the human touch is countered by establishing an agenda for assessment of subjectivity” [92 p. 484].

The members of the research group had different positions, experiences, and perspectives; their knowledge and pre-understanding were considered both strengths and threats to credibility and reflexivity. Throughout the research process, the members of the research 
group challenged each other's interpretations and pre-understanding, in order to ensure trustworthiness [125]. The research group also addressed the potential problems related to the researchers' pre-understanding and discussed the benefits and challenges to credibility these might pose. In qualitative research, the different ways of approaching the same subject result in an increased understanding of complex phenomena, not in a failure of credibility [92].

One possible pre-understanding the research team might have developed from data in study 1 is that high frequency users of OTCAs had more difficulties, such as pain and reduced sleep, in their lives. This may have resulted in a greater focus on difficulties and to a lesser extent on resilience.

Although the interviewer (SS) emphasised her role as a researcher, her background as a psychiatric nurse might have been in focus for some of the informants. During the interviews, she may also have used psychiatric interview techniques that revealed more in-depth information compared to other interview approaches. Furthermore, the adolescents' expectations of the interviewer, who had presented herself as a researcher with a special interest in adolescents with a high consumption of OTCAs, may have affected their focus. When they mentally prepared themselves for being interviewed, they may have focused on pain and problems in their life. The interviewer (SS) was aware of this potential bias and tried to avoid acting as a therapist by asking open-ended thematic questions per the interview guide.

The fact that the interviewer was female may have made the girls, who made up most of the interviewees, feel more comfortable and willing to disclose information than the boys. 
The inclusion criterion for the adolescents participating in study two and 3 was a high consumption (daily to weekly) of OTCAs. The researchers did not have any possibility to control the adolescents' use of OTCAs. This may have opened for adolescents with a certain need for expressing their experiences, thoughts, and feelings choosing to participate.

The interviews were conducted at an office in the adolescents' schools or at an office at the researcher's work place, and it is possible that the surroundings affected the participants.

\section{Transferability}

The aim of research in general is to produce information that can be shared and applied beyond the study setting $[92,125,131]$. To ensure a high degree of transferability in studies 2 and 3, a research protocol was developed. Activities that ensured methodological coherence, such as recruiting participants, development of the interview guides, data collection and analysis, including discussing theoretical perspectives, were described in the study protocol $[138,140]$.

One potential limitation of the present study was that, of the 19 participants, there were only 3 boys. Perhaps additional points of view would have emerged if more boys were included in our sample. Another limitation was the ethical requirement or adolescents below sixteen years of age to gain their parents written consent. This may have excluded students who did not want to fully disclose their OTCA use to their parents. Principals at 20 schools were asked to give their permission for informing and recruiting participants from their schools, but only five from sub-urban and five from urban areas gave such permission. We did not recruit adolescents from all these ten schools, and there may be other adolescents with special experiences that we did not access. This also means that we do not have participants from 
rural areas in studies 2 and 3. Including adolescents from rural areas may perhaps have yielded other stories and expanded our knowledge. However, we do not believe that our results are geographically biased, since a previous study did not find a difference in the consumption of OTCAs among adolescents living in urban regions compared to those in rural regions of Norway [16].

The adolescents in study 1 were 15 to 16 years old. In studies 2 and 3, the participants were 14 to 16 years old. It is possible that choosing a broader range of ages would have yielded other results. However, we thought that these age groups would give us a broad view of individuals in the developmental stage of adolescence, physically, psychologically, and socially.

We did not find that socioeconomic differences affected the use of OTCAs among the participants in study 1 . In studies 2 and 3, the informants had different socioeconomic situations, but told similar stories about life experiences, pain, and use of OTCAs. We may therefore assume that it is not primarily the adolescents' socioeconomic situation that leads to a high use of OTCAs.

To ensure trustworthiness, the research group estimated the number of participants in studies 2 and 3 based on experience from similar studies among adolescents [139]. Participants were included until no new information related to the use of OTCAs was detected [123]. Our number of participants is rather high, and with in-depth interviews, each lasting approximately one hour, we developed a large amount of material. However, a lot of material does not necessarily guarantee transferability, and might result in a superficial analysis, as the researchers cannot test reflexivity and look at counterhypotheses [92]. To counteract this in 
the material from the interviews, the computer programme NIVO 10 was used for organising, storing, ordering, and retrieving information. This was a helpful tool in working with the raw material from the interviews. It is, however, important to keep in mind that the programme cannot perform the analysis itself [92].

During the analysis, the researchers read and reread the material to gain thorough knowledge of the study material, and they discussed meaningful units and interpretations. When disagreement arose, they reread the material and continued the discussion; this process lasted until a shared understanding arose. Through this process, the researchers also became familiar with the content of the data and their meaning, and were able to ascertain what in the material was relevant when trying to answer the research question [92]. They also considered whether the interpretations seemed relevant in view of their own experiences as clinicians.

\section{Conformability}

Conformability concerns objectivity, which means to recognise that knowledge is partial and situated, and to account adequately for the effects of the positioned researcher $[92,131]$. During all steps of the research process, the effect of the researcher should be assessed, and later shared [92].

To strive for conformability, the researchers had regular meetings for planning and implementing the study and further analysing the data. The interviews were transcribed verbatim and each interviewer received a copy of all transcripts.

Working with the analysis in study 2 , each researcher first read all the interviews with the adolescents during several meetings in the research group. Then, each researcher presented 
one interview with meaningful units and interpretations highlighted, the other researchers challenged the presented material, and through a discussion an agreement arose. The main findings from each interview were compared to the whole material in order to identify differences and similarities.

Working with the analysis in study 3 , each researcher presented material from a dyad of one adolescent and his or her mother, on the level of common sense. Similarities and differences regarding the adolescent (about the adolescent, the pain, the use of OTCAs, the father and the mother) were used to identify meaningful units and interpretations.

Mostly a common understanding and agreement was achieved without marked disagreements. This might indicate that the group was too similar in their pre-understanding or that, through different perspectives, a common broader insight arose.

\section{Dependability}

Dependability concerns whether we may have confidence in the "truth" of the findings [131]. This is about the stability of data and conditions over time, and whether the study can be repeated with the same or similar participants and in the same or similar conditions by a different researcher [125]. The participants, the conditions, and the setting in other studies will differ from our studies ( 2 and 3 ), and the same data cannot be reproduced. The process in the study is therefore reported in detail so that other researchers may repeat a similar study.

\section{Authenticity}

Authenticity refers to the extent to which researchers fairly and faithfully show a range of different realities $[125,133]$. We used a Norwegian-American adolescent to translate the 
quotes so they would be useful to an English-speaking audience. By using an adolescent, we tried to be faithful to the "adolescent's expression" when presenting the statement. Also, by presenting meaningful interpretations as quotes, we hoped to invite the reader into an experience of the adolescents' lives. This may also enable readers to develop a heightened sensitivity to the issues described [125]. There is, however, a risk that by translating the quotes into another language within another culture, we are giving rise to a possible different interpretation. 


\section{Discussion of results}

The overall aim of the thesis was to increase knowledge about adolescents with a high consumption of OTCAs. Based on the three presented papers, it became clear that childhood and upbringing affected the adolescents' development of self-worth and self-esteem. Mothers, who in most families were the main caregivers, highly influenced the development of security and autonomy. Furthermore, conflict at home and among peers, tests, exams, and physical pain stressed the adolescents and hampered their quality of life. These themes are not mutually independent; they may instead reinforce each other. However, the discussion points out some interesting and useful relationships between our findings and the theories presented earlier.

In the quantitative study (study 1), we found that adolescents with a daily to weekly consumption of OTCAs showed the following patterns more often than low-frequency users:

- having pain in three or more body parts,

- sleeping less,

- having paid spare-time work,

- drinking more caffeinated drinks,

- participating in binge drinking,

- having lower self-esteem,

- having less ambitious educational plans and

- being more frequently absent from school.

Adolescents with frequent use of OTCAs might be experiencing their everyday life as stressful. The pain they experience is a reaction to this stress, as well as a signal that they need professional support. In study 2, including 19 adolescents, the results showed that the 
adolescents' everyday lives were hampered by pain, which reduced their ability to manage challenges and tasks. The adolescents did not feel satisfied with themselves, their appearance, or with their achievements. Their expectations for themselves seemed often to be without any limit, and they adapted and adjusted to feel appreciated. Maternally inherited pain seemed common, and methods of pain self-appraisal, including OTCA use, often mimicked maternal patterns. Both the adolescents (study 2 and 3) and mothers (study 3 ) described the adolescents' childhood and upbringing as stressful. The adolescents told stories indicating that they had been raised under unpredictable circumstances, including long lasting family conflicts, several occasions of moving house, and peer-group problems. Feeling torn between the parents because of family conflicts and longing for a good friend were experiences considered stressful by the adolescents. In the third study, we achieved deeper insight into the life experiences of the adolescents through dyadic analyses of the stories told by the adolescents and their mothers. The mothers also appeared to be the primary caregiver, often with no support from the father or the extended family. They had a high impact on their adolescents' everyday life, pain experience, and use of OTCAs. The adolescents' stories revealed that they seemed physically, socially, and psychologically highly dependent on their mothers. However, or perhaps as part of this, they longed for good relations with their fathers and peers in particular. According to the adolescents, OTCAs were used to relieve pain, calm down, manage social life, and feel more focused.

Most of the adolescents participating in study 2 and 3 had lived with serious family problems and conflicts throughout their childhood. This was confirmed by the findings in study 3 , where it became clear that many of the mothers had a confrontational and emotionally oriented relation to the adolescents' fathers, often characterised by bitterness. The adolescents 
were highly aware of these conflicts, and they were both bothered and stressed by them. Several expressed a longing for a better relation to their fathers.

The transition from childhood to adolescence is characterised by the need to establish an independent identity. The adolescents in our studies were at the stage of life where they should naturally move from being highly dependent on their main caregiver to developing their own identity, and to a far greater extent protect their own interests and wellbeing $[2,4]$. The adolescents' childhood and upbringing may affect their identity development, and they seem to have learned to adapt and adjust to be accepted $[2,87]$. In such cases, the adolescents might undermine their own needs in order to be valued. The findings in study 1 showed that the adolescents who consumed rather high amounts of OTCAs had lower self-esteem than those who seldom or never used OTCAs. Adapting to the behaviour of others and adjusting to presumed expectations might have hampered these adolescents' possibilities for development of self-worth and self-esteem as part of their identity achievement. Successes, such as high marks and good achievements, appear to be "a must" to feel self-worth, but it seemed as if achieved successes do not give a lasting feeling of being good enough.

In study 2 and 3, adolescents and mothers talked about stressful family lives, sometimes caused by illness and deaths, sometimes by conflicts, mental illness, and substance abuse. This might indicate that these adolescents have lacked a secure and supportive foundation for exploring their selves in relation to the environment [2]. Study 1 showed that adolescents with frequent use of OTCAs had lower self-esteem and reduced future educational ambitions compared to those who used OTCAs less frequently. As mentioned earlier, identity is a concept that includes self-esteem, self-worth, and self-respect [10,87]. It may be that the youth strive to maintain a self-image that protects their self-esteem and maintains self-respect. 
This can stress the youth, especially when exposed to pressures from the outside world as well. When the stresses are experienced as too huge to cope with on their own, adolescents with a secure parental relation have an opportunity to return to the family environment for support to cope with stresses and strains. Many of the interviewed adolescents seemed to lack this option for avoiding stressful situations and challenges. According to Erikson's theory of development of identity, childhood, upbringing, and parents are important for how adolescents cope with challenges and stresses. Not having a secure base when exploring life, or being pushed to confirm the parents' views, might reinforce development of a foreclosed or diffused identity. This means that the adolescents might be hampered in their attempts at figuring out how to be true to own beliefs and ideals. This situation might also terminate the transition to the moratorium status, which means that the adolescent does not challenge him or herself, nor the social relationships, to find a secured identity $[4,86]$. It seems like most of the adolescents in our study do not have a high level of exploration, or a high commitment to an identity. Low exploration, using avoidance and adapting as "techniques", seemed common (study 2). According to the theory about development of identity presented earlier, both foreclosed and diffused adolescents are characterised by low exploration; however, foreclosed individuals have made a commitment to an identity and diffused individuals have not $[5,86$, 91].

Several of the adolescents had moved between residences several times, some moved weekly between their parents' residences. This was experienced as stressful and complicated the adolescent's interaction with peers. Growing up in unstable and unpredictable environment may increase these adolescents' need for control through planning and organisation, and possibilities for exploring life and deal with stresses are eclipsed in order to gain control and avoid threatening situations. It is also possible that the adolescents themselves are afraid of 
losing control because they do not feel they have a secure base at home, and thus, they may avoid moving into the moratorium status. In this status, they would explore and reflect upon different alternative behaviours [5].

A combination of low self-esteem, the mother's strong influence, and lack of any significant others might have led to strong dependence between adolescents and mothers, hampering the development of a secured identity. Low exploration of own possibilities, strengths, and difficulties can cause identity confusion and dependence on others for a sense of worth and self-esteem.

Through the stories in study 2 and 3, a very close relationship between the mothers and adolescents emerged. The adolescents highly admired their mothers and tried to adjust to and fulfil their expectations. Autonomy and independence from mothers might be hard to achieve, because the adolescents, as the results from the three studies showed, lacked trust in their own worth and in others' confidence in them. At the same time, the adolescents understood their mothers made sacrifices to support them, as the results from study 2 and 3 showed. It is possible that the adolescents felt guilty should they speak up against their mothers.

One interpretation of the stories told by adolescents and their mothers in study two and 3 is that, without the adolescents and their mothers being aware of it, pain is perceived as an acceptable feeling more so than expressions of sorrow, grief, fear, and anger. The adolescents' expressions of pain resulted in attention and care from the mothers. Moreover, between mothers and adolescents, pain management and the use of OTCAs seemed to have become a way of giving and attaining attention and care. 
The adolescents may lack significant others as role models in addition to their mothers, and they do not seem to have other adults who could be trusted or someone to support them if they get into a conflict with their mothers. The significance of attachment is mirrored in situations of conflicts and disagreement with individuals in whom one aspires to belonging and trust. Autonomy in these situations reflects the degree of attachment security. Such autonomy is of the utmost importance in establishing social relationships [81]. Behaviour that maintained a relationship while disagreeing, or behaviour that avoided undermining such a relationship, predicted attachment security [81]. It is possible that the threat of being rejected by the mothers, on whom the participating adolescents seem highly dependent, creates fear and intimidation, which again may inhibit the adolescents' capacity for reflecting and acting autonomously.

Several of the interviewed adolescents expressed longing for a good friend (study 2). A highquality friendship is associated with high levels of prosocial behaviour, intimacy, and other positive features, and low levels of conflicts, rivalry, and other negative features [141]. Such friendship quality has been assumed to have direct effects on many aspects of children's social development, including their self-esteem and social adjustment. Lack of a high-quality friendship might increase the adolescents' dependence on their mother, giving her the role as "a best friend". In adolescence, both peers and parents are considered important for experiencing a high quality of life [141]. Best friend interactions, as well as markers of popularity within a broader peer group, are unique, additive links to security $[81,142,143]$. Safe attachment to parents at home may be associated with less conflict with peers. Perhaps such safe attachment attained at home may be transferred to relationships with peers. The ability to express autonomy without conflict may be important for personality development. Interactions in which one has to manage peer pressure appear as a major autonomy challenge 
and key identity developmental task [143]. Study 1 showed that adolescents who frequently used OTCAS more often are engaged in binge-drinking than others. Perhaps intake of alcohol cover their feelings of insecurity, which are again caused by lower self-esteem. Possibly, secure adolescents convey to their peers that they are not likely to be particularly susceptible to pressuring tactics, and hence they receive fewer direct threats to their autonomy in the form of peer pressure to engage in negative behaviour [144]. One explanation might be that there are mechanisms by which secure adolescents establish their capacity for autonomous thought and behaviour, as they form new relationships by establishing such relationships in ways that leave them less likely to experience pressuring behaviour. Peer-relationship qualities directly contribute to security in adolescent attachment organisation, whereas early attachment, between mother and infant, influence attachment later in life [145]. One interesting point is that peer-relationship qualities are predictive of attachment security even after accounting for qualities of mother-adolescent relationships and father-adolescent relationships [144].

Adolescents' attachment relationships are found to be connected to social behaviours beyond the mother-child relationship in early adolescence [146]. It is possible that the secure adolescents tend to create relationships characterised by a balance of autonomy and relatedness in order to establish their own secure bases from which to explore and to do this across relationships [147].

The adolescents reported having high expectations for themselves and that they feel pressured in everyday life (studies 2 and 3). In study 1, we found that adolescents with a high use of OTCAs had less ambitious future educational plans than others. Through the adolescents' stories in study 2 , it emerged that they wanted a career that required higher education, such as law and medicine. It is possible that the adolescents in the face-to-face interviews felt they had to demonstrate their willingness for success and their ambitions. At the same time, they 
voiced doubts regarding the achievement of their ambitions; pain, stress, and fatigue impeded their belief in success. According to the results in studies 2 and 3, the adolescents seemed to have acquired their expectations from others, mainly their mothers. Adolescents' individual expectations and values are found to be influenced by their social context, such as parents, teachers, peers, neighbourhood, and community, as well as by previous academic achievement [147]. Once established, an individual's expectations and values influence the individual's academic performance, persistence, and academic subject choice [147]. According to the findings in studies 2 and 3, the mothers had high expectations for their children's careers and the adolescents seemed to have adapted to and even enhanced these expectations. Nevertheless, the adolescents also said they doubted they would be able to fulfil these expectations. Such discrepancies can possibly lead to negative achievement outcomes and might be reasons for the adolescents' feelings of never being successful enough [148, 149]. Studies 2 and 3 also showed that mothers underpinned their children's opportunities for success by emphasising their children's capabilities and highlighting earlier achievements. The adolescents strived to be successful by achieving high marks and good results. This indicates the important influence of both parental expectations and perceived parental expectations on adolescents' academic achievement, which is pointed out in another study as well [150]. It also appears that the adolescents' and mothers' expectations were mutually reinforcing each other. This is in line with Zhang et al. (2011), who found that parents' expectations influence students' expectations and students' expectations influence parents' expectations, both of which independently influence and are influenced by the adolescents' achievement [151]. The adolescents' continuous struggle for success might cause a high level of stress, which over time might influence biopsychosocial mechanisms and cause illnesses, as described in several others studies $[11,96,152]$. 
Among the adolescents interviewed in study 2 a feeling of fatigue and tiredness was common, and study 1 showed that the adolescents experienced pain from several parts of their bodies, slept less, worked more in their spare time, and had a higher intake of caffeinated drinks than others. This might indicate that the adolescents, in addition to a difficult upbringing and childhood, also experienced more stress and pressure in everyday life. Reduced sleep might increase the feeling of tiredness and lead to a higher intake of caffeinated drinks. It also became clear that many of the adolescents had a high absentee rate from school (studies 1 and 2), and struggled with their schoolwork due to fatigue and pain (study 2). Several felt they did not perform well enough, even if they tried. Coping strategies are described by other researchers as behavioural and cognitive responses used by the adolescents to master, tolerate, or reduce the demands of a stressful situation $[95,96]$. Furthermore, the ability to cope effectively with stress, such as pain, pressure, and expectations has been viewed as a crucial component of resilience among children and adolescents and important in influencing patterns of positive growth and development [97]. The adolescents interviewed in study 2 seem to have learned that avoidance and adapting is the best way to cope with stress. They had also learned that pain is an acceptable way of expressing physical, psychological, and social discomfort. The ability to cope and the attainment of defined goals relate to self-efficacy. According to research, self-efficacy is important for the successful management of pain [51]. Perhaps some adolescents who frequently experience pain may strive hard to attain their goals as a way of gaining approval. As a replacement for other ways of gaining approval, these goals may be unrealistically high. Not attaining such goals may be taken as a sign of low selfefficacy by the adolescents. An experience of pain can then legitimise the lack of success, both for the adolescent and the surroundings. 
Many of the adolescents in study 2 expressed a feeling of loneliness. Through studies 2 and 3 , it appeared that the adolescents' families had a relatively weak and limited social network. There were frequently ongoing and long-lasting conflicts among family members. Some adolescents described a feeling of being torn between their parents. This might have led to a feeling of loneliness in the family and an insecure parental relationship. Many of the adolescents also said they felt like outsiders among their peers, which might be the best predictor of adolescent loneliness. The perception of being an incompetent or rejected person among peers may then manifest itself into feelings of loneliness; such mechanisms are also described by other researchers $[153,154]$. In another Norwegian study, as many as $12 \%$ of adolescents reported being lonely and feeling like outsiders regarding social companionship [155]. In addition, another Norwegian study by Helseth and Misvær (2010) found that adolescents' relationships with peers are vital to the experience of quality of life, and without friends, it is almost impossible to be happy [143]. Being friendless in an environment where friendship has a high value will most likely have a negative impact on an adolescent's selfimage. To adolescents, being friends with oneself is also crucial to quality of life. As the adolescents in Helseth and Misvær's study [143] describe it: "if you are satisfied with who you are and dare to be yourself and let the others see you, it is easier to get friends too". Having a nice family and parents you can talk to and feel secure with seem to be important for the adolescents' quality of life. Parents who show their care and who can strike a balance between freedom and control are characterised as good parents by adolescents [141]. It appears that families, and especially parents, create an essential, secure base in life; when this base functions well, it is often not noticed or commented on by the adolescents. However, having quarrels in the family, or parents that do not trust their adolescents or do not give them a certain amount of freedom, are factors that are described as having a negative impact on the adolescents' quality of life. 
Several adolescents (study 2) said they had been bullied over time; this was also confirmed by the mothers in study 3 . The adolescents described how they tried to avoid situations where they may be bullied. Bullying is a deliberate, repeated, or long-term exposure to negative acts performed by a person or group of persons regarded as being of higher status or greater strength than the victim [156 p. 341]. Reduced self-esteem, anxiety, or previous depression, which affected some of the adolescents in our studies, may make these adolescents more likely to be bullied [157]. Vulnerable children, such as adolescents with unsupportive parents, as experienced by some of the adolescents in study 2, are found to be at increased risk of being a victim of bullying [158-160]. Further, bullying makes the victims feel helpless, lonely, and excluded, just as the adolescents in study 2 described [161]. The high-frequency users of OTCAs in study 1 had reduced self-esteem compared to those who used pain medication less. In studies 2 and 3, it became apparent that the adolescents had experienced themselves as victims of conflict within their families and among peers. When an adolescent does not have a supportive family environment, victimisation is associated with a decrease in self-esteem $[162,163]$. This indicates that the combination of family problems and bullying increases the negative effect on the adolescents' self-esteem, which again influences the development of identity negatively. Children who have been bullied also have a higher prevalence of health problems, which negatively influences quality of life [164-167]. Further, victims of bullying are found to use more OTCAs than what would be expected from their high level of physical and psychological symptoms [168]. Passive coping strategies, such as avoidance and adaptation (study 2), are by other researchers found to be the most commonly used ways of coping among those who are victims of bullying, and these types of strategies are likely to escalate the problem $[169,170]$. The use of OTCAs may be another passive strategy for adolescents who are victims of bullying as an alternative to seeking help to cope 
with negative emotions. Similar mechanisms are described in a study by Hunter et al (2004) [171]. Being a victim of bullying is also found to increase the risk for depression in adulthood [172-174]. Further, it might also be a precursor of later psychiatric problems in some adolescents $[175,176]$. Earlier studies show a clear association between being a victim of bullying and suicidal ideation $[177,178]$, which some of the adolescents interviewed said they had been contemplating. Other studies have also shown that among females, frequent victimisation leads to suicidality above and beyond other risk factors $[178,179]$. In general, being a victim of bullying in childhood is found to increases the risk of internalising symptoms later $[163,180]$. This could in turn entail that even if adolescents have had a secure childhood and upbringing, bullying in itself may cause stresses, serious psychosocial problems, and increased use of OTCAs.

Pain was a significant problem among the adolescents, hampering everyday life, possibilities, and achievements. Study 1 revealed that 15 to 16 -year-olds who used OTCAs as frequently as daily or weekly experienced more pain than others. The pain was more often located in three or more different body parts (often reflecting general pain). These findings were supported by the results of study 2 . The negative impact of pain has in other studies shown to increase when children experience pain in several locations $[57,58,181]$. The interviewed mothers said they had visited different doctors and therapists with their adolescents without getting a diagnosis that could explain the pain problems. The adolescents, who stated that they suffered from severe pain and that understanding what caused the pain was difficult, supported these stories. Some were unsure whether their 'pain' was really pain and several linked pain to stress. Other researchers have found that frequent pain stresses the body and over time might increase pain sensitivity [73, 182]. Further, that self-efficacy influences cognitive development and psychobiological functioning [50,93]. Self-efficacy plays an important role 
in coping, including coping with pain [51]. The adolescents in study 2 have learned coping strategies through observation, imitation, and modelling significant others. Furthermore, frequent pain increases the risk for the adolescents of developing chronic pain and a continuing use of pain medication in adulthood [29]. Not knowing how to identify and rate pain might cause life-threatening conditions, because the adolescents may not evaluate the significance of their pain correctly, as the results in study 2 revealed about a girl who kept silent on symptoms of acute and serious illness. Thus, a continuous, high consumption of OTCAs might be a sign of something being wrong, and it may reflect difficulties in life based on physical, psychological, and social trauma.

The adolescents acted to conceal their personal and family problems, and they seemed to have learned that pain is an accepted way to express their discomfort. OTCAs are suitable for treating various types of pain [183], but the medication also seems to be used to cover signals of underlying problems and possible long-term psychosocial health problems among the adolescents in study 2 . The adolescents attributed biological, psychological, and social factors to their pain and use of pain medication, even though this was outside the indication for use. Even after several visits to doctors and various therapists, the causes for the adolescents' physical symptoms remained medically unexplained. Research shows that such unexplained medical symptoms are associated with depression and anxiety [184]. However, the pain affects the adolescents' everyday life and their health in general [185]. Research has shown that the word "existential pain" can cover both an individual's suffering and be a clinically important factor that may reinforce existing physical pain or even be the primary cause of pain [185]. Some of the adolescents in our studies might have had existential pain, which is translated into physical pain or causes the experience of pain in everyday life. The use of OTCAs might give some of these adolescents a verification of physical pain, which again may 
possibly be experienced as less threatening than accepting internal or personal causes of discomfort. One way of understanding frequent use of OTCAs might be that the experience of pain legitimises the use of OTCAs as a solution to difficulties in life; the need for OTCAs confirms existing pain, and the effect of OTCAs on pain emphasises that the pain is caused by a physical condition.

Some of the participants in study 2 described how they may have manipulated themselves by focusing on bodily sensations, thus increasing pain perception. In such cases, they had a way out of the situation by using OTCAs. As mentioned earlier, the word 'pain' might in certain circumstances be a proxy for some adolescents to describe their feelings. Several participants said they felt unsure about whether they could manage daily life without access to OTCAs and he adolescents both justify and trivialise their use of OTCAs.

The mothers engaged naturally in caregiving to alleviate pain and improve their children's health. Between mother and adolescent, pain seemed to have become an acceptable way of expressing difficulties, grief, and fear. Furthermore, as a way of care, relieving pain was possibly seen as a shared project: the mother managing the pain, and the adolescent receiving support and treatment. In this context, OTCAs could be a tool to both gain and give attention and care. The findings in study 3 indicated that mothers link the adolescents' pain to their own experience of pain and their maternal ancestors' pain experiences.

OTCAs were described as a tool for both preventing and managing pain, stress, and fatigue (study 2). Preventatively, the medication was used before potentially challenging situations to calm down, improve performance, feel more comfortable, and stay focused. Since many of the adolescents who experienced frequent pain did not obtain professional medical help and 
were not offered other treatment, the use of OTCAs was the only alternative available to them. Their mothers fully supported the practice of using OTCAs.

The lack of a definitive medical diagnosis or better treatment options for pain seemed to motivate the adolescents to continue the use of OTCAs, and the mothers to support such use (studies 2 and 3). OTCAs are available in gas stations and grocery stores. This ubiquitous availability may give the impression that these medicines are safe and perpetuate high consumption.

Our results from studies 2 and 3 reveal that mothers transfer their attitude to pain and use of OTCAs to their children, as pointed out in another Norwegian study [21]. Earlier research has shown that maternal use of OTCAs is found to be significantly associated with selfmedication with OTCAs in schoolchildren [189].

Related to the biopsychosocial model stress may be a precipitant to pain, while family conflicts, adverse childhood experiences, loneliness, and bullying can be intervening variables, as shown in another study [12]. Study 1 showed that adolescents who frequently used OTCAs worked in their spare time more often than other participants did. According to other research, stress may have a significant impact on the adolescents' perception and behaviour regarding pain and their quality of life, influencing their physical, emotional, social, and school functioning $[11,12]$. The adolescents seem to experience their childhood, upbringing, and everyday life as stressful. Further, their everyday life was marked by pressure and high expectations. Lack of security and confidence might substantiate or even increase stress. Studies from a biological perspective show that such stress raises the levels of 
cytokines, creates resistance to steroids in a dose-response fashion, reflecting allostatic overload, and predisposes for pain [7, 99, 186].

The adolescents in study 2 tried to avoid stress by controlling what they could (i.e. pain) and using techniques such as avoidance, and adapting. The adolescents' actions and behaviour were possibly influenced by their expectations of the outcome. They seemed to have learned that expressing pain and the need for OTCAs lead to sympathy and care. Such socially learned behaviour might be maintained when the adolescents experience that the behaviour leads to actions that meet their needs; such mechanisms are described in other studies [51, 93]. The adolescents might exercise control in expectation of gaining benefits, which could help them avoid stressors [10]. The adolescents' self-efficacy can then play a major role in how they approach goals, tasks, and challenges, as described by Badura [50]. Furthermore, social experience is by other researchers found to be closely related to attachment, and important in personality development [10]. The adolescents seemed to have learned coping strategies through observation, imitation, and by modelling their mothers [94]. In accordance with other studies such coping strategies might be ineffective over time, and ultimately act against their initial goal: to master, tolerate, or reduce the demands of stressful situations [95, 96]. The ability to cope effectively with stressors such as pain, pressure, and expectations is found to be important in influencing patterns of positive growth and development among adolescents [97].

The adolescents in study 2 experienced complex intersecting problems, including reduced self-esteem, frequent pain from several body parts, fatigue, sleeping problems, lack of concentration, feelings of loneliness, stress, worry, sadness, and anxiety. Such experiences are in research found to affect quality of life negatively [105]. As an illustration of the load of problems described by the adolescents interviewed in study 2 and confirmed by the mothers 
in study 3 , some had eating problems, more than half had been bullied, and almost one third had required support from the Child Protective Services. Some expressed serious symptoms of conditions like anxiety and depression, some described suicidal thoughts, some reported self-harming, and some had severe chest pain associated with challenges. Most of the adolescents (study 2) also concealed their inner feelings; they expressed dissatisfaction with themselves, their appearance, and their achievements. Research have showed that feeling good, being satisfied with oneself, having an overall positive attitude, and a positive selfimage are important for having a good quality of life [110, 141, 187]. Adolescents' self-image is in earlier research found to be associated with the ability to make friends, andjust like good family relations, friends are important for quality of life [141, 187, 188]. As described earlier, several had been bullied over time, which is found to affect quality of life negatively [110, 161]. Pain, depressive symptoms, psychological disturbance, and reduced quality of life are found to be associated with loneliness and bullying $[153,154,188]$. The participants in our study reported suffering from severe pain, which research shows that in itself affects quality of life negatively [161]. In an earlier study by Haraldstad et al. (2011), frequent pain is found to hamper possibilities for managing school performance and leisure activities [57]. This might increase a feeling of being a failure and give lower self-esteem. It is also possible that, in addition to family problems, continuous pain and negative feedback from peers over time give the adolescents negative feelings about themselves and reduce their self-image. We observed gaps between the adolescents' idealised images of being successful and how they rated themselves. Closing or reducing these gaps might increase quality of life.

The results from study 1 illustrates that high frequency use of OTCA can be a warning sign of a troubled life. This should be acknowledged by the school nurses, who offer low threshold services to the general population of young people. Adolescents at risk should also be offered 
support by professionals who understand biopsychosocial functioning. Only explaining the risk associated with high use of OTCAs or giving other warnings will not necessarily help. These adolescents must be approached with open interest in how they manage their lives and how they interact with their main caregivers and peers.

Paper 2 and 3 contribute with a deeper understanding of the complex interactions between each adolescent and their significant others. These papers describe the importance of involving the family in the therapeutic process of helping the high consumers of OTCA. The consumers often lack self-understanding and have poor management strategies for difficulties, both of which may be improved through therapy. However, the papers also describe that the pain in many of the families is a project which keeps the adolescents and the mother close. Therefore, interacting on the pain project as a professional should be done with deep understanding, knowledge and respect. This may require time, patience and endurance. Elements from family therapy and cognitive therapy may be applied in the project of helping the adolescents towards healthy development. More research is needed to design and examine appropriate intervention.

According to our findings, biological predispositions, family environment, cognitive appraisal, coping strategies, and perceived social support all seem to influence adolescents' use of OTCAs. The biobehavioural model of paediatric pain might be useful in designing an instrument for mapping and further developing an intervention for assisting adolescents, who feel a need for frequent use of OTCAs [12]. 


\section{Ethical experiences and reflections}

Initially we stressed that our studies should not put extra burdens or risk on the informants.

We also established precautions to protect those who needed support because their health was threatened. In two cases, the researcher helped the adolescent establish contact with the school health nurse.

Nobody questioned the researchers about the ethics of this study, nor about its confidentiality policy. It might be that people in general trust health professionals as researchers. Some wanted to be interviewed at an office in school, others at the researchers' office. The participants seemed to be satisfied with the information and arrangement in general, as well as our flexibility when planning a place and time for the interviews.

We experienced that the adolescents who participated in the qualitative study were well prepared and had reflected on their participation. They also expressed that they were pleasantly surprised by the researcher's interest in their challenges in life. Several cried during the interview as they spoke about difficult experiences. Nevertheless, when asked at the end of the interviews, they said it had been good to talk about these issues with another person. It must be pointed out that the researcher occasionally empathised with the adolescent and wished to give professional help and support. The researchers appreciated receiving guidance from the experienced main supervisor, since at times during the interviews they felt worried on behalf of the adolescents and even guilty for not giving give health care support and guidiance.

The researchers let the adolescents themselves invite their parents to join the qualitative study in order to ensure that they really did want their parents to participate. This recruitment 
procedure worked out well and gave the researchers opportunities to increase the information given to the potential participant. Several participants contacted the researcher asking for more information before signing the informed consent form. Participants was also informed that they had access to the information that was registered about them and coud correct errors in this information. None of the participants used any of these options. Perhaps the participants had thought through what they were comfortable about sharing with the researchers. On the other hand, it might be that we had not informed them clearly enough about these options. While reading the transcripts, it became clear that both adolescents and their mothers were focused, well prepared, and willing to tell their stories. Because of their preparation, we believe that the participants were highly aware of the aim of the study and willing to share their stories.

Feelings of sadness and sorrow shine through in several of the interviews and it might be that the participants' insight increased as they put their feelings and experiences into words. Summing up the interview by focusing on how the interview had been and what could have been done differently was a significant benefit to both the interviewee and the interviewer. Using this way to round off the interview moved thoughts and feelings away from previously difficult experiences and reduced the negative emotions that had been touched on.

The qualitative interviews created an emotional link between the researcher and the research participants, and preparing for this was paramount. The researcher conducting the interviews was a psychiatric nurse. She experienced that her professional background was a strength she could draw on to carry out the interviews in a gentle manner, and to make sure that the interviewee was adequately taken care of. It is a challenge to carry out a meaningful and respectful conversation with a person you do not know; even more challenging when the 
conversation has a specific purpose. This requires kindness and humility, as well as planned and targeted communication. Self-reflection and guidance from the main supervisor were needed, and functioned as hugely supportive in this regard.

Some adolescents wanted to participate in our studies but stated that their parents did not let them. Others told us that they wanted their mothers to participate but they refused. The adolescents expressed that they were sorry about this. It might be that our information to the parents was not always good enough, or that they wanted to protect their child and themselves. It might also be that their reasons were plainly a lack of time and perceived benefit. However, in these cases the researchers were clear that there was no obligation to participate and that it was fully acceptable not to participate or give permission to participate. 


\section{Conclusion}

A high consumption of OTCAs was significantly associated with more pain, less sleep at night, lower self-esteem, less ambitious educational plans, higher absence from school, having paid spare-time work, more episodes of binge drinking and daily intake of caffeinated drinks. According to the interviewed adolescents and their mothers' stories, childhood and upbringing were marked by conflict, stress, and strains. Reduced self-esteem may in itself indicate reduced capacity for handling stress and strain. Stressful experiences early in life, such as family conflicts, might have affected attachment and hampered identity development. Persistent stress may also have affected adolescents' biopsychosocial development, which further may have affected their perception of pain.

Mothers had a strong influence on the adolescents' everyday life. Attachment to the mother seemed to have had a noticeable impact on the adolescents' experience, rating, and expression of pain throughout childhood. Coping with difficult situations and stresses by attempting to mask symptoms by using OTCAs may perpetuate and amplify underlying problems. A high consumption of OTCAs may thus be a warning sign of adolescents with possible health threatening conditions and reduced quality of life.

The adolescents' everyday lives were hampered by pain, reducing their ability to fulfil their expectations. The adolescents did not feel satisfied with themselves, or with their appearance. Frequent pain, conflicts between the parents, feelings of loneliness, and being bullied may be stressors that individually might reduce the adolescent's quality of life. These factors may also be mutually reinforcing and cause high amounts of stress, which over time might lead to health complaints and pain. 
Erikson (1963) claimed that personality is shaped over the life span, which implies that experiences later in life can heal or ameliorate problems in early childhood $[2,4]$. In this stage of life, it may be of the utmost importance to support the adolescents in coping with stresses and strain, such as pain. Interventions to increase the adolescents' ability to handle stressful life events, emotional pressure, and daily hassles could possibly reduce their future need for OTCAs. A Danish study found that the association between frequency of complaints and medicine use was stronger among students who had not re-visited the school nurse compared to the students who had. This might indicate that the school nurse is in a position to reduce the students' proneness to use medicine [189].

Through the three studies presented in this thesis, possible perspectives that might lead to novel approaches identifying, guiding, and supporting adolescents with frequent pain and high consumption of OTCAs are identified. Individual tasks, family matters, and bullying must be considered both in mapping and in designing interventions. However, more research is needed to design a guide for professional mapping and health interventions. 


\section{References}

1. Choudhury, S., Blakemore, S.J., \& Charman, T. (2006). Social cognitive development during adolescence. Social cognitive and affective neuroscience, 1(3), 165-174.

2. Erikson, E.H. (1993). Childhood and society. London: WW Norton \& Company.

3. Christie, D., \& Viner, R. (2005). Adolescent development. Bmj, 330(7486), 301-304.

4. Erikson, E.H. (1968). Youth and crisis. New York - London: WW Norton \& Company.

5. Marcia, J.E. (1980). Identity in adolescence. Handbook of adolescent psychology. J. Adelson. New York, NY, Wiley-Interscience.

6. Viner, R.M., Ozer, E.M., Denny, S., Marmot, M., Resnick, M., Fatusi, A., et al. (2012). Adolescence and the social determinants of health. The Lancet, 379(9826), $1641-1652$.

7. Miller, G.E., Chen, E., \& Parker, K.J. (2011). Psychological stress in childhood and susceptibility to the chronic diseases of aging: moving toward a model of behavioral and biological mechanisms. Psychological bulletin, 137(6), 959-97.

8. Dodge, K.A. \& Pettit, G.S. (2003). A biopsychosocial model of the development of chronic conduct problems in adolescence. Developmental psychology, 39(2), 349.

9. Ainsworth, M.D.S. (1997). The Bowlby-Ainsworth attachment theory. Behav Brain Sci., 1 .

10. Bandura, A. (1997). Self-efficacy: the exercise of control. New York: Freeman.

11. Danese, A. \& McEwen, B. (2012). Adverse childhood experiences, allostasis, allostatic load, and age-related disease. Physiol Behav., 106(1), 29-39.

12. Sawyer, M.G., Carbone, J.A., Whitham, J.N., Roberton, D.M., Taplin, J.E., Varni, J.W., et al. (2005). The relationship between health-related quality of life, pain, and 
coping strategies in juvenile arthritis-A one year prospective study. Quality of life research, 14(6), 1585-1598.

13. Legemiddelverket. Statens legemiddelverk. 2016 20.05.2016]; Available from: http://www.legemiddelverket.no/.

14. Lagerløv, P., Holager, T., Helseth, S., Rosvold, E.O. (2009). Selvmedisinering med reseptfrie smertestillende legemidler hos 15-16-åringer [Self-medication with overthe-counter analgesics among 15-16 years old teenagers]. Tidsskrift for Den norske legeforening, 129(15), 1447-1450.

15. Sakshaug, S., Strøm, H., Berg, C., Blix, H.S., Litleskare, I., Granum, T. (2015). Drug Consumption in Norway 2010-2014. Legemiddelstatistikk, 2015(1).

16. Furu, K., Skurtveit, S., \& Rosvold, E. (2005). [Self-reported medical drug use among 15-16 year-old adolescents in Norway]. Tidsskrift for den Norske laegeforening: tidsskrift for praktisk medicin, 125(20), 2759-2761.

17. Holstein, B., Andersen, A., Due, P., Hansen, E.H. (2009). [Children's and adolescent's use of medicine for aches and psychological problems: secular trends from 1988 to 2006]. Ugeskrift For Laeger, 171(1-2), 24-28.

18. Westerlund, M., Brånstad, J.O., \& Westerlund, T. (2008). Medicine-taking behaviour and drug-related problems in adolescents of a Swedish high school. Pharmacy World \& Science, 30(3), 243-250.

19. SSB. Folkemengde og befolkningsendringar [Population and population changes], 1 . januar 2016. 2016 20.05.2016]. Available from: https://www.ssb.no/befolkning/statistikker/folkemengde/aar-per-1-januar/2016-02-19

20. Wu, L.T., Pilowsky, D.J., \& Patkar, A.A. (2008). Non-prescribed use of pain relievers among adolescents in the United States. Drug And Alcohol Dependence, 94(1-3), 111. 
21. Holager, T., Lagerlov, P., Helseth, S., Rosvold, E.O. (2009). Holdninger til bruk av reseptfrie smertestillendelegemidler blandt 15-16 åringer [Attitudes to over-thecounter analgesics among 15-16 year-old teenagers]. Tidsskrift for Den Norske Legeforening, 129(15), 1451-1454.

22. Fouladbakhsh, J.M., Vallerand, A.H., \& Jenuwine, E.S. (2012), Self-treatment of pain among adolescents in an urban community. Pain management nursing, 13(2), 80-93.

23. Kirkeby, M.J., Hansen, C.D., \& Andersen, J.H. (2014). Socio-economic differences in use of prescribed and over-the-counter medicine for pain and psychological problems among Danish adolescents—a longitudinal study. European journal of pediatrics, 173(9), 1147-1155.

24. Jensen, J.F., Gottschau, M., Siersma, V.D., Graungaard, A.H., Holstein, B.E., Knudsen, L.E. (2014). Association of maternal self-medication and over-the-counter analgesics for children. Pediatrics. 133(2), e291-e298.

25. Mitka, M. (2004). When Teens Self-treat Headaches, OTC Drug Misuse Is Frequent Result. JAMA: Journal of the American Medical Association, 292(4), 424-425.

26. Buczak, A., Lukasik, I., \& Witek, A. (2010). [Use of painkillers by Polish secondary school students and the influence of TV commercials]. Gesundheitswesen (Bundesverband der Arzte des Offentlichen Gesundheitsdienstes (Germany), 72(11), 808-812.

27. Holmstrom, I.K., Bastholm-Rahmner, P., Bernsten, C., Roing, M., Bjorkman, I. (2014). Swedish teenagers and over-the-counter analgesics - responsible, casual or careless use. Research in social \& administrative pharmacy, 10(2), 408-418.

28. Lagerløv, P., Rosvold, E.O., Holager, T., Helseth S. (2016). How adolescents experience and cope with pain in daily life: a qualitative study on ways to cope and the use of over-the-counter analgesics. BMJ open, 6(3), e010184, 1-8. 
29. Koushede, V., \& Holstein, B.E. (2009). Sense of coherence and medicine use for headache among adolescents. Journal of Adolescent Health, 45(2), 149-155.

30. Williams, C.M., Maher, C.G., Latimer, J., McLachlan, A.J., Hancock, M.J., Day, R.O., et al. (2014). Efficacy of paracetamol for acute low-back pain: a double-blind, randomised controlled trial. The Lancet, 384 (9954), 1586-1596.

31. Diener, H.C., \& Limmroth, V. (2004). Medication-overuse headache: a worldwide problem. The Lancet Neurology, 3(8), 475-483.

32. Evers, S., \& Marziniak, M. (2010). Clinical features, pathophysiology, and treatment of medication-overuse headache. The Lancet Neurology, 9(4), 391-401.

33. Silberstein, S., Olesen, J., Bousser, M.G., Diener, H.C., Dodick, D., First, M., et al. (2005). The International Classification of Headache Disorders, (ICHD-II)—revision of criteria for 8.2 Medication-overuse headache. Cephalalgia, 25(6), 460-465

34. Zwart, J.A., Dyb, G., Hagen, K., Svebak, S., Holmen, J. (2003). Analgesic use: A predictor of chronic pain and medication overuse headache. The Head-HUNT Study. Neurology, 61(2), 160-164.

35. Koushede, V., Ekholm, O., Holstein, B.E., Andersen, A., Hansen, E.H. (2011). Stress and use of over-the-counter analgesics: prevalence and association among Danish 25 to 44-year-olds from 1994 to 2005. International journal of public health, 56(1), 81-87.

36. Romeo, R. D., \& McEwen, B. S. (2006). Stress and the adolescent brain. Annals of the New York Academy of Sciences, 1094(1), 202-214.

37. Steinberg, L. (2005). Cognitive and affective development in adolescence. Trends in cognitive sciences, 9(2), 69-74.

38. Lupien, S.J., McEwen, B.S., Gunnar, M.R., Heim, C. (2009). Effects of stress throughout the lifespan on the brain, behaviour and cognition. Nature Reviews Neuroscience, 10(6), 434-445. 
39. McIntosh, N., Helms, P., Smyth, R.L., Forfar, J.O., Arneil, G.C. Forfar \& Arneil's textbook of pediatrics. 7 ed. Edinburgh: Churchill Livingstone; 2003.

40. Freud, S., \& Bonaparte, P.M. (1954). The origins of psychoanalysis. Imago London.

41. Piaget, J. (1976). Piaget's theory, in Piaget and his school : a reader in developmental pscyhology, B. Inhelder, H., Chipman H., and Zwingmann C., Editors. Springer: New York. [p.11-32].

42. Piaget, J., \&Inhelder, B. (2013). The growth of logical thinking from childhood to adolescence: An essay on the construction of formal operational structures. (First publ. 1958). Abingdon: Routledge.

43. Gatchel, R.J., Peng, Y.B., Peters, M.L., Fuchs, P.N., Turk, D.C. (2007). The biopsychosocial approach to chronic pain: Scientific advances and future directions. Psychological Bulletin, 133(4), 581-624.

44. Gatchel, R.J. (2005). Clinical essentials of pain management. Washington: American Psychological Association.

45. Wheeler, M.D. (1991). Physical changes of puberty. Endocrinology and metabolism clinics of North America, 20(1), 1-14.

46. Spear, B.A. (2002). Adolescent growth and development. Journal of the American Dietetic Association. Suppl., 23-29.

47. Sisk, C.L., \& Foster, D.L. (2004). The neural basis of puberty and adolescence. Nature neuroscience, 7(10), 1040-1047.

48. Beauchamp, M.H., \& Anderson, V. (2010). SOCIAL: an integrative framework for the development of social skills. Psychological bulletin, 136(1), 39-64.

49. Blakemore, S.J. (2008). The social brain in adolescence. Nature Reviews Neuroscience, 9(4), 267-277. 
50. Bandura, A. (1992). Self-efficacy mechanism in psychobiologic functioning, in Selfefficacy: Thought control of action, R. Schwarzer, Editor. Hemisphere: Washington. [p. 355-409].

51. Bandura, A., O'Leary, A., Taylor, C.B., Gauthier, J., Gossard, D. (1987). Perceived self-efficacy and pain control: opioid and nonopioid mechanisms. Journal of personality and social psychology, 53(3), 563.

52. Slade, P.D. (1994). What is body image? Behaviour research and therapy, 32(5): p.497-502.

53. Smolak, L. (2004). Body image in children and adolescents: where do we go from here? Body image, 1(1), 15-28.

54. Merskey, H. (1994). IASP Task Force on Taxonomy (Classification of chronic pain). Seattle, WA: International Association for the Study of Pain Press (Also available online at www.iasp-pain.org).

55. McCaffery, M., \& Beebe, A. (1989). Pain: Clinical manual for nursing practice. St. Louis, Missouri: Mosby

56. Craig, K.D. (2009). The social communication model of pain. Canadian Psychology / Psychologie canadienne, 50(1), 22-32.

57. Haraldstad, K., Sørum, R., Eide, H., Natvig, G.K., Helseth, S. (2011). Pain in children and adolescents: prevalence, impact on daily life, and parents' perception, a school survey. Scand J Caring Sci, 25(1), 27-36.

58. Perquin, C.W., Hazebroek-Kampschreur, A.A., Hunfeld, J.A., Bohnen, A.M., van Suijlekom-Smit, L.W., Passchier, J., et al. (2000). Pain in children and adolescents: a common experience. Pain, 87(1), 51-58. 
59. Roth-Isigkeit, A., Thyen, U., Stöven, H., Schwarzenberger, J., \& Schmucker, P. (2005). Pain among children and adolescents: restrictions in daily living and triggering factors. Pediatrics, 115(2), e152-e162.

60. Hoftun, G. B., Romundstad, P. R., Zwart, J. A., \& Rygg, M. (2011). Chronic idiopathic pain in adolescence-high prevalence and disability: the young HUNT Study 2008. PAIN®, 152(10), 2259-2266.

61. Gold, J.I., Yetwin, A.K., Mahrer, N.E., Carson, M.C., Griffin, A.T., Palmer, S.N., et al. (2009). Pediatric chronic pain and health-related quality of life. Journal of pediatric nursing, 24(2), 141-150.

62. Groenewald, C.B., Essner, B.S., Wright, D., Fesinmeyer, M.D., Palermo, T.M. (2014). The economic costs of chronic pain among a cohort of treatment-seeking adolescents in the United States. The Journal of Pain, 15(9), 925-933

63. Brattberg, G. (2004). Do pain problems in young school children persist into early adulthood? A 13-year follow-up. European Journal of Pain, 8(3), 187-199.

64. Jones, G.T., Silman, A.J., Power, C., Macfarlane, G.J. (2007). Are common symptoms in childhood associated with chronic widespread body pain in adulthood? Results from the 1958 british birth cohort study. Arthritis \& Rheumatism, 56(5), 1669-1675.

65. Petersen, S., Bergström, E., \& Brulin, C. (2003). High prevalence of tiredness and pain in young schoolchildren. Scandinavian journal of public health, 31(5), 367-374.

66. Hoftun, G.B., Romundstad, P.R., \& Rygg, M. (2013). Association of parental chronic pain with chronic pain in the adolescent and young adult: family linkage data from the HUNT study. JAMA pediatrics, 167(1), 61-69.

67. Eccleston, C., Crombez, G., Scotford, A., Clinch, J., Connell, H. (2004), Adolescent chronic pain: patterns and predictors of emotional distress in adolescents with chronic pain and their parents. Pain, 108(3), 221-229. 
68. Eccleston, C., Wastell, S., Crombez, G., Jordan, A. Adolescent social development and chronic pain. European Journal of Pain. 2008;12(6), 765-774.

69. Esteve, R., \& Marquina-Aponte, V. (2012). Children's pain perspectives. Child: care, health and development, 38(3), 441-452.

70. Goubert, L., Vervoort, T., Cano, A., Crombez, G. (2009). Catastrophizing about their children's pain is related to higher parent-child congruency in pain ratings: an experimental investigation. European Journal of Pain, 13(2), 196-201.

71. Brodal, P. (2004). The central nervous system: structure and function. Oxford University Press.

72. Melzack, R., \& Wall, P.D. (1967). Pain mechanisms: a new theory. Survey of Anesthesiology, 11(2), 89-90.

73. McEwen, B.S., \& Wingfield, J.C. (2003). The concept of allostasis in biology and biomedicine. Hormones and behavior, 43(1), 2-15.

74. Slater, R., Fabrizi, L., Worley, A., Meek, J., Boyd, S., Fitzgerald, M. (2010). Premature infants display increased noxious-evoked neuronal activity in the brain compared to healthy age-matched term-born infants. Neuroimage, 52(2), 583-589.

75. Hermann, C., Hohmeister, J., Demirakça, S., Zohsel, K., Flor, H. (2006). Long-term alteration of pain sensitivity in school-aged children with early pain experiences. Pain, $125(3), 278-285$.

76. Danese, A., Moffitt, T.E., Harrington, H., Milne, B.J., Polanczyk, G., Pariante, C.M., et al. (2009). Adverse Childhood Experiences and Adult Risk Factors for Age-Related Disease: Depression, Inflammation, and Clustering of Metabolic Risk Markers. Archives of pediatrics \& adolescent medicine, 163(12), 1135-1143. 
77. Chapman, D.P., Whitfield, C.L., Felitti, V.J., Dube, S.R., Edwards, V.J., Anda, R.F. (2004). Adverse childhood experiences and the risk of depressive disorders in adulthood. Journal of affective disorders, 82(2), 217-225.

78. Härmä, A.M., Kaltiala-Heino, R., Rimpelä, M., Rantanen, P. (2002). Are adolescents with frequent pain symptoms more depressed? Scandinavian journal of primary health care, 20(2), 92-96.

79. Bretherton, I. (1992). The origins of attachment theory: John Bowlby and Mary Ainsworth. Developmental psychology, 28(5), 759.

80. Bowlby, J. (1952). Maternal care and mental health (Vol. 2). Geneva: WHO.

81. Allen, J.P., McElhaney, K.B., Land, D.J., Kuperminc, G.P., Moore, C.W., O'BeirneKelly, H., et al. (2003). A secure base in adolescence: Markers of attachment security in the mother-adolescent relationship. Child development, 74(1), 292-307.

82. Marsh, P., McFarland, F.C., Allen, J.P., Mcelhaney, K.B., Land, D. (2003). Attachment, autonomy, and multifinality in adolescent internalizing and risky behavioral symptoms. Development and Psychopathology, 15(02), 451-467.

83. Cummings, E.M., \& Davies, P. (1996). Emotional security as a regulatory process in normal development and the development of psychopathology. Development and Psychopathology, 8(01), 123-139.

84. Rutter, M., \& Sroufe, L.A. (2000). Developmental psychopathology: Concepts and challenges. Development and psychopathology, 12(03), 265-296.

85. Erikson, E. H. (1962). Youth: Fidelity and diversity. Daedalus, 5-27.

86. Markstrom-Adams, C., Hofstra, G., \& Dougher, K. (1994). The ego-virtue of fidelity: A case for the study of religion and identity formation in adolescence. Journal of Youth and Adolescence, 23(4), 453-469.

87. Santrock, J.W. (2009). Life-span development. McGraw-Hill Boston, MA. 
88. DuBois, D.L., \& Hirsch, B.J. (2000). Self-esteem in early adolescence: From stock character to marquee attraction. The Journal of Early Adolescence, 20(1), 5-11.

89. Erikson, E.H. (1964). Psychological reality and historical actuality. Insight and responsibility. [p. 159-215].

90. Kroger, J., \& Marcia, J.E. (2011). The identity statuses: Origins, meanings, and interpretations, in Handbook of identity theory and research. Springer, New York, [p. $31-53]$.

91. Marcia, J.E. (1966). Development and validation of ego-identity status. Journal of personality and social psychology, 3(5), 551-558.

92. Malterud, K. (2001). Qualitative research: standards, challenges, and guidelines. The lancet, 358(9280), 483-488.

93. Bandura, A. (1993). Perceived Self-Efficacy in Cognitive Development and Functioning. Educational Psychologist, 28(2), 117-148.

94. Luszczynska, A., U. Scholz, \& Schwarzer R. (2005). The general self-efficacy scale: Multicultural validation studies. The Journal of psychology, 139(5), 439-457.

95. Folkman, S., Lazarus, R. S., Gruen, R. J., \& DeLongis, A. (1986). Appraisal, coping, health status, and psychological symptoms. Journal of personality and social psychology, 50(3), 571-579.

96. Folkman, S., \& Moskowitz, J.T. (2000). Stress, Positive Emotion, and Coping. Curr Dir Psychol Sci, 9(4), 115-118.

97. Werner, E. E. (2000). Protective factors and individual resilience. Handbook of early childhood intervention, 2, 115-132.

98. Bowers, K.S. (1968). Pain, anxiety and perceived control Journal of Consulting and Clinical Psychology, 32(5), 596-602. 
99. Karatsoreos, I.N., \& McEwen, B.S. (2011). Psychobiological allostasis: resistance, resilience and vulnerability. Trends in cognitive sciences, 15(12), 576-584.

100. Repetti, R.L., Robles T.F., \& Reynolds B. (2011). Allostatic processes in the family. Development and Psychopathology, 23(Special Issue 03), 921-938.

101. Danese, A., Moffitt, T. E., Harrington, H., Milne, B. J., Polanczyk, G., Pariante, C. M \& Caspi, A. (2009). Adverse childhood experiences and adult risk factors for agerelated disease: depression, inflammation, and clustering of metabolic risk markers. Archives of pediatrics \& adolescent medicine, 163(12), 1135-1143.

102. Ferrans, C.E. (2005). Definitions and conceptual models of quality of life. Outcomes assessment in cancer: Measures, methods, and applications, 14-30.

103. Wahl, A., \& Hanestad, B. (2004). Måling av livskvalitet i klinisk praksis. En innføring [Measuring quality of life in clinical practice; an introduction]. Bergen: Fagbokforlaget.

104. Næss, S. (2001). Quality of life as psychological well-being. Tidsskrift for den Norske lægeforening: tidsskrift for praktisk medicin, ny række, 121(16), 1940-1944.

105. Næss, S., Mastekaasa, A., Moum, T., Sørensen, T. (2001). Livskvalitet som psykisk velvare [Quality of life as psychological wellbeing]. NOVA-rapport. 2001(3).

106. Ravens-Sieberer, U., Erhart, M., Wille, N., Wetzel, R., Nickel, J., Bullinger, M. (2006). Generic health-related quality-of-life assessment in children and adolescents. Pharmacoeconomics, 1;24(12), 1199-1220.

107. WHO Int. Health (Definition). 2016 20.05.2016]; Available from: http://www.who.int/about/definition/en/print.html.

108. Padilla, G., Grant, M., Ferrell, B., Presant, C. (1996). Quality of life-cancer. Quality of life and pharmacoeconomics in clinical trials New York: Lippincott-Raven, 301-8. 
109. Frisén, A., (2007). Measuring health-related quality of life in adolescence. Acta Paediatrica, 96(7), 963-968.

110. Haraldstad, K., Christophersen, K. A., Eide, H., Nativg, G. K., \& Helseth, S. (2011). Predictors of health-related quality of life in a sample of children and adolescents: a school survey. Journal of clinical nursing, 20(21-22), 3048-3056.

111. Di Maio, M., Gridelli, C., Gallo, C., Manzione, L., Brancaccio, L., Barbera, S., et al. (2004). Prevalence and management of pain in Italian patients with advanced nonsmall-cell lung cancer. British journal of cancer, 90(12), 2288-2296.

112. Cain, K.C., Headstrom, P., Jarrett, M.E., Motzer, S.A., Park, H., Burr, R.L., et al. (2006). Abdominal pain impacts quality of life in women with irritable bowel syndrome. The American journal of gastroenterology, 101(1), 124-132.

113. Langeveld, J.H., Koot, H.M., \& Passchier, J. (1997). Headache intensity and quality of life in adolescents. How are changes in headache intensity in adolescents related to changes in experienced quality of life? Headache: The Journal of Head and Face Pain, $37(1), 37-42$.

114. Hunfeld, J., Passchier, J., Perquin, C., Hazebroek-Kampschreur, A., Suijlekom-Smit, V., Van Der Wouden, J. (2001), Quality of life in adolescents with chronic pain in the head or at other locations. Cephalalgia, 21(3), 201-206.

115. Merlijn, V. P., Hunfeld, J. A., van der Wouden, J. C., Hazebroek-Kampschreur, A. A., Passchier, J., \& Koes, B. W. (2006). Factors related to the quality of life in adolescents with chronic pain. The Clinical journal of pain, 22(3), 306-315.

116. Felce, D., \& Perry, J. (1995). Quality of life: Its definition and measurement. Research in developmental disabilities, 16(1), 51-74.

117. Rosenberg, M. (1965). Society and the adolescent self-image., ed. N.P.U.P. Princeton. 
118. Tams, K. (2004). Moderate effects of hearing loss on mental health and subjective well-being: Results from the Nord-Trondelag Hearing Loss Study. Psychosom Med, 66(5), 776-782.

119. Lerdal, A., Andenæs, R., Bjørnsborg, E., Bonsaksen, T., Borge, L., Christiansen, B., et al. (2011). Personal factors associated with health-related quality of life in persons with morbid obesity on treatment waiting lists in Norway. Quality of Life Research, 20(8), 1187-1196.

120. Sakshaug, S. Legemiddelforbruket i Norge 2007-2011 (Drug Consumption in Norway 2007-2011), Nasjonalt folkehelseinstitutt (Norwegian Institute of Public Health), Legemiddelstatistikk, 2012 (1).

121. Brinkmann, S. (2011). Interviewing and the production of the conversational self, in Qualitative inquiry and global crises, N.K. Denzin and M.D. Giardina, Editors. Routledge; Left Coast Publishing: Abingdon, [p. 56-75].

122. Kvale, S. and Brinkmann, S. (2009). Interviews: Learning the craft of qualitative research interviewing. Los Angeles. Sage.

123. Morse, J.M. (1995). The significance of saturation. Qualitative health research, 5(2), 147-149.

124. QSR International. Nvivo 10 2016; Available from: http://www.qsrinternational.com/product.

125. Polit, D.F., \& Beck, C.T. (2014). Essentials of nursing research: Appraising evidence for nursing practice. Philadelphia: Lippincott Williams \& Wilkins.

126. Kvale, S., \& Brinkmann, S. (2010). Det kvalitative forskningsintervju (The qualitative research interviewing). 2 ed. Oslo: Gyldendal Akademisk.

127. Eisikovits, Z., \& Koren, C. (2010). Approaches to and outcomes of dyadic interview analysis. Qualitative Health Research, 20(12), 1642-1655. 
128. Polit, D.F. and Beck, C.T. (2008). Nursing research: Generating and assessing evidence for nursing practice. Philadelphia: Lippincott Williams \& Wilkins.

129. Brinkmann, S., \& Kvale, S. (2008). Ethics in qualitative psychological research. The Sage handbook of qualitative research in psychology, 24(2), 263-279.

130. LoBiondo-Wood, G., \& Haber, J. (2014). Nursing research: Methods and critical appraisal for evidence-based practice. Elsevier Health Sciences.

131. Lincoln, Y.S., \& Guba, E.G. (1985). Naturalistic inquiry. Beverly Hills, Sage.

132. Jootun, D., McGhee, G., \& Marland, G.R. (2009). Reflexivity: promoting rigour in qualitative research. Nursing Standard, 23(23), 42-46.

133. Guba, E. G., \& Lincoln, Y. S. (1994). Competing paradigms in qualitative research. Handbook of qualitative research, 2(163-194), 105.

134. NTNU-HUNT. The HUNT study. Updated 2016 20.05.2016]; Available from: http://www.ntnu.edu/hunt.

135. Kaasa, S., \& Loge, J.H. Quality of life in palliative care: principles and practice. Palliative medicine, 2003. 17(1), 11-20.

136. Del Boca, F. K., \& Darkes, J. (2003). The validity of self-reports of alcohol consumption: state of the science and challenges for research. Addiction, 98(2), 1-12.

137. Steingrımsdóttir, O.A., Vøllestad, N.K., Røe, C., Knardahl, S. (2004). Variation in reporting of pain and other subjective health complaints in a working population and limitations of single sample measurements. Pain, 110(1), 130-139

138. Coutts, E., \& Jann, B. (2011). Sensitive questions in online surveys: Experimental results for the randomized response technique (RRT) and the unmatched count technique (UCT). Sociological Methods \& Research, 40(1), 169-193.

139. Shenton, A.K., (2004). Strategies for ensuring trustworthiness in qualitative research projects. Education for information, 22(2), 63-75. 
140. Morse, J.M., Barrett, M., Mayan, M., Olson, K., Spiers, J. (2008). Verification strategies for establishing reliability and validity in qualitative research. International journal of qualitative methods, 1(2), 13-22.

141. Winger, A., Ekstedt M., Wyller, V.B., Helseth, S. (2014). 'Sometimes it feels as if the world goes on without me': adolescents' experiences of living with chronic fatigue syndrome. Journal of clinical nursing, 23(17-18), 2649-2657.

142. Berndt, T. J. (2002). Friendship quality and social development. Current directions in psychological science, 11(1), 7-10.

143. Helseth, S., \& Misvær, N. (2010). Adolescents' perceptions of quality of life: what it is and what matters. J Clin Nurs, 19(9-10), 1454-1461.

144. Main, M., Kaplan, N., \& Cassidy, J. (1985). Security in infancy, childhood, and adulthood: A move to the level of representation. Monographs of the society for research in child development, 66-104.

145. Allen, J.P., Moore, C., Kuperminc, G., Bell, K. (1998). Attachment and adolescent psychosocial functioning. Child development, 69(5), 1406-1419.

146. Ainsworth, M.D.S., Bell, S.M., \& Stayton, D.F. (1974). Infant-mother attachment and social development: Socialization as a product of reciprocal responsiveness to signals, in The integration of a child into a social world. Cambridge University Press: New York, NY, US. [p. 99-135].

147. Allen, J.P., Porter, M., McFarland, C., McElhaney, K.B., Marsh, P. (2007). The relation of attachment security to adolescents' paternal and peer relationships, depression, and externalizing behavior. Child development, 78(4), 1222-1239

148. Crowell, J.A., Treboux, D., Gao, Y., Fyffe, C., Pan, H., Waters, E. (2002). Assessing secure base behavior in adulthood: Development of a measure, links to adult 
attachment representations and relations to couples' communication and reports of relationships. Developmental psychology, 38(5), 679-693.

149. Wigfield, A., \& Eccles, J.S. (2002). The development of competence beliefs, expectancies for success, and achievement values from childhood through adolescence, in Development of achievement motivation, A. Wigfield and J.S. Eccles, Editors. Elsevier science: Burlington. 91, V120.

150. Hao, L., \& Bonstead-Bruns, M. (1998). Parent-child differences in educational expectations and the academic achievement of immigrant and native students. Sociology of Education, 175-198.

151. Zhang, Y., Haddad, E., Torres, B., Chen, C. (2011). The reciprocal relationships among parents' expectations, adolescents' expectations, and adolescents' achievement: A two-wave longitudinal analysis of the NELS data. Journal of youth and adolescence, 40(4), 479-489.

152. Sawyer, S.M., Afifi, R.A., Bearinger, L.H., Blakemore, S.J, Dick, B., Ezeh, A.C., et al. (2012). Adolescence: a foundation for future health. The Lancet, 379(9826), 16301640.

153. Demir, A., \& Tarhan, N. (2001). Loneliness and social dissatisfaction in Turkish adolescents. The Journal of Psychology, 135(1), 113-123.

154. Mahon, N.E., Yarcheski, A., Yarcheski, T.J., Cannella, B.L., Hanks, M.M. A (2006). meta-analytic study of predictors for loneliness during adolescence. Nursing research, 55(5), 308-315.

155. Nordahl, T. (2000). En skole - to verdener: et teoretisk og empirisk arbeid om problematferd og mistilpasning $i$ et elev-og laererperspektiv. [One School-Two Worlds]. Norsk institutt for forskning om oppvekst velferd og aldring [Norwegian Institute for research on of society and the welfare state], NOVA-rapport, 2000(11). 
156. Olweus, D. (1993). Victimization by peers: Antecedents and long-term outcomes, in Social withdrawal, inhibition, and shyness in childhood, K. Rubin and J. Asendorpf, Editors, Lawrence Erlbaum: Hillsdale. [p. 315-341].

157. Kaltiala-Heino, R., Fröjd, S., \& Marttunen, M. (2010). Involvement in bullying and depression in a 2-year follow-up in middle adolescence. European child \& adolescent psychiatry, 19(1), 45-55.

158. Van Cleave, J., \& Davis, M.M. (2006). Bullying and peer victimization among children with special health care needs. Pediatrics, 118(4), e1212-e1219.

159. Nordhagen, R., Nielsen, A., Stigum, H., Köhler, L. (2005). Parental reported bullying among nordic children: a population-based study. Child: care, health and development, 31(6), 693-701.

160. Hay, D.F., A. Payne, \& Chadwick, A. (2004). Peer relations in childhood. Journal of child psychology and psychiatry, 45(1), 84-108.

161. Kvarme, L.G., Helseth, S., Sæteren, B., Natvig, G.K. (2010). School children's experience of being bullied-and how they envisage their dream day. Scand J Caring Sci, 24(4), 791-798.

162. Conners-Burrow, N.A., Johnson, D.L., Whiteside-Mansell, L., McKelvey, L., Gargus, R.A. (2009). Adults matter: Protecting children from the negative impacts of bullying. Psychology in the Schools, 46(7), 593-604

163. Stadler, C., Feifel, J., Rohrmann, S., Vermeiren, R., Poustka, F. (2010). Peervictimization and mental health problems in adolescents: are parental and school support protective? Child Psychiatry \& Human Development, 41(4), 371-386.

164. Wang, J., Iannotti, R.J., \& Nansel, T.R. (2009). School bullying among adolescents in the United States: Physical, verbal, relational, and cyber. Journal of Adolescent health, 45(4), 368-375. 
165. Due, P., Holstein, B.E., Lynch, J., Diderichsen, F., Gabhain, S.N., Scheidt. P., et al. (2005). Bullying and symptoms among school-aged children: international comparative cross sectional study in 28 countries. The European Journal of Public Health, 15(2), 128-132.

166. Pozzoli, T., \& Gini, G. (2010). Active defending and passive bystanding behavior in bullying: The role of personal characteristics and perceived peer pressure. Journal of abnormal child psychology, 38(6), 815-827.

167. Gini, G., \& Pozzoli, T. (2009). Association between bullying and psychosomatic problems: A meta-analysis. Pediatrics, 123(3), 1059-1065.

168. Due, P., Hansen, E.H., Merlo, J., Andersen, A., Holstein, B.E. (2007). Is victimization from bullying associated with medicine use among adolescents? A nationally representative cross-sectional survey in Denmark. Pediatrics, 120(1), 110-117

169. Sharp, S. (1995). How much does bullying hurt? The effects of bullying on the personal wellbeing and educational progress of secondary aged students. Educational and Child Psychology, 12(2), 81-88.

170. Mahady Wilton, M. M., Craig, W. M., \& Pepler, D. J. (2000). Emotional regulation and display in classroom victims of bullying: Characteristic expressions of affect, coping styles and relevant contextual factors. Social development, 9(2), 226-245.

171. Hunter, S.C., Boyle, J.M., \& Warden D. (2004). Help seeking amongst child and adolescent victims of peer-aggression and bullying: The influence of school-stage, gender, victimisation, appraisal, and emotion. British Journal of Educational Psychology, 74(3), 375-390.

172. Due, P., Merlo, J., Harel-Fisch, Y., Damsgaard, M.T., Holstein, B.E., et al. (2009). Socioeconomic inequality in exposure to bullying during adolescence: a comparative, 
cross-sectional, multilevel study in 35 countries. American Journal of Public Health, 99(5), 907-914.

173. Hansen, K.L., Melhus, M., Høgmo, A., Lund, E. (2008). Ethnic discrimination and bullying in the Sami and non-Sami populations in Norway: the SAMINOR study. International Journal of Circumpolar Health, 67(1), 99-115.

174. Ttofi, M.M., Farrington, D.P., Lösel, F. (2011). Do the victims of school bullies tend to become depressed later in life? A systematic review and meta-analysis of longitudinal studies. Journal of Aggression, Conflict and Peace Research, 3(2), 63-73.

175. Arseneault, L., Walsh, E., Trzesniewski, K., Newcombe, R., Caspi, A., \& Moffitt, T. E. (2006). Bullying victimization uniquely contributes to adjustment problems in young children: a nationally representative cohort study. Pediatrics, 118(1), 130-138.

176. Bowes, L., Maughan, B., Caspi A., Moffitt T.E., Arseneault L. (2010). Families promote emotional and behavioural resilience to bullying: Evidence of an environmental effect. Journal of Child Psychology and Psychiatry, 51(7), 809-817

177. Kim, Y.S., Leventhal B.L., Koh Y-J., Boyce W.T. (2011). Bullying increased suicide risk: prospective study of Korean adolescents. Archives of Suicide Research. 2009;13(1), 15-30.

178. Klomek, A. B., Sourander, A., \& Gould, M. S. (2011). Bullying and suicide. Psychiatric Times, 28(2), 27-31.

179. Sourander, A., Klomek, A.B., Ikonen, M., Lindroos, J., Luntamo, T., Koskelainen, M., et al. (2010). Psychosocial risk factors associated with cyberbullying among adolescents: A population-based study. Archives of general psychiatry, 67(7), 720728. 
180. Sourander, A., \& Gould, M. (2010). The association of suicide and bullying in childhood to young adulthood: a review of cross-sectional and longitudinal research findings. Canadian Journal of Psychiatry, 55(5), 282-288.

181. Petersen, S., Brulin, C., \& Bergström, E. (2006). Recurrent pain symptoms in young schoolchildren are often multiple. Pain, 121(1), 145-150.

182. McEwen, B.S. (2006). Stress, adaptation, and disease: Allostasis and allostatic load. Annals of the New York Academy of Sciences, 840(1), 33-44.

183. Infomed online. Paracetamol: Indications Updated 3. October 2015]; Available from: http://www.infomed.ch/100drugs/paraind.html.

184. Henningsen, P., Zimmermann, T., \& Sattel, H. (2003). Medically Unexplained Physical Symptoms, Anxiety, and Depression: A Meta-Analytic Review.

Psychosomatic medicine. 65(4), 528-533.

185. Strang, P., Strang, S., Hultborn, R., \& Arnér, S. (2004). Existential pain-an entity, a provocation, or a challenge?. Journal of pain and symptom management, 27(3), 241250.

186. Miller, G.E., \& Chen, E. (2010). Harsh family climate in early life presages the emergence of a proinflammatory phenotype in adolescence. Psychological science.

187. Dew, T., \& Huebner, E.S. (1994). Adolescents ' perceived quality of life: An exploratory investigation. J Sch Psychol, 32.

188. Krayer, A., Ingledew, D., \& Iphofen, R. (2008). Social comparison and body image in adolescence: a grounded theory approach. Health Educ Res, 23(5), 892-903.

189. Borup, I.K., Andersen, A., \& Holstein, B.E. (2010). Re-visit to the school nurse and adolescents' medicine use. Health Education Journal. 
190. Helseth, S., Lagerløv, P., Holager, T., Johansen, O., \& Rosvold, E. O. (2009). Ungdom og bruk av reseptfri smertestillende medisin. Nordic Journal of Nursing Research, $29(3), 28-31$

191. World Medical Association. (2013). World medical association Declaration of Helsinki: Ethical principles for medical research involving human subjects. JAMA, 310(20), 2191-2194. doi: 10.1001/jama.2013.281053

192. The Regional Committees for Medical and Health Research Ethics (REK) in Norway De nasjonale forskningsetiske komiteene. Kongens gate 14. 0153 Oslo

193. Helseth, S., \& Slettebø, Å. (2004). Research involving children: some ethical issues. Nursing Ethics, 11(3), 298-299.

194. Juritzen, T. I., Soberg, H. L., Røe, C., Saebu, M., Engen, G., Bliksvaer, T., \& Engebretsen, E. (2017). The One or the Many: Quantified Subjectivity and Aggregated Uniqueness in Qualitative Rehabilitation Research. Qualitative health research, 27(1), $51-59$ 



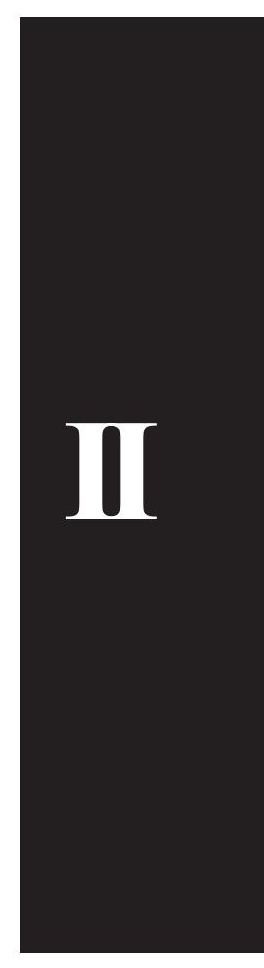





\title{
High use of over-the-counter analgesic; possible warnings of reduced quality of life in adolescents - a qualitative study
}

\author{
Siv Skarstein ${ }^{1 *}$, Per Lagerløv ${ }^{2}$, Lisbeth Gravdal Kvarme ${ }^{1}$ and Sølvi Helseth ${ }^{1}$
}

\begin{abstract}
Background: Use of over-the-counter analgesics among adolescents has increased markedly. High consumption of over-the-counter analgesics among adolescents is associated with frequent pain, lower self-esteem, reduced sleep, lower educational ambition, binge drinking, higher caffeine consumption, and part-time employment. Knowledge about life experiences of adolescents who frequently use over-the-counter analgesics may be useful to prevent health problems. The purpose of the study was to increase knowledge about adolescents who suffer from frequent pain and have a high consumption of over-the-counter analgesics.
\end{abstract}

Methods: A qualitative study, employing one-on-one, in-depth interviews using a thematic interview guide. Data were collected in Norway in 2013-2014. Three boys and sixteen girls; aged 14-16 years, who continuously consumed over-the-counter analgesics were recruited from ten high schools in urban and suburban districts. Candidate participants were excluded if they were medically diagnosed with an acute or chronic illness, requiring extended use of over-the-counter analgesics within the last year. The interviews were taped, transcribed and analysed as text according to Kvale's three contexts of interpretation: self-understanding, common sense and theory.

Results: All participants disclosed unresolved physical and psychosocial distress characterized as pain. Frequent pain from various body parts made everyday life challenging. Methods of pain self-appraisal and over-the-counter analgesics use often mimicked maternal patterns. Participants reported being raised under unpredictable circumstances that contributed to long lasting family conflicts and peer-group problems. Participants wanted to feel appreciated and to be socially and academically successful. However, pain reduced their ability to manage everyday life, hampered experienced possibilities for success, and made social settings difficult.

Conclusions: Childhood experiences influence how adolescents experience pain and use over-the-counter analgesics. Coping with difficult situations or attempting to mask symptoms with over-the-counter analgesics can perpetuate and amplify underlying problems. High consumption of over-the-counter analgesics and frequent pain may be warning signs of adolescents with possible health threatening conditions and reduced quality of life. These adolescent might be in need of support from school nurses and General Practitioners. This study identifies new perspectives that may lead to novel approaches to identify, guide, and support adolescents with frequent pain and high consumption of over-the-counter analgesics.

\footnotetext{
* Correspondence: siv.skarstein@hioa.no

${ }^{1}$ Department of Nursing, Oslo, and Akershus University College of Applied

Sciences, 4St. Olavsplass, Oslo NO-0130, Norway

Full list of author information is available at the end of the article
} 


\section{Background}

Adolescents, aged 12-17, frequently use over-thecounter analgesics (OTCAs) to alleviate common ailments and Norwegian studies shows that during the last two decades, this use has increased markedly [1-3]. The most selling OTCAs in Norway are paracetamol and ibuprofen [4]. Similar tendencies are found in Sweden, Denmark and in the United States $[1,5,6]$. OTCA medicine abuse, broadly defined as the systematic overuse of non-prescription medicine [7], is a serious global health challenge [8]. High consumption of OTCA among adolescents is associated with frequent pain, lower selfesteem, reduced sleep, lower educational ambition, binge drinking, higher caffeine consumption, and part-time employment [9]. These adolescents' ability to handle stress appears to be discordant with the kind of situations to which they are exposed, and the wear and tear associated with allostatic mechanisms counteracting stress may heighten their pain experience [9]. In general an increasing number of adolescents state they experience frequent pain [10]. Anxiety and depression show a strong relation to chronic pain and may contribute to the development and, more surely, to the preservation of pain [11]. OTCAs may also be a preferred way for some adolescents to deal with perceived health problems [12], and some adolescents use OTCAs to treat stress [13].

Childhood is important for attachment, development of identity, and learned strategies for coping with stress and pain [14-16]. Research suggests that familial methods of managing pain are evident in adolescents' OTCA use; intergenerational transmission of information about pain and pain management has been traced to maternal domiciliary practices [17]. Early identification and targeted interventions for adolescents challenged by chronic pain and overuse of OTCAs may result in decreased pain-related disability and improved quality of life (QOL) [10, 18]. WHO defines QOL as: 'the individual's perception of his or her position in life, within the cultural context and value system he or she lives in, and in relation to his or her goals, expectations, parameters and social relations. It is a broad ranging concept affected in a complex way by the person's physical health, psychological state, level of independence, social relationships and their relationship to salient features of their environment [19]. Most researchers agree on some characteristics of the concept QOL [20] and one point of consensus is that QOL is a multidimensional concept, which includes the physical, psychological, and social dimension of life. Secondly, QOL is a subjective phenomenon, insofar as all individuals have their own perspectives on their well-being and their lives. Thirdly, QOL is a normative concept based on the individual's expectations, values, goals and understanding of the meaning of life [20, 21]. Quality of life when young is the basis for quality of life in adulthood [22]. Thus, in this paper, the adolescents' life circumstances and family problems will be in focus.

Recent studies have focused on the increasing prevalence of pain and the concomitant rise in the use of OTCAs among adolescents. However, little research has sought to expand understanding from the perspective of adolescents with frequent pain who also consume potentially harmful amounts of OTCAs.

\section{Purpose of the study}

The purpose of this study was to gain a deeper understanding and increase our knowledge about adolescents who suffer from frequent pain and have a high consumption of OTCAs. Such knowledge may aid school nurses and general practitioners (GPs) in the identification of adolescents at risk for chronic pain, continuous and high use of OTCAs, and in finding effective interventions.

\section{Methods}

This study has a qualitative design, with qualitative indepth interviews of adolescents, to provide new knowledge, insights, and representations of common issues as a practical guide to future research and intervention.

We used a convenience sample based on participant self-selection. Principals in 20 randomly chosen schools representing; urban, sub-urban and rural districts in South of Norway, were by phone invited to participate. Principals of ten schools gave written consent to inform and recruit adolescents at their schools. One of the researchers visited these ten schools and gave a $15 \mathrm{~min}$ presentation of the project to all classes in 9th and 10th grades, a total of 52 classes with an average on 25 students in each. The adolescents were given written information about the project including a study information package with a combined bookmark/ruler that contained brief information about the study and the researchers' contact information. This information package also included information for the parents. The adolescents did not receive any compensation for participation.

Eligible participants included students between 14-16 years of age using OTCAs either daily, or on a one- to several times a week schedule, for at least four continuous weeks within the last year. Participants were required to be able to read and understand the Norwegian language. Exclusion criteria were being medically diagnosed with an illness or injury requiring extended use of OTCAs within the last year.

The research group developed and employed a thematic interview guide addressing the adolescents' life history and family life, OTCA usage, pain, stress, coping, peer relations, eating habits, sleep, activities, and important life events. However, participants were given the 
opportunity to steer the conversation so that their stories and experiences appeared spontaneously [23, 24]. Interviews were carried out from September 2013 until March 2014. Participants were recruited and interviewed until we were confident that no new themes were emerging [25]. One researcher (the psychiatric nurse) conducted the one-on-one interviews, lasting approximately one hour, at an office at the adolescents' schools or at an office at the researcher's work place.

The interviews were audio recorded and transcribed verbatim. The audio files and the transcribed material were uploaded within the Nvivo 10 computer program [26] for organization, review, and analysis.

A hermeneutic approach was taken in the analysis, involving an interpretive circular process of moving back and forth between the raw data and the interpretations [27]. In the analysis process, the researchers listened to audio recordings, and read and re-read the transcripts. The analysis was done in three different contexts: selfunderstanding, common sense and theory [28]. In the first context, the transcribed interviews were read and summarised in a condensed form, following broad categories that emerged from the data, such as: family life and childhood, friendship, school life, about myself, pain, health, use of OTCAs, important life events, support from professionals, quality of life, health, self-harming and suicidal tendencies. All interviews were then reread and coded, after which categories were assigned using descriptive terminology; for example: 'family and childhood'. The next step was to interpret the meaning of these findings. During the interpretation patterns emerged that form the basis for the presentation of our findings: Table 1 outlines the analysis process.

Group consensus usually emerged for most of the interpretations. When any doubt or disagreement arose, the researchers went back to the data, reassessed the meaning of the participant's expressions, and brought this into new discussions. Through this repetitive process, a broader understanding emerged. In the third context, the findings were interpreted and discussed in the light of theories of adolescent development research and QOL.

\section{Trustworthiness}

Our research group, consisting of a general practitioner, two public health nurses, and a psychiatric nurse, considered a qualitative design with a hermeneutic approach to be suitable in order to achieve trustworthiness of our findings [29]. Activities that ensured methodological coherence, sampling sufficiency, a relationship between sampling, data collection, analysis, and theoretical understanding, were discussed at regular meetings in the research group [30].

To give an accurate picture of the adolescents' expressions, we present representative quotes from the interviews in the results. These quotes were viewed as meaningful units and were extracted directly from the transcripts and translated into English, and then back into Norwegian by an English-Norwegian translator. Importantly, we chose a girl, who was 17 years of age and familiar with the style of language the adolescents used, as translator.

\section{Consent and ethical considerations}

The Regional Committees for Medical and Health Research Ethics (REC) in Norway, approved the study in autumn 2012, study number: 2012/1460a. Data and material from the study are kept in the department of Nursing, Oslo and Akershus University Collage of Applied Sciences, Oslo, Norway. The ethical principles highlighted in the Declaration of Helsinki [31] were followed. Participation was voluntary and required written informed consent. For participants younger than 16 years of age, written informed consent from their parents was required.

In each school, the school nurse was informed about the study and was prepared to support adolescents at any health risk. By signing a consent form, the adolescents also agreed to consult the school nurse if the interviewer

Table 1 Analysis of the adolescents' expressions obtained from thematic, semi-structured interviews ${ }^{a}$

\begin{tabular}{|c|c|c|}
\hline Self-understanding & Common sense & Theoretical understanding \\
\hline $\begin{array}{l}\text { How does the participant reflect and } \\
\text { understand his or her own expressions? }\end{array}$ & $\begin{array}{l}\text { How do people, in general, think critically about } \\
\text { the statement below? }\end{array}$ & $\begin{array}{l}\text { A scientifically tested assumption of an } \\
\text { expression as a phenomenon or in connection } \\
\text { to nature. }\end{array}$ \\
\hline $\begin{array}{l}\text { The stress makes me really tired, and then it } \\
\text { becomes too much for me; then it is okay with } \\
\text { painkillers. It is a nice solution to stress'. }\end{array}$ & $\begin{array}{l}\text { 'Something is experienced as stressful in the } \\
\text { adolescent's life. Stresses makes the adolescent } \\
\text { feeling tired. Painkillers are used to cope with } \\
\text { the feeling of stress'. }\end{array}$ & $\begin{array}{l}\text { 'Successful adaptation to stress includes the } \\
\text { ways in which individuals manage their } \\
\text { emotions, think constructively, regulate and } \\
\text { direct their behaviour, control their autonomic } \\
\text { arousal, and act on the social and non-social } \\
\text { environments, to alter or decrease sources of } \\
\text { stress' [29]. }\end{array}$ \\
\hline
\end{tabular}

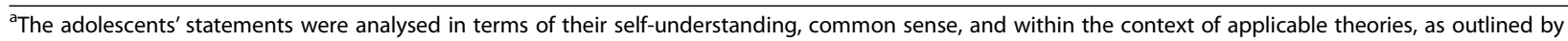
Kvale and Brinkman [28] 
deemed it necessary. The participants were informed that they were free to withdraw from the project at any time.

\section{Results}

The sample consisted of 19 adolescents, ranging from 14 to 16 years old. Participants were recruited from the ninth and tenth grades in five of the ten participating high schools in Norway. Selected demographics and psychosocial problems of the 19 interviewed adolescents are shown in Table 2.

In addition to frequent pain, having needed support from Child Protective Services, having experienced persistent bulling and having had eating problems was surprisingly common.

The adolescents reported pain in several parts of the body; almost all reported frequent headaches. The pain reduced their ability to manage everyday life, hampered experienced possibilities for success, and made social settings difficult. The participants had lived with their pain for a long time, some said they have had pain from childhood, others said they had recognized pain problems from beginning of adolescence. None reported that any treatments had brought lasting relief. The adolescents often described serious problems within their family and peer groups. Several exerted much energy to conceal personal and family problems. To appear successful, the adolescents valued excelling on tests and exams, as well as achieving success in sports, art, and culture. They felt that such success was essential in order to feel good. Furthermore, looking good and being popular among their peers were considered significant.

Table 2 Selected demographics and psychosocial problems of the 19 interviewed adolescents ${ }^{a}$

\begin{tabular}{lll}
\hline Demographics & Number \\
\hline Gender & Male & 3 \\
& Female & 16 \\
School location & Urban & 8 \\
& Rural & 11 \\
Living with & Both parents & 8 \\
& One parent & 6 \\
& Part-time with each parent & 4 \\
Psychosocial problems & Other caregivers & 1 \\
Required support from Child & Yes & \\
Protective Services & No & 6 \\
Experienced eating problems & Yes & 13 \\
& No & 6 \\
Experienced persistent bullying & Yes & 13 \\
& No & 9 \\
\hline
\end{tabular}

a'The subjects' ages ranged from 14 to and including 16 years
They all struggled to fit in with their peers and to feel valued. The main theme emerging from the adolescents' stories could be summed up in the following statement: High consume of OTCAs and pain in everyday life: warnings of reduced QOL in adolescents. The following three sub-themes elaborate on the overall theme:

- Pain and use of OTCAs

- Being raised under unpredictable conditions

- Wanting to feel appreciated and appear successful

These three sub-themes are not mutually exclusive; still, we chose this tripartite division to organize and structure the diverse and rich information the adolescents shared with us during their interviews. The numbers in parentheses following the quotations refer to the subject's transcribed interview.

\section{Pain and use of OTCAs}

The adolescents said they experienced continuous pain over years, one said she had had stomach pains from she was about 4 years old. They all stated that their pain problems had escalated. Generally, the adolescents said their pain was located in different parts of the body. It might have started in one part of the body, but had spread to other parts. Nearly all reported suffering from headaches, and that these were especially troublesome. The adolescents said they struggled to understand the reason for their pain and to rate their pain, some said further that they were reluctant to bother others with complaints. For example, one girl stated that she was so used to having stomach pains that she did not disclose this fact prior to her departure on a trip. After being brought to hospital following a fainting episode during her trip, the doctors found she needed immediately surgery, due to a life threatening and very painful condition.

The majority of participants reported that they had visited different kinds of doctors and health professionals because of pain or fatigue. They often received a tentative diagnosis, supporting their feeling of something being medically wrong. This seemed problematic as it left the individual in a liminal place relative to a solution. One girl explained:

'Actually, I'm often sick because my immune system is weak. When I went to the doctor, I found out that I had allergies, so that could be one of the reasons. I often have headaches, as well as being tired a lot. I often think that it's allergy, but you never know... My shoulder got inflamed in seventh grade in gym class... We went to the doctor, and he almost laughed because it hurt so much, but then they found out that I had an inflammation. So we went to a physical therapist and an osteopath'. (P.14) 
Several mentioned stress as a cause of their pain. Like this girl, some said they used OTCAs to combat stress and fatigue:

'Stress makes me really tired, and then it gets to be too much for me, and so it's nice to take a painkiller. It's a nice solution to stress'. (P.6)

Some said they felt better by taking OTCAs before a potentially challenging situation, such as a social event, exams, athletic training, and competitions. Some said they used OTCAs both to calm down and to keep focused. OTCAs were described as a tool for both preventing and managing pain, stress, and fatigue. The following girl used OTCAs to feel better when dating a boyfriend:

'I actually had a boyfriend last year. Every time I met him, I would take an ibuprofen before I left so I wouldn't feel so tired when I was with him. Then I was like more happy and alive... I felt that it helped a lot, but it was probably psychological'. (P.6)

The adolescents disclosed a sense of shame about their OTCA use. Most of them stated that lately their OTCA use had diminished markedly. Others said they hoped to reduce OTCA use in the future. Eventually, it emerged that they still used OTCAs to a rather great extent, even if they reported experiencing little or no effect, as shown by this girl's statement:

'Earlier I took painkillers three times a day ... or two. It depended on how the school day was. But now I have reduced my consumption a lot. Yeah, so the question is what I have in class at school. If I had a double language session, that can be quite boring, so I take two pills and then I'll also have a little snack. I took a dose when I came here. I did not take anything yesterday... I do not think I took any yesterday. Yes, before my French class I took some pain medication. But otherwise it has been reduced. Perhaps about every second day I'll take one or two doses. (P.4-girl)'.

Without access to OTCAs, several participants said they felt unsure about whether they could manage daily life. The adolescents sometimes both justified and trivialized their OTCA use, mentioning uncertainty about the source of pain:

'If it wasn't for the fact that the pain medication worked, I would have thought my pain was psychological. It is like when I am in pain, I make myself believe that the pain is much worse than it actually is. I have a very low pain threshold.
Everything hurts all the time. I think that I make myself believe it hurts, even more than it actually does. I think that by taking the medication I am telling myself that the pain is so bad that I need medication, and if I need medication, then the pain must be bad. I end up thinking I'm in more pain than I actually am. If there were no pain medication, I think that I would feel a lot less pain'. (P.2-girl)

Almost all said they talked mainly to their mother about pain and several said that their mother and maternal ancestors had similar problems. Several adolescents said their mothers supported them in the use of OTCAs and sometimes mothers shared their own prescribed pain medication. Mothers also initiated help-seeking for pain from public and private health professionals on behalf of their adolescents.

\section{Being raised under unpredictable conditions}

The majority of the adolescents had experienced a disrupted family life with sadness and grief and this had influenced their childhood. Worries about others' wellbeing were common. Some had incompetent caregivers and a childhood characterized by feelings of unpredictable danger, worries, and uncertainty. Others grew up in a climate in which the family expressed feelings of sadness. The following quotes from two girls illustrate this range of feelings. The first girl explained how she had to protect herself and a younger sister from a drugged and mentally ill mother after they were placed in another home by the Child Protective Service:

'... my mother broke into our house and demanded to get us back. This happened on multiple occasions. One of the times she came, I took my sister and hid under the table. Then I covered her eyes, and she had to cover her own mouth so she wouldn't start screaming. I had to sort of shade my own eyes and ears, because I couldn't cover them myself since I had to cover hers...' (P.15).

Another girl explained the family climate like this:

'I've never felt unsafe, but I have often been sad, because there have been many conflicts. Mom has been sad and mom has been mad. Dad talked badly about mom, and mom talked badly about dad. I have often felt sad'. (P.5)

Another theme mentioned was frequent changes of residence, either temporarily or permanently. Some moved weekly between their parents and described this as stressful. Some said this repeatedly disrupted ties to peers. Moving was one reason given by some for feeling 
that they did not fit in. One of the boys reflected on how this resulted in him being bullied:

'I think we moved eight or nine times, or something like that. I was bullied in elementary school, most likely because of all the moving, so I was probably affected a lot by it'. (P.7)

Several of the adolescents spoke about challenges caused by broken homes and forming new family relationships involving a diversity of biological and nonbiological parents and siblings. Illnesses and deaths of close relatives causing long lasting worries, insecurity, sorrows and grief were often mentioned by some of the adolescents. Several, like the following boy, described living with a mentally unstable parent who abused alcohol and other substances:

'He wasn't normal or like normal people. He couldn't control himself and was out of control, and sometimes he got really pissed or angry'. (P.19)

This same boy had learned strategies in childhood to protect himself:

'When I'd come home in the evening, my dad was often drinking. If I noticed that, I usually biked to a friend's house. Then I'd tell my dad that I made plans to sleep over at a friend's house, and then I'd go over to someone else's and sleep there. I'd feel good for having avoided a big problem, because I never knew what would happen'. (P.19)

A memorable aspect of the adolescents' childhood was that their parents were preoccupied with their own careers or had a heavy work-load caring for disabled relatives. According to the adolescents, several parents had health problems, especially mothers. The adolescents' stories revealed that many of them received little or no help from their extended family. One of the girls had recurrent nightmares that might be connected to a feeling of needing help, but not getting it:

'I dreamt that I got killed, and my family watched without helping. I try to forget it, but it always comes back, so I wouldn't dare sleep'. (P.10)

Despite their difficulties at home, the adolescents were very loyal to their parents, and it was important for them to be able to make their parents proud. Outside the home, they tried to conceal problems within the family and felt threatened when their family problems were revealed. For some of the adolescents, it was difficult to establish close friendships for fear of exposing their problems at home. If a conflict arose between one's own desire for friendship and protecting family secrets, family loyalty took precedence. Some related stories of their loyalty to each parent being tested when their parents were in conflict.

\section{Wanting to feel appreciated and to appear successful}

Throughout the interviews, it became clear that the adolescents pressured themselves intensely to perform well, especially on visible tasks. This sentiment was clear in this girls' statement:

'I am happy with my grades, but I want to focus more and not be so passive. It's easy for me to postpone things; actually I postpone most things. I want to learn to do things and not postpone them to the last minute. I get mostly 5's in all my subjects; in some I get 6's [a score of six is the highest score attainable]. I'm mostly between a 5 and a 6 , so I'm not happy'. (P.18)

Most of the adolescents were preoccupied with attaining and maintaining a good appearance, such as expressing polite behaviour, having fit bodies, and dressing properly. Several, like this girl, expressed dissatisfaction with themselves and said they often tried to change their appearance through intensive dieting and exercise:

'It was mostly that I didn't like who I was, so I tried to improve my confidence by dieting... that was when I started using painkillers'. (P.6)

The adolescents said they strived for acceptance, and they tried to comply with others' expectations, like this girl:

'Now I'm focusing on doing well in school as well as trying to remember everything I need to do at home. I still want to be with friends, though. I'm trying, but it's hard living up to everyone's expectations'. (P.4)

The adolescents needed to maintain control, which was experienced as stressful, as expressed by one girl:

'I'm not one who gives up easily. I don't give up, and I'm really sort of stressed ... I feel I always need to have control'. (P.10)

Many of our adolescents were extremely attentive to signals indicating social conflict within their peer group. To avoid conflicts some, like this girl, lay awake at night thinking about what to say and how to behave.

'You never know what the other girls are saying behind your back, so you go around thinking about it'. (P.13) 
Almost every adolescent in this study mentioned a fear of getting involved in social conflicts, both at home and at school. Tremendous energy was expended trying to avoid these difficulties. Several, like the girl quoted below, had been bullied and learned to avoid conflicts:

'I've had conflicts with one of the girls, and it's like social suicide if you become her enemy'. (P.11)

Declining to take part in conflicts, even when a friend is bullied, was experienced as being cowardly. Yet, this might be necessary. Some expressed an inner feeling of guilt and a pressure to speak up. At the same time, they didn't want to attract attention. A girl explained how she suppressed her feelings:

'I don't really like conflicts, so I often say what other people want to hear. I hate it when I feel like people don't like me'. (P.18)

In several of the adolescents' stories, their feelings of loneliness and their desire to put on a successful facade eventually emerged. In the beginning of the interviews, the adolescents mostly related their 'success' stories. This included telling the interviewer about their many friends, as revealed by this girl:

'I have many friends here as well as many from all over Norway, because I've moved around so much'. (P.15)

Later on in the interviews, many participants expressed a longing for a close friend, one they could trust, be open with, and reveal their real feelings to without putting on a facade of a 'successful' appearance. Mostly, the adolescents kept hoping that they would find a good friend, like this girl:

'I don't feel like I have a good friend, someone that I can tell everything to ... I have a good feeling that I will find this friend in high school'. (P.3)

Some of the adolescents had thought about taking their own lives; a few engaged in self-harm such as cutting themselves. Many said that they had been rejected by parents and/or friends, and this left them in a very fragile state, as shown in the following excerpt from one of the girls' interview:

'I thought nobody liked me, and there was no reason to live, because I was going to die someday anyway. I did not want anyone to help me. I felt afraid and ashamed. I did not dare tell my parents. I had no need to tell anyone'. (P.11)
The findings presented illustrate how the need to feel appreciated and appear successful cause stresses that affect the use of OTCAs, as this girl expresses:

'I have always felt quite different really... never felt that I've fitted right in. In lots of situations I've felt I must adapt myself properly... and it's like the worst feeling in the world to me. Now I'm really just trying to be myself, and it works much better. It is so difficult to adapt to everything. You get really tired of it and very stressed. It's so tiring beyond the teens. I think there are lots of people who feel that way, girls at least. So I do not think it was a coincidence that just I went on painkillers. Yeah, it sounds like I'm talking about drugs here, but somehow painkillers is something you feel is well known, and they're available without prescription, so they're so easy to get and a very easy solution at things' (P.12).

In this and other instances, the availability and perceived safety profile of OTCAs reinforced ongoing analgesic usage. The lack of definitive medical solutions or alternative interventions for ongoing pain, unpredictable family circumstances, and social stressors motivated adolescents to take OTCAs both preemptively and during pain precipitating events.

\section{Discussion}

The adolescents in the present study experienced complex intersecting problems including moderate-to-severe pain, fatigue, sleeping problems, lack of concentration, feelings of loneliness, stress, worry, sadness, and anxiety. They struggled hard for success in various areas and had high expectations for their achievements. Most reported serious family problems throughout their childhood. As an illustration of the load of psychosocial problems described, many also talked about serious eating problems, more than half had been bullied and almost one third had required support from the Child Protective Services. The adolescents described continuous feelings of not being good enough. In addition, they missed having a close friend. The adolescents used OTCAs to deal with the various problems, even though the problems often were outside the known medical indications for OTCAs. Most participants had tentative or incomplete medical insights into their pain leading to uncertainty and rationalization regarding their need for OTCAs. According to the adolescents, mothers were the prime care givers throughout their childhood and the mothers engaged naturally in caregiving to alleviate pain and improve their child's health. Several had transitioned from mother-assisted OTCA use to become more autonomous. 


\section{Pain is a complex concept}

The adolescents stated that they suffered from severe pain and that understanding the source of their pain was difficult. Some were unsure whether their 'pain' was really pain. Some linked pain to stress. Others described how they may have manipulated themselves by focusing exhaustively on bodily sensations, thus giving themselves a reason to use OTCAs. In our analysis, the word 'pain' seemed to be a proxy for adolescents to describe their feelings when these became troublesome, regardless of the source. In the biomedical literature, pain is defined as 'an unpleasant sensory and emotional experience associated with actual or potential tissue damage, or described in terms of such damage [32]. Pain can also be characterized in more personal terms as 'whatever a person who feels pain says it is and may not be caused by external, physical trauma' [33]. While these definitions are helpful, they understate the subjective experience of pain by emphasizing bodily pathology. The aetiology of chronic or persistent pain is often unknown, and a complete understanding of pain must take into account biological, psychological and social factors to achieve a bio-psycho-social understanding [34]. In expanding conceptualization of pain, Flor \& Turk [35] suggest that pain affects the whole person and is regarded as more than a sensation or a symptom of a disease. This underscores that defining the concept of pain completely constitutes a challenge [36]. However, interpreting one's difficulties as 'experiencing pain' gives adolescents access to something they can use to treat their troublesome life, namely OTCAs. OTCAs are suitable for treating various types of pain [37], but the medication can also cover signals of underlying health conditions. In the present study, adolescents acted to conceal their personal and family problems, and they seemed to have learned that pain is an accepted way to express their discomfort with life experiences.

\section{Childhood experiences, stress, and pain}

The current study shows how participants' individual needs for establishing predictability, stability, attention, and continuity were not properly met [38, 39]. Child development is shaped in the interplay between genetic and environmental influences [40]. Children form attachments to their caregiver, even if the caregiver is insensitive and unresponsive during social interactions [16]. Open communication of pain effect, inhibition of pain effect, and exaggeration of pain effect may reflect adaptations to different relationship contexts. This has important implications for an individual's future life experiences, because experiencing attachment shapes how a child expresses pain to caregivers and later also to others [41]. In the present study, expressing pain may have been an acceptable way for these adolescents to express needs beyond physical discomfort, needs that resulted in attention and care. The types of pain experienced have been described as being inherited [42]. Expressing pain may be a well-known characteristic of family members; thus, when adolescents express pain, a sense of belonging to the family may result. Furthermore, pain can be a learned and acceptable way to express negative thoughts and emotions. Associations have been found between depression, pain, and functioning [43]. Over time, this pattern may influence appraisal and coping [44]. Maternal OTCA use is associated with child self-medication with OTCAs [45]. Mechanisms by which mothers transmit information to adolescents about pain and pain management primarily involve verbal communication and modelling [17]. Shared attitudes and painmanagement strategies underscore the role of mothers as models and essential facilitators of their adolescents' transition towards autonomy in pain management [46]. The complexity of attachment, ways of communicating, and ways of coping should be considered to be important factors in understanding and supporting adolescents who experience frequent pain and have a high consumption of OTCAs. Demands and threats placed on adolescents early in life can be hard for them to handle, especially when neither their family nor their social network have resources to intervene. Early life experiences are intimately embedded into the regulation of stress systems in ways that shape an organism's future responses [40]. Adverse or unfavourable childhood experiences can make adolescents vulnerable to challenges and stresses later in life [47]. Increased demands on adolescents with unstable and unpredictable childhood experiences might over time lead to allostatic overload with increased pain sensitivity [48]. This seems to be one possible explanation for the persistent pain experiences expressed in the interviews. Adolescents in the present study said they felt intense social pressure resulting in stress and fatigue. Successful adaptation to stress includes the ways in which individuals manage their emotions, the ability to think constructively, the ability to regulate and direct their behaviour, the ability to control their autonomic arousal, the way they act in social and non-social environments, and the ability to alter or decrease sources of stress [49]. High consumption of OTCAs may be an adapted behaviour which vulnerable adolescents in general use to manage life challenges and stresses [50]. Others have found that teenagers appear to have an attitude towards OTCAs that ranges from casual to careless, and some use OTCAs for their sedative effects [51]. Our analysis supports these findings.

\section{Managing pain: influence of social acceptance}

The adolescents described experiencing relationship problems with parents and friends. Almost all struggled 
intensely to fit in, and several were bullied. Unsatisfactory social relations are associated with feelings of loneliness $[52,53]$. At the same time, the adolescents sought to present an ideal picture of themselves and to make a good impression. To accomplish this, it was important to establish a positive self-image. Good relations with peers and parents preserve a positive feeling of one's own value, social position, and competence [54]. Problems with establishing and maintaining relationships during adolescence may be related to being raised in unstable families [55]. Reports of feelings of fear and anxiety connected to events considered as stressful were common; thus, the adolescents in this study made great efforts to avoid conflicts and to control unpredictable situations and challenges. The adolescents said that they avoided speaking up, even though they wanted to. Avoiding conflicts has been described as both an automatic, involuntary response and a controlled, voluntary response [56]. To the adolescents in our study, controlling both behaviour and emotions was important in order to hide their vulnerabilities. This may indicate low self-esteem and low self-efficacy, which are also associated with anxiety and depression $[57,58]$. The relative contribution of behavioural and cognitive responses varies, depending on the stress context, the adolescents' developmental level, and how they have learned to respond to stress [56]. Expressing emotions as pain may be a learned, controlled and accepted way our adolescents used to vent their feelings.

\section{Life experiences and QOL}

Most of the adolescents expressed dissatisfaction with themselves, their appearance, and their achievements. They seemed to have learned to conceal their inner feelings in order to be accepted and included both in the family and among peers. According to adolescents in another Norwegian study, specifically feeling good, being satisfied with oneself, having an overall positive attitude, and a positive self-image were important for having a good QOL [53]. Adolescents' self-image is associated with the ability to make friends [59], and good family relations are further important for QOL $[53,60]$. Most of the adolescents in our study had experienced both family conflicts and problems in peer relations. Several had been bullied over time, which is associated with psychological health complaints such as depressive symptoms, psychological disturbance and with pain problems [60]. Further, bulling affects QOL negatively $[52,61]$. The participants in our study reported suffering severe pain, which in itself affects QOL negatively [61]. Frequent pain hampers possibilities for managing school performance and leisure activities [62]. It is possible that in in addition to family problems, continuous pain and negative feedback from peers over time give the adolescents a negative feeling about themselves and reduce their self-image. We observed gaps between the adolescents' idealized images of being successful and how they rated themselves. Closing or reducing these gaps might increase QOL [63].

\section{Strengths and weaknesses}

The main author, who conducted the interviews, has specialized in psychiatric nursing. During the interviews, she may have used psychiatric interview techniques which revealed more in-depth information, in comparison to other interview approaches. Also, the fact that the interviewer was female may have made the girls, who made up the majority of the interviewees, feel more comfortable and willing to disclose information than the boys. A potential limitation of the present study is that, of the 19 participants, only 3 were boys. Perhaps additional, different viewpoints would have been revealed if more boys had been included in our sample. Another limitation was the ethical requirement to inform parents of the study. This may have excluded students who did not want to fully disclose their OTCA use to their parents. Further, we did not recruit adolescents from all ten schools and there may be other adolescents with special experiences to which we did not have access. We do not believe our results are geographically biased. A previous study failed to find a difference in the consumption of OTCAs among adolescents living in urban regions compared to those in rural regions of Norway [2]. We were also aware that the background, position, and preconceptions of the researchers could potentially affect the focus and perspectives, and the research group voiced this as an important consideration. Despite potential limitations, we believe this study provides useful information on adolescents who have frequent pain and a high use of OTCAs. If the findings are recognized as useful, they may be transferrable within the framework of qualitative research [64].

\section{Conclusions}

Childhood experiences affect adolescents' pain experience and OTCA use. Appraisal of pain and use of OTCAs may be learned. Expressing pain may also provide a way for adolescents to receive support from caregivers. Furthermore, expressing pain can serve as a proxy and an 'acceptable' way of revealing unpleasant thoughts and feelings. Indeed, experiences early in life might influence the regulation of stress systems in ways that shape one's future responses with regard to pain expression. Coping with stress by avoiding it or hiding its symptoms can perpetuate or even amplify underlying problems. These complex mechanisms may reduce adolescents QOL and must be considered in order to 
identify, map and support adolescents with severe pain and a high consumption of OTCAs.

Our findings apply to the practice of both school nurses and general practitioners supporting adolescents. Health professionals should be aware that frequent pain and high use of OTCAs may be caused by complex and serious conditions that the adolescents may attempt to conceal. Social support is found to increase optimism and improve health in early adolescence and this may be a target for an intervention [65]. The adolescents may need a stronger network of assistance to deal with pain and the use of OTCAs. Future research and interventions targeting frequent pain and high OTCA use among adolescents might want to consider adolescent knowledge about analgesia in addition to networks of social support for individuals experiencing pain.

\section{Competing interests}

The authors declare that they have no competing interests.

\section{Authors' contribution}

All authors have contributed substantially to the study and preparation of the manuscript. SS, PL, LGK and SH participated in the design of the study, analysis and interpretation of data. SS, PL, LGK and SH have been involved in drafting the manuscript and revising it critically. All authors have participated sufficiently in the work to take public responsibility for the content. SS, PL, LGK and SH have given final approval of the version to be published.

\section{Acknowledgements}

We are grateful to and thank the participants, the school nurses, the teachers, and the principals who so generously supported this study. We also want to thank our colleague Assistant Professor Craig Dale at Lawrence S. Bloomberg Faculty of Nursing University of Toronto, Canada, for his wise comments.

We also thank the Department of Nursing, Oslo and Akershus University College of Applied Sciences, Oslo, Norway for provided financial support.

\section{Author details}

${ }^{1}$ Department of Nursing, Oslo, and Akershus University College of Applied Sciences, 4St. Olavsplass, Oslo NO-0130, Norway. ${ }^{2}$ Department of General Practice/Family Medicine, Institute of Health and Society, The Medical Faculty, University of Oslo, Oslo, Norway.

Received: 29 October 2015 Accepted: 24 February 2016 Published online: 03 March 2016

\section{References}

1. Holstein B, et al. Children's and adolescent's use of medicine for aches and psychological problems: secular trends from 1988 to 2006. Ugeskrift For Laeger. 2009;171(1-2):24-8.

2. Furu K, Skurtveit S, Rosvold E. Self-reported medical drug use among 15-16 year-old adolescents in Norway. Tidsskrift for den Norske laegeforening: tidsskrift for praktisk medicin, ny raekke. 2005;125(20):2759-61.

3. Lagerlov $P$, et al. Selvmedisinering med reseptfrie smertestillende legemidler hos 15-16-åringer (Self-medication with over-the-counter analgesics among 15-16-year-old teenagers in Norway). Tidsskr Nor Laegeforen. 2009;129(15):1447-50.

4. Sakshaug S, et al. Drug Consumption in Norway 2010-2014. Norway: Norwegian Institute of Public Health; 2010-2014.

5. Westerlund M, Brånstad J-O, Westerlund T. Medicine-taking behaviour and drug-related problems in adolescents of a Swedish high school. Pharm World Sci. 2008;30(3):243-50.

6. Wu L-T, Pilowsky DJ, Patkar AA. Non-prescribed use of pain relievers among adolescents in the United States. Drug Alcohol Dependence. 2008:94(1-3):1-11.
7. Lessenger JE, Feinberg SD. Abuse of prescription and over-the-counter medications. J Am Board Fam Med. 2008;21(1):45-54.

8. Conca AJ, Worthen DR. Nonprescription drug abuse. J Pharm Pract. 2012;25(1):13-21.

9. Skarstein $\mathrm{S}$ et al. High frequency use of over the counter analgesics among adolescents: reflections of an emerging difficult life, a cross sectional study. Scand J Caring Sci. 2014;28(1):49-56.

10. King $S$ et al. The epidemiology of chronic pain in children and adolescents revisited: A systematic review. Pain. 2011;152(12):2729-38.

11. Hoftun GB, Romundstad PR, Rygg M. Factors associated with adolescent chronic on-specific pain, chronic multisite pain, and chronic pain with high disability: The Young-HUNT Study 2008. J Pain. 2012;13(9):874-83.

12. Koushede $V$, Holstein BE. Sense of coherence and medicine use for headache among adolescents. J Adolesc Health. 2009;45(2):149-55.

13. Koushede $V$ et al. Stress and use of over-the-counter analgesics: prevalence and association among Danish 25 to 44-year-olds from 1994 to 2005. Int J Public Health. 2011;56(1):81-7.

14. Erikson EH. Childhood and Society, rev. ed. New York: Norton; 1963.

15. Marcia JE. Development and validation of ego-identity status. J Pers Soc Psychol. 1966;3(5):551

16. Ainsworth MDS. The Bowlby-Ainsworth attachment theory. Behav Brain Sci. 1978;1(03):436-8.

17. Hatchette JE et al. Maternal influences in adolescents' pain self-management: A qualitative investigation. Vulnerable Child Youth Stud. 2006;1(2):159-69.

18. Felce D, Perry J. Quality of life: Its definition and measurement. Res Dev Disabil. 1995;16(1):51-74.

19. WHOQOL G. The World Health Organization quality of life assessment (WHOQOL): development and general psychometric properties. Soc Sci Med. 1998:46(12):1569-85.

20. Wahl AK, Hanestad BR. Måling av livskvalitet i klinisk praksis: en innføring [Measuring the quality of life in clinical practice: an introduction] Fagbokforlaget. 2004.

21. Eiser C, Morse R. The measurement of quality of life in children: past and future perspectives. J Dev Behav Pediatr. 2001;22(4):248-56.

22. Bisegger $C$, et al. Health-related quality of life: gender differences in childhood and adolescence. Soz Praventivmed. 2005;50(5):281-91.

23. Brinkmann S. Interviewing and the production of the conversational self. In: Qualitative inquiry and global crises. 2011. p. 56-75.

24. Kvale S, Brinkmann S. Interviews: Learning the craft of qualitative research interviewing. Sage. 2009

25. Morse JM. The significance of saturation. Qual Health Res. 1995;5(2):147-9.

26. Edhlund B, McDougall A. NVivo 10 essentials. Lulu. com. 2013.

27. Polit DF, Beck, CT. Essentials of nursing research: Appraising evidence for nursing practice. Lippincott Williams \& Wilkins. 2013.

28. Kvale S, Brinkmann S. Det kvalitative forskningsintervju (The qualitative research interviewing). 2nd ed. Oslo: Gyldendal Akademisk; 2010.

29. Graneheim UH, Lundman B. Qualitative content analysis in nursing research: concepts, procedures and measures to achieve trustworthiness. Nurse Educ Today. 2004;24(2):105-12.

30. Morse JM et al. Verification strategies for establishing reliability and validity in qualitative research. Int J Qual Methods. 2008;1 (2):13-22.

31. Association WM. Declaration of Helsinki. Ethical principles for medical research involving human subjects. 2009.

32. Merskey H, Spear F. The concept of pain. J Psychosom Res. 1967;11(1):59-67.

33. McCaffery M et al. Pain. Mosby. 1994.

34. Abbruzzese EA, Birchler T, Ehlert U. Effects of psychosocial stress on the gene expression of the clock genes hPER1 and hPER2 in humans. Psychology. 2014;5(01):70.

35. Flor H, Turk DC. Cognitive and learning aspects. In: Wall and Melzack's Textbook of Pain. 2006. p. 241-58.

36. Strang $P$ et al. Existential pain an entity, a provocation, or a challenge? J Pain Symptom Manag. 2004;27(3):241-50.

37. Infomed online. Paracetamol: Indications Updated 3. October 2015]; Available from: http://www.infomed.ch/100drugs/paraind.html. Accessed Oct. 3.

38. Prior V, Glaser D. Understanding attachment and attachment disorders: Theory, evidence and practice. 2006: Jessica Kingsley Publishers.

39. Bornstein $\mathrm{MH}$, Krasnegor NA. Stability and continuity in mental development: Behavioral and biological perspectives. Psychology Press. 2013.

40. Danese A, McEwen B. Adverse childhood experiences, allostasis, allostatic load, and age-related disease. Physiol Behav. 2012;106(1):29-39. 
41. Kozlowska K. Attachment relationships shape pain-signaling behavior. J Pain. 2009;10(10):1020-8

42. Foulkes T, Wood JN. Pain genes. PLoS Genet. 2008;4(7):e1000086.

43. Tan $\mathrm{G}$, et al. Negative emotions, pain, and functioning. Psychol Serv. 2008:5(1):26

44. Folkman S, Moskowitz JT. Stress, Positive Emotion, and Coping. Curr Dir Psychol Sci. 2000;9(4):115-8.

45. Jensen JF, et al. Association of maternal self-medication and over-thecounter analgesics for children. Pediatrics. 2014;133(2):e291-8.

46. Hatchette JE, et al. The role of peer communication in the socialization of adolescents' pain experiences: a qualitative investigation. BMC Pediatr. 2008;8(1):2.

47. Danese A, et al. Adverse Childhood Experiences and Adult Risk Factors for Age-Related Disease: Depression, Inflammation, and Clustering of Metabolic Risk Markers. Arch Pediatr Adolesc Med. 2009;163(12):1135.

48. Evans GW, et al. Cumulative risk, maternal responsiveness, and allostatic load among young adolescents. Dev Psychol. 2007:43(2):341.

49. Compas BE, et al. Coping with stress during childhood and adolescence: problems, progress, and potential in theory and research. Psychol Bull. 2001;127(1):87.

50. Koushede $V$, et al. Young adults' medicine use for headache: The combined effect of socioeconomic position and perceived stress, and the contribution of sense of coherence. Res Soc Adm Pharm. 2012:8(6):533-41.

51. Holmström IK, et al. Swedish teenagers and over-the-counter analgesicsResponsible, casual or careless use. Res Soc Adm Pharm. 2014;10(2):408-18.

52. Kvarme LG, et al. School children's experience of being bullied-and how they envisage their dream day. Scand J Caring Sci. 2010;24(4):791-8.

53. Helseth S, Misvær N. Adolescents' perceptions of quality of life: what it is and what matters. J Clin Nurs. 2010;19(9-10):1454-61.

54. Kvello $\varnothing$. Barns og unges vennskap [Child and Adolescent Friendship] Trondheim Norges Teknisk-Naturvitenskapelige Universitet, Fakultet For Samfunnsvitenskap Og Teknologiledelse, Pedagogisk Institutt. 2006

55. Allen JP, Land D. Attachment in adolescence. In: Handbook of attachment: Theory, research, and clinical applications. 1999. p. 319-35.

56. Compas BE. Coping with stress during childhood and adolescence. Psychol Bull. 1987;101(3):393.

57. Muris P. Relationships between self-efficacy and symptoms of anxiety disorders and depression in a normal adolescent sample. Personal Individ Differ. 2002;32(2):337-48.

58. Dumont M, Provost MA. Resilience in adolescents: Protective role of social support, coping strategies, self-esteem, and social activities on experience of stress and depression. J Youth Adolesc. 1999:28(3):343-63.

59. Dew T, Huebner ES. Adolescents' perceived quality of life: An exploratory investigation. J Sch Psychol. 1994;32(2):185-99.

60. Due P. Socio-epidemiological Studies of Adolescent Health: Investigating Inequalities and the Role of Bullying. National Institute of Public Health, University of Southern Denmark. 2013

61. Haraldstad K, et al. Predictors of health-related quality of life in a sample of children and adolescents: a school survey. J Clin Nurs. 2011;20(21-22):3048-56.

62. Haraldstad $\mathrm{K}$, et al. Pain in children and adolescents: prevalence, impact on daily life, and parents' perception, a school survey. Scand J Caring Sci. 2011;25(1):27-36.

63. Krayer A, Ingledew D, Iphofen R. Social comparison and body image in adolescence: a grounded theory approach. Health Educ Res. 2008;23(5):892-903.

64. Sandelowski M. The problem of rigor in qualitative research. Adv Nurs Sci. 1986;8(3):27-37.

65. Mahon NE, et al. Mediational models of health practices in early adolescents. Clin Nurs Res. 2007:16(4):302-16.

\section{Submit your next manuscript to BioMed Central and we will help you at every step:}

- We accept pre-submission inquiries

- Our selector tool helps you to find the most relevant journal

- We provide round the clock customer support

- Convenient online submission

- Thorough peer review

- Inclusion in PubMed and all major indexing services

- Maximum visibility for your research

Submit your manuscript at www.biomedcentral.com/submit
( Biomed Central 



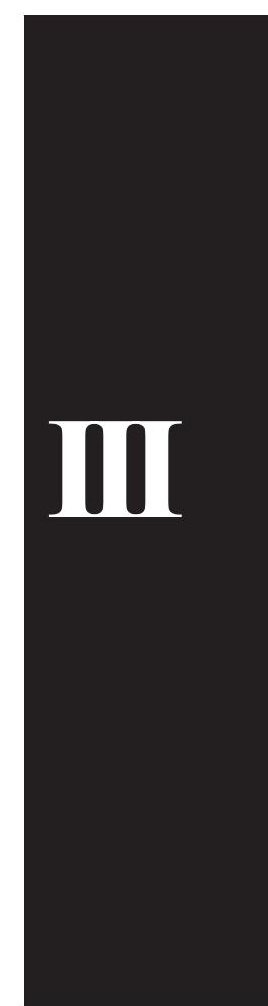





\section{Paper 3}

\section{Title: Pain management and development of identity in}

\section{adolescents who frequently use of over-the-counter analgesics:}

\section{a qualitative study}

\section{Author and Co-author's}

Siv Skarstein ${ }^{\mathrm{a}, *}$, Per Lagerløv ${ }^{\mathrm{b}, 1}$, Lisbeth Gravdal Kvarme ${ }^{\mathrm{a}, 2}$, Sølvi Helseth ${ }^{\mathrm{a}, 3}$

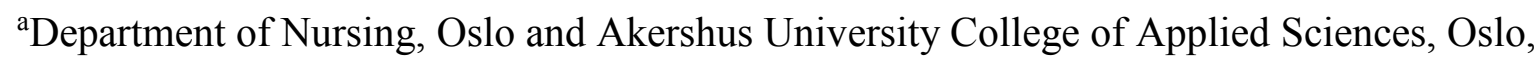
Norway

${ }^{b}$ Department of General Practice/Family Medicine, Institute of Health and Society, The Medical Faculty, University of Oslo, Oslo, Norway

${ }^{1}$ Email address: per.lagerlov@medisin.uio.no (P. Lagerløv)

${ }^{2}$ Email address: lisbeth.gravdal-kvarme@hioa.no (L. Gravdal Kvarme)

${ }^{3}$ Email address: Solvi.Helseth@hioa.no (S. Helseth)

\section{Corresponding author:}

Siv Skarstein

Department of Nursing, Oslo and Akershus University College of Applied Sciences, Postboks 4. St. Olavs plass, 0130 Oslo, Norway. Tel: +4767235000.

E-mail address: siv.skarstein@hioa.no

\section{Financial support}

The Department of Nursing, Oslo, and the Akershus University College of Applied Sciences, Oslo, Norway provided financial support. 


\section{ABSTRACT}

\section{Aim and objectives:}

Frequent self-medication with analgesics among adolescents is associated with general pain, several physical pain points, low self-esteem and low ambitions for the future. This study aims to describe pain management and conditions that may influence the development of identity in adolescents frequently using over-the-counter analgesics.

\section{Design:}

Qualitative individual interviews with adolescents and their mothers were conducted and transcribed. Further, they were analysed as dyads.

\section{Setting and participants:}

Students aged $14-16$ in $9^{\text {th }}$ and $10^{\text {th }}$ grade in 10 Norwegian junior high schools self-reporting at least weekly use of analgesics were asked to participate. Those who wanted to take part brought a consent letter to their parents, also inviting the parent to participate.

\section{Results:}

Six girls, two boys and their mothers were included. The teenagers were highly dependent on their mothers. They had often been bullied, lacked good relationships with peers, avoided conflicts and strived to be accepted. Their mothers felt solely responsible for their upbringing and showed great concern for all the pain experienced by their child. A close relationship between mother and child influenced how the adolescent managed their pain, including their use of over-the-counter analgesics. Three main themes were identified in the stories of mother and child; "Vulnerable adolescents", "Mother knows best" and "Pain is a shared project". 


\section{Conclusions:}

Pain among adolescents may be amplified by a difficult family situation and insecure relationships with peers. Strategies within the family may sustain pain as a shared project keeping the adolescent and main caregiver close together, and this might be hampering identity development. To help adolescents with pain and high consumption of over-thecounter analgesics, the adolescents' relationship with parents should be targeted in interventions. Guidance on pain assessment, pain management, including appropriate use of over-the-counter analgesics, should be included. 
What does this paper contribute to the wider global community?

High use of OTCAs among adolescent might signal that the he or she is struggling with complex psychosocial problems

In supporting an adolescent struggling with pain and high consumption of OTCAs, what should be targeted is the pain management strategies within the family.

Keywords (MeSH terms): adolescents, non-prescription drugs, over-the-counter analgesics, identity, pain management, qualitative research 


\section{INTRODUCTION}

Adolescents frequently use non-prescribed analgesics, also called over-the-counter analgesics (OTCAs), and their use of OTCAs has increased in the past two decades (Wu, Pilowsky, \& Patkar, 2008). OTCA drug misuse is a global health challenge (Conca \& Worthen, 2012; Groenewald, Essner, Wright, Fesinmeyer, \& Palermo, 2014; Lessenger \& Feinberg, 2008). High use of OTCAs among youth is associated with frequent pain from various parts of the body, reduced sleep, more part-time work and lower self-esteem (Skarstein et al., 2014). Continuous use of OTCAs to combat pain and to avoid stress can keep adolescents from learning healthier coping strategies. Such use may also lead to lifelong medicine use (Koushede \& Holstein, 2009). Teens' attitudes towards use of OTCAs vary, and may range from responsible to careless (Hansen, Holstein, Due \& Currie, 2003; Holmström, BastholmRahmner, Bernsten, Röing, \& Björkman, 2014). The strategies of pain management within the family influence adolescents' use of OTCAs. The fact that the family interacts differently during pain seem related to adolescents' pain perception and management (Lagerløv, Rosvold, Holager, \& Helseth, 2016). Furthermore, parents' and especially the mother's information about pain and pain management can influence the adolescents' perception of pain and their pain management (Hatchette, McGrath, Murray, \& Allen Finley, 2006; Jensen et al., 2014; Simons, Claar, \& Logan, 2008). Therefore, there might be reasons to assume that attachment to mothers in childhood and upbringing are important for future pain management, including use of OTCAs. In this perspective, mothers have a significant influence on the child's thoughts, feelings and behaviour (Ainsworth, Bell, \& Stayton, 1994; Allen, Moore, Kupermince, \& Bell, 1998). Erikson (1993) points out that a person's psychosocial development takes place in interaction with the surroundings. Further, Erikson points out that a person's identity is shaped and stabilized during adolescence. In this context, identity is a concept that includes self-esteem, self-worth and self-respect (Bandura, 1997; Santrock, 
2009). Questions like "who am I, how do I fit in and what are my direction in life?" become present. There is limited understanding of the connection between identity development, pain management and use of OTCAs among adolescents. Exploring the connection, as has been done in this study, might be useful for designing interventions to support adolescents with pain and frequent use of OTCAs.

This study aims to describe pain management and conditions that may influence the development of identity in adolescents frequently using analgesics, through interviewing adolescents and their mothers.

\section{METHODS}

\section{Study design}

A qualitative design was chosen. This included face-to-face, in-depth interviews with adolescents and their mothers, which were conducted separately. The interviews were analysed as dyads, and each dyad included an adolescent and his or her mother.

\section{Settings and participants}

Six girls, two boys and their mothers were included. The sample was based on selfselection. The adolescents recruited their parents. All participants voluntarily participated with informed written consent.

Adolescents were recruited from $9^{\text {th }}$ and $10^{\text {th }}$ grades in five Norwegian schools in urban and suburban areas. To be eligible, both adolescents and mothers had to be able to read and understand Norwegian. The adolescents must have used OTCA on a daily or weekly basis 
within the past year. The exclusion criteria were acute or chronic illness requiring OTCAs within the past year.

Twenty random schools were invited by a letter to the headmaster. The principals of ten schools let us recruit adolescents from their schools and gave written confirmation to inform and recruit adolescents at their schools. The ten schools that refused participation were already involved in many other projects.

One researcher, a psychiatric nurse, visited all 10 schools and presented information about the project to 52 classes. The adolescents also received written information about the project and contact information to bring home to their family, with a request for participation of parents whose adolescents consented to participate. It was a requirement that adolescents younger than sixteen years of age, volunteered with consent at the level of parents. Adolescents and parents contacted the researcher by telephone to schedule a time for an interview.

The same researcher conducted all interviews. The interviews were conducted either in a meeting room at the adolescents' school or in the researcher's office dependent on what each participant preferred. Interviews lasted about one hour.

Participants were recruited and interviewed until the research group was confident that no new themes emerged and saturation was reached (Morse, Barrett, Mayan, Olson, \& Spiers, 2002). The audio files and the transcribed material were organized and saved in the program NVivo 11 (QSR International, 2016).

Although fathers were not excluded from participation, mothers were common participating parent, only one father participated. Therefore, we chose to focus on mother and adolescents in this study. Lack of participation from fathers was not unexpected and in line with a similar study, as mothers typically take charge of the issues that are related to their children's health (Hatchette, 2006). 


\section{Interview guides}

Two thematic, semi-structured interview guides were developed: one for adolescents and a separate one for their mothers. Thematic areas in the interview guides were developed in collaboration with a team of experienced school nurses from secondary schools. Both interview guides were designed with open-ended questions to gain broad and complimentary information. As far as possible and without losing relevance to the theme, the participants were allowed to speak freely and share their thoughts and experiences. The interview guide for the adolescents had prompts such as "Tell me about your life". The focus of the interviews of the mothers was primarily on their youth's life. In advance, we had interviewed their child, but information from this interview was not brought in, referred to or in any other way used in the interview with the mothers. The mothers' interview guide also included general prompts such as “Tell me about your adolescent's life". On this basis, topics such as family, friends, school, coping strategies, feelings, leisure-time activities, health, pain, pain management and use of OTCAs were explored.

\section{Data analysis}

The dyadic analysis are inspired and structured by the theory of Kvale and Brinkmann (2008) and done within the three contexts:

1.) Self-understanding; this refers to how the participants reflect and understand their own expressions

2.) Common sense; this refers to how people in general think critically about the statement

3.) Theory; the meaning of the findings are interpreted according to a chosen framework, in this case Erik Erikson's theory of identity $(1993$; 1968). 
Table 1 Example of mother-adolescent dyad statements from interviews with mothers and their adolescents who frequently used analgesics.

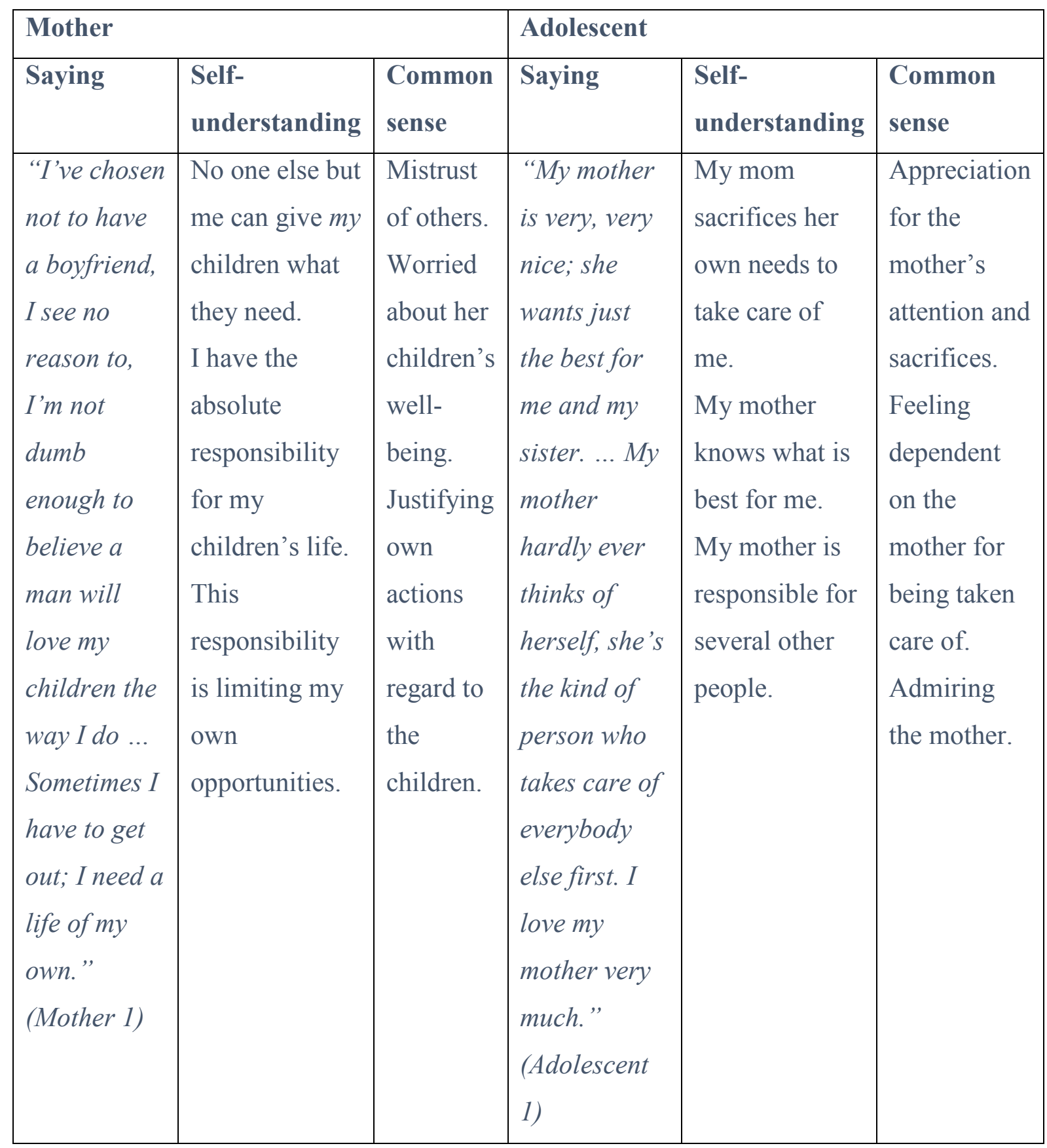

The researchers read the transcripts several times and organized the quotes, first for each of the participants, then for pairs of mothers and adolescents. The quotes were organized into the following categories: OTCAs, pain and health, the adolescent, the mother, the father, and health care support. Each researcher formed a preliminary impression of each participant's 
statements, and possible meaningful interpretations in the context of self-understanding were noted. Further, the researcher used critical common sense to interpret and comment upon the participant's sayings. The sayings within each category were then analysed as dyads; a dyad included one adolescent and his or her mother (Eisikovits \& Koren, 2010). The findings from the analyses of the dyads were then analysed across the whole material. Sometimes doubt or disagreement occurred between the researchers; in such cases they went back to the raw material, and read and interpreted the meaning of the participant's expressions again. Through this back and forth process, we searched for common patterns within, or differences between, the participants' stories. These findings were organized into main themes. A broader understanding arose through this process.

Representative quotes from the interviews are presented in the results, in order to give an accurate picture of the adolescents' and their mothers' expressions. Quotes were translated into English, then further back into Norwegian by English-Norwegian translators. To translate the quotes from the adolescents, we chose a 17-year-old girl, and her Norwegian-American mother translated the mothers' quotes.

\section{Trustworthiness}

The research group was comprised of a psychiatric nurse, a general practice physician and two public health nurses. The research group addressed the potential problems related to the researchers' pre-understanding and discussed the benefits and challenges to reliability.

\section{Ethical considerations}

The study was approved by the Regional Committees for Medical and Health Research Ethics in 2012 (study number: 2012/1460). One of the parents had to give their consent for their child to participate in the study. The youths and their parents received verbal and written 
information about the study. The adolescents recruited their parents, and then both parents and adolescents signed the same consent form. The adolescents were always interviewed before their mothers. The researcher then ensured that the adolescent voluntarily had invited their parent to participate. Through the consent form, the participants were ensured confidentiality and the right to withdraw from the study. They were also informed that the interviews would be tape-recorded.

The school nurses in each school were informed about the study. They were prepared to give support for health risks identified in the interviews. The adolescents agreed to consult the school nurse if the interviewer deemed it to be necessary by signing a consent form. In two cases, such consultations were established. To ensure a high degree of confidentiality, we have not given gender to quotes from the adolescents that participated. On the one hand, it could be interesting to know what boys and girls said, but since we did not specifically investigate gender differences, we chose to avoid this for confidentiality reasons. The ethical principles highlighted in the Declaration of Helsinki were used as guidelines for the study (World Medical Association, 2009). 


\section{RESULTS}

Sixteen participants were interviewed: eight adolescents (two boys and six girls, aged 14-16 years) and their mothers. Some characteristics are presented in table 2.

\begin{tabular}{|l|c|c|}
\hline Table 2 Characteristics of the interviewees in the study of adolescents frequently using \\
over-the-counter analgesics and their mothers. \\
\hline Adolescents (n=8) & Boys & Girls \\
\cline { 2 - 3 } & 2 & 6 \\
\hline Living mainly with mother & 0 & 3 \\
\hline Living with both mother and father & 1 & 5 \\
\hline Living with siblings & 2 & 3 \\
\hline Living in urban areas & 0 & 3 \\
\hline Living in suburban areas & & 3 \\
\hline Mothers (n=8) & & 3 \\
\hline Living without husband and unemployed & 2 \\
\hline Living with husband and employed & & 3 \\
\hline Living without husband and employed
\end{tabular}

Almost half of the adolescents lived with both parents, and the other half lived only with their mother as the primary caregiver. The adolescents expressed daily pain in several parts of their bodies and used OTCAs from daily to once a week. They described everyday life as a struggle to perform well, to be accepted and to fit in. Most of them had experienced being bullied or being an outsider among their peers. They all tried to avoid conflicts. The mothers had the main responsibility for the upbringing of their child, even in families with both parents present. Mothers who lived without a partner struggled financially. Mothers worried about their adolescent's health and spent much effort trying to help their child; several expressed this as a lonely struggle without support from other adults. The stories given 
by the adolescents and their mothers' stories described the adolescents' life, pain, use of OTCAs and treatments in the same way. The descriptions differed in terms of the mothers and adolescents' experience of the adolescent's strengths and difficulties. The themes that emerged from the analysis were "Vulnerable adolescents", "Mother knows best" and "Pain is our project" and this will be described below.

\section{Theme 1: Vulnerable adolescents}

The stories all showed that the adolescents felt a sense of responsibility, that they focused on being successful and that they made commitments to be accepted and included both in the family and among their peers. Several adolescents said that they avoided expressing their opinions and needs so as not to be excluded or bullied.

I was bullied; they excluded me and said pretty nasty things. It wasn't physical violence, but I was hurt by what others said to me when I was a child. Nowadays, I shy away from conflicts both at school and among peers. If there are conflicts in the family, I accept what the others say. I say OK even if I know that it's wrong and even if I know I'm right, just to end it, because I don't like conflicts.

(Adolescent 1)

Many of the adolescents described family conflicts; conflicts between parents were especially stressful. Both the stories from the adolescents and the mothers revealed a series of conflicts, illnesses and bullying that put the adolescents under stress for years. Some adolescents described difficult events, such as the sudden death of a close relative, as constantly present in their mind, even if it happened years ago. Most of the adolescents mentioned longing for a close friend and feeling lonely. This, combined with the wish to spend more time with their father, may indicate a need for broader social network. The 
mothers did not mention these aspects; some mothers seemed to consider themselves to be able to fulfil all the adolescents' basic needs.

\section{Theme 2: Mother knows best}

The mothers' stories revealed that they were proud of their children and their children's achievements, appearance and behaviour. They also described their adolescents as socially well-adjusted with several friends. The adolescents said that they loved, admired and relied on their mothers and depended on her support in daily life. All mothers stated that they had the main responsibility for their child's upbringing, with little support from the father or the extended family.

The stories revealed that mothers and adolescents were very close and spent much of their leisure time together. Initially, they seemed to be well-informed about each other's lives. The mothers appeared to believe that their child told them everything of importance. The adolescents' stories revealed that they controlled what they told their mother and what they kept to themselves.

I just want a father like the others. My father is sick in the head, he twists everything and always makes me feel bad, that's what he's best at. He makes me feel guilty for everything that goes wrong. He twists my mind so I can't tell what's really going on, and my mom doesn't know what's happening to me. (Adolescent 8)

The mother said:

We talk about everything. I have taught my child that. We talk with no filter. (Mother 8) 
The mothers had strong opinions about whom the adolescents kept in contact with, how they should behave and what they should do. The adolescents seemed to have more or less accepted this control over their lives, and did not want to disappoint their mothers. Mothers made decisions that influenced the adolescents' lives, such as moving to a new home, changing schools and recreational activities. They acted as managers for their children; for example, one mother retouched a photo of her daughter and sent it to a dancing competition. Only at the very last moment did she show her daughter the photo and ask for her approval to send it. Several mothers told of they taken action when their child was bullied by peers, by involving school employees or making direct contact with the bullies and their parents. Some mothers controlled their adolescent's social life by reading their mail and messages, choosing suitable friends and ending the child's association with undesirable companions.

The stories told by both adolescents and their mothers show that the mothers seem to sacrifice their own lives with the intention of taking care of their adolescent and other relatives. The adolescents were well aware of their mother's sacrifices and expressed great appreciation. The mothers said that they tried to ensure that their child had everything needed to succeed in life. However, some mothers longed to prioritize their own needs.

I've chosen not to have a boyfriend, I see no reason to. I'm not dumb enough to believe a man will love my children the way I do ... Sometimes I have to get out; I need a life of my own. (Mother 1)

Her child, like several of the adolescents, knew well that the mother sacrificed her own needs and resources to support them, and the adolescents seemed to idolize their mothers.

My mother is very, very nice; she wants just the best for me and my sister. Her own mother is very ill with multiple sclerosis and in a wheelchair; my mom is really nice to her, too. My mother hardly ever thinks of herself; she's the kind of 
person who takes care of everybody else first. I love my mother very much.

(Adolescent 1)

\section{Theme 3: Pain is a shared project}

Mothers and adolescents gave similar descriptions of the pain experienced by the adolescents, the consequences and treatment. Both of them said that the adolescent experienced pain almost daily and that this pain kept the adolescents from being successful at school and in sports, recreational activities and social life. Furthermore, they agreed that the adolescent's pain problems seemed to escalate over time. Doctors and therapists might be consulted, but when their recommendations differed from the mother's own view of what was best, their advice was not necessarily followed.

The stories revealed that mothers and adolescents talked about the adolescent's pain together, rated the pain and made strategies about how to manage the pain and who to involve. Neither the adolescents nor their mothers seemed to involve the fathers in the pain problems or pain management.

I always get a headache when I don't get enough sleep, and now I'm starting to see the connections. My mom said, "You get a headache every time you study for exams." And I really do. (Adolescent 5)

The stories seem to put the mother in the role as the provider of pain management and the adolescent in the role of the receiver of treatment.

On Friday, we'll go to another town ... I have heard there's a very good orthopaedist there. We'll spend the day there and try to figure out what to do. (Mother 2) 
The adolescents' pain and ways of finding solutions were important topics in the conversations between the mothers and adolescents. Both groups saw pain as an acceptable reason for attention and intimacy. One mother said; "The pain in her legs is often bad, and we often sleep in the same bed." (Mother 1). Several adolescents mentioned that massage from their mother gave them some relief from pain. This may indicate that the adolescents felt devotion in return for the mother's support and thus legitimized the mother's role and function.

Throughout the stories from both mothers and adolescents, it seemed clear that the adolescents were incorporated into a family pattern.

When I kick my leg, I get a headache. I have a long history of pain. I am not sure if it is genetic, but I think all women in our family respond to life like this. We experience life rather similarly, we are all sensitive, and at the same time, we are seen as very strong. We manage everything immediately, in a way. In addition, I think we always have hunched shoulders and shallow breath. The way we live our lives gives us headaches and pains. (Mother 5)

Several mothers urged their adolescent to try private health care such as homeopathy, naturopathy, chiropractic, massage and physiotherapy, and stated that they used these therapies themselves. The adolescents said rather unambiguously that none of these treatments gave lasting relief, although some seemed to have developed a close relationship with their therapist of several years and referred to "my therapist".

Mothers and adolescents reported that using analgesics increased the adolescent's ability to manage daily life. Mother taught the adolescent how to take OTCAs and to ensure that OTCAs were available. Several of the mothers referred to information about highest recommended dosage in the leaflet for each variation of pain medication their child was using. Further, they stated that they knew their adolescent did not use more than was recommended. 
Some adolescents said that they also use their mother's prescribed pain medication, but the mothers did not mention this. The mothers said that they controlled the adolescent's use of OTCAs, whereas several adolescents noted that in addition to the medication that they received at home, they bought OTCAs themselves and borrowed medication from friends.

The impact of fathers in everyday life of adolescents during pain was not always prominent even among families where both parents were present, as revealed in the stories told by the adolescents and their mothers.

\section{DISCUSSION}

The adolescents in our study were vulnerable; they adjusted their behaviour according to what they believed was expected from them. Their mothers played a dominant part in their lives, and the adolescents seemed to have had few opportunities to explore the world on their own. Moreover, they seemed to have a limited social network. The demands made on the adolescents throughout their childhood seemed to be more than they could handle, and they learned to adapt and adjust to receive attention and care. Many of the adolescents had experienced bullying and exclusion by their peers, and they continued to undermine themselves to be accepted and fit in. Pain seemed to have become an acceptable way of expressing difficulties, grief and fear. The adolescents perceived that their mother was the primary person who looked after them. Mothers engaged naturally in caregiving to alleviate pain and to improve their child's health. Relieving pain was seen as a shared project; the mother managed the pain project, and the adolescent received support and treatment. OTCAs were used as a token for giving and receiving attention and care.

Identity is formed through childhood and adolescence when the interplay between individual and surroundings has an impact on identity formation (Erikson, 1962, 1968, 1993). 
Especially important is the key caregiver, a role that is often culturally and historically assigned to the mother. Many of the adolescents had experienced challenges and conflicts early in life, like illness and death among close relatives, and some of these experiences seemed unprocessed and like a constant burden. Ego identity refers to a continuity with the past, meaning in the present and direction for the future (Côte \& Levine, 1983). Family dysfunction has been found to have a negative effect on emotional adjustment (Eccleston, Crombez, Scotford, Clinch, \& Connell, 2004; Eccleston, Wastell, Crombez, \& Jordan, 2008). Unresolved crises leave individuals struggling with their identity (Schultz \& Schultz, 2016). This may also influence the reactions to stress (Folkman, Lazarus, Gruen, \& DeLongis, 1986; Folkman \& Moskowitz, 2000). Through the interviews, it seems like reality is designed by mothers who leave the adolescents' personal experiences, feelings and thoughts unseen. Because of their fear of exclusion or conflict, the adolescents undermine themselves and adapt. This may indicate that the adolescents are not moving on from the identity diffusion status or are locked in the foreclosure status of identity development (Erikson, 1968).

The mothers in this study frequently linked the adolescents' pain to their own and their maternal ancestors' pain, and the adolescent repeated and copied these stories. It could be the mother's attempt to give their adolescent a sense of attachment and belonging. It may thus be considered a way of giving the adolescent an identity, albeit an identity that is not based on the adolescent's own perception and that does not sustain fidelity to his or her own identity (Erikson, 1968).

The interviewed adolescents seemed to long for closeness but mentioned not feeling attached to anyone other than their mother. In adolescence, it is important to be able to rely on others beyond the primary caregivers to test fidelity and to achieve a positive identity (Erikson, 1968). The mothers did not seem to be aware of this and did not address it. The interviewed adolescent often described that they avoided expressing their need for others, 
such as their father, to avoid conflict or rejection by their mother. Perhaps this produces negative emotions with no acceptable outlet. Over time, such strategies of avoidance could hamper the development of fidelity and result in continuous strive for own identity.

The mothers of the interviewed adolescents seemed to act authoritatively; they planned and controlled their adolescent's daily life, while at the same time, they let it be known that they made sacrifices to support others. It is possible that such attitude can give the adolescents a feeling of guilt and shame when they express their own needs and feelings. Expression of pain could be an acceptable way of expressing discomfort and might elicit attention and support from the mother. It has been stated in the literature that adolescents with authoritarian parents have decreased academic self-esteem and family self-esteem compared to adolescents with indulgent parents (Martinez \& Garcia, 2007). In an earlier study, we found that adolescents with high use of OTCAs had lower self-esteem and lower ambition for future education than did adolescents who seldom or never use OTCAs (Skarstein et al., 2014).

The mothers in our study played an important role in their child's upbringing and seemed to receive little support. The attitudes to their own parental role were without much reflection and correction. These family and social structures ought to be explored further.

Identity, self-esteem and self-efficacy are all mutually dependent (Bandura, O’Leary, Taylor, Gauthier, \& Gossard, 1987), and must be then considered in their entirety when treating adolescents with frequent pain and high consumption of OTCAs. Bandura (1997) defined self-efficacy as belief in one's ability to succeed in specific situations. One's sense of self-efficacy can play a major role in how one approaches goals, tasks and challenges. Bandura's social cognitive theory emphasizes the role of observational learning and social experience in personality development. According to this theory, self-efficacy also plays an important role in coping with pain (Bandura, 1997; Bandura et al., 1987). Furthermore, that training in cognitive control strengthens perceived self-efficacy both to withstand and to 
reduce pain (Bandura et al., 1987). People learn through observation, imitation and modelling (Luszczynska, Scholz, \& Schwarzer, 2005). The adolescents in this study seemed to use coping strategies that they had learned mainly from their mother, even if these strategies were not actually effective in combating pain.

The interviewed adolescents' everyday lives were ruled by their assessment of expectations from others, mainly from their mothers, but also from their school and peers. The worries of the mother restricted the child's possibilities, capabilities and resources. This may cause identity foreclosure or an identity status developed by an individual without many opportunities. Further, identity foreclosure can contribute to identity crises in adolescents when the "security blanket" of their assumed identity is removed, and a foreclosed individual may go into crisis, not knowing what to do and not be able to rely on the familiar norms and rules (Marcia, 1980). Pain and use of OTCAs might constitute a kind of substitute "security blanket" for these adolescents. Pain becomes an acceptable reason for not managing daily challenges and may trigger sympathy and understanding. Perhaps both adolescents and their mother retain some self-respect when explaining their difficulties as somatic pain.

\section{Strengths and limitations}

All interviews were conducted by the main author, who is a board-certified psychiatric nurse. In presenting herself as a researcher and not being involved as therapist, her clinical experience may have promoted the ability to obtain in-depth information.

The research group included participants from different disciplines who analysed the findings together. Most interviewees were of the same gender as the interviewer, which may have lessened barriers of communication across genders. Only two of the eight adolescent participants were boys, and the findings may be more transferable to girls than to boys. 
A limitation of this study is the small sample size. Recruitment of adolescents and their families was difficult, and only one father responded to our request for participation in this study. Adolescents who consume high amounts of OTCAs are likely to represent a heterogeneous range of "typologies"; some might lead a life quite detached from their caregivers. Such adolescents might be unlikely to accept an invitation tothis type of study. Other adolescents might, in contrast, live in close (or even enmeshed) parental relationships, as suggested by the present study, where peer bullying was among the observed background factors. These latter adolescents might be far more likely to bring the study invitation home and end up as participants in dyads. We should thus be careful not to transfer the experiences from this study to all adolescents frequently using OTCAs.

In this study, we have included adolescents and their mothers. It is quite possible that we would have made other discoveries and gained a broader knowledge if we had been able to include the adolescents' fathers.

The interviews were conducted mainly in urban and suburban areas in southern Norway. However, an earlier study of the consumption of OTCAs among adolescents did not reveal differences between urban and rural regions in Norway (Furu, Skurtveit, \& Rosvold, 2005). When our findings are recognized and their usefulness is acknowledged by the reader, they are considered transferable within the framework of qualitative research (Sandelowski, 1986).

Through this study, we have identified some possible perspectives that might lead to novel approaches to identify, guide, and support adolescents with frequent pain and high consumption of OTCAs. Individual tasks, family matters, and bullying must be considered both in mapping and in designing interventions. However, more research is needed to design a guide for professional mapping and health interventions. 


\section{CONCLUSION}

The adolescents in this study were vulnerable and struggled in their identity development. Appraisal of pain, main management in general and the use of OTCAs seemed to be learned from mothers. OTCAs might be a token in handling difficulties, which were translated as pain. Managing stress and pain by avoiding challenges could maintain and amplify these adolescents' underlying problems. Having few opportunities to explore life's challenges by themselves, the adolescents in this study struggled to discover their own uniqueness, their similarities to others and their own strengths and weaknesses. Systematic interventions targeting pain, stress and frequent use of OTCAs should consider the interplay between the adolescents and other important figures, such as peers and parents. Further, guidance on pain assessment and pain management, including appropriate use of over-the-counter analgesics, should be included.

Even though this knowledge has relevance for many adolescents consuming high amounts of OTCA, it is probable that it does not describe all such adolescents. Further research is needed to explore adolescents not reached in our study. 


\section{References}

Ainsworth M. D. S., Bell, S. M., \& Stayton, D. F. (1994). Infant-mother attachement and social development: Socialization as a product of reciprocal response to signals, in the integration of a child into a social world. New York: Cambrigde University Press

Allen J.P., Moore, C., Kuperminc, C., \& Bell, K. (1998). Attachement and adolescent psychosocial functioning. Child Development, 69(5), 1406-1419.

Bandura, A. (1997). Self-efficacy: the exercise of control. New York: Freeman.

Bandura, A., O’Leary, A., Taylor, C. B., Gauthier, J., \& Gossard, D. (1987). Perceived selfefficacy and pain control: opioid and nonopioid mechanisms. Journal of Personality and Social Psychology, 53(3), 563-571.

Conca, A. J., \& Worthen, D. R. (2012). Nonprescription drug abuse. Journal of Pharmacy Practice, 25(1), 13-21. doi:10.1177/0897190011431148

Côte, J. E., \& Levine, C. (1983). Marcia and Erikson: The relationships among ego identity status, neuroticism, dogmatism, and purpose in life. Journal of Youth and Adolescence, 12(1), 43-53.

Eccleston, C., Crombez, G., Scotford, A., Clinch, J., \& Connell, H. (2004). Adolescent chronic pain: patterns and predictors of emotional distress in adolescents with chronic pain and their parents. Pain, 108(3), 221-229. doi:10.1016/j.pain.2003.11.008

Eccleston, C., Wastell, S., Crombez, G., \& Jordan, A. (2008). Adolescent social development and chronic pain. European Journal of Pain, 12(6), 765-774. doi:10.1016/j.ejpain.2007.11.002

Elo, S., \& Kyngäs, H. (2008). The qualitative content analysis process. Journal of Advanced Nursing, 62(1), 107-115.

Erikson, E. H. (1968). Identity: Youth and crisis. London: Faber \& Faber.

Erikson, E. H. (1993). Childhood and society. New York: Norton. 
Folkman, S., Lazarus, R. S., Gruen, R. J., \& DeLongis, A. (1986). European Journal of Pain. Journal of Personality and Social Psychology, 50(3), 571-579. doi:10.1037/00223514.50.3.571

Folkman, S., \& Moskowitz, J. T. (2000). Stress, Positive Emotion, and Coping. Current Directions in Psychological Science, 9. doi:10.1111/1467-8721.00073

Furu, K., Skurtveit, S., \& Rosvold, E. (2005). [Self-reported medical drug use among 15-16 year-old adolescents in Norway]. Tidsskrift for den Norske Laegeforening, 125(20), $2759-2761$.

Groenewald, C. B., Essner, B. S., Wright, D., Fesinmeyer, M. D., \& Palermo, T. M. (2014). The Economic Costs of Chronic Pain Among a Cohort of Treatment-Seeking Adolescents in the United States. Journal of Pain, 15(9), 925-933. doi:10.1016/j.jpain.2014.06.002

Hansen, E. H., Holstein, B. E., Due, P., \& Currie, C. E. (2003). International survey of selfreported medicine use among adolescents. Annals of Pharmacotherapy, 37(3), 361366. doi:10.1345/aph.1C111

Hatchette, J. E., McGrath, P. J., Murray, M., \& Allen Finley, G. (2006). Maternal influences in adolescents' pain self-management: A qualitative investigation. Vulnerable Children and Youth Studies, 1(2), 159-169. doi:10.1080/17450120600872332

Holmström, Inger K., Bastholm-Rahmner, P., Bernsten, C., Röing, M., \& Björkman, I. (2014). Swedish teenagers and over-the-counter analgesics - Responsible, casual or careless use. Research in Social and Administrative Pharmacy, 10(2), 408418.doi.org/10.1016/j.sapharm.2013.06.004

Jensen, J. F., Gottschau, M., Siersma, V. D., Graungaard, A. H., Holstein, B. E., \& Knudsen, L. E. (2014). Association of maternal self-medication and over-the-counter analgesics for children. Pediatrics, 133(2), e291-298. doi:10.1542/peds.2013-1107 
Lagerløv P, Rosvold EO, Holager T, Helseth S. (2016). How adolescents experience and cope with pain in daily life: a qualitative study on ways to cope and the use of over-thecounter analgesics. BMJ Open. 1;6(3):e010184. doi: 10.1136/bmjopen-2015-010184.

Koushede, V., \& Holstein, B. E. (2009). Sense of coherence and medicine use for headache among adolescents. Journal of Adolescent Health, 45(2), 149-155. doi:10.1016/j.jadohealth.2008.12.009

Brinkmann, S., \& Kvale, S. (2008). Ethics in qualitative psychological research. In C. Willig, \& W. Stainton-Rogers (Eds.), The SAGE handbook of qualitative research in psychology, 263-279. London: Sage Publications, Incorporated.

Lagerløv, P., Holager, T., Helseth, S., \& Rosvold, E. O. (2009). [Self-medication with overthe-counter analgesics among 15-16 year-old teenagers]. Tidsskrift for den Norske laegeforening: tidsskrift for praktisk medicin, 129(15), 1447-1450.

Lessenger, J. E., \& Feinberg, S. D. (2008). Abuse of prescription and over-the-counter medications. Journal of the American Board of Family Medicine, 21(1), 45-54. doi:10.3122/jabfm.2008.01.070071

Luszczynska, A., Scholz, U., \& Schwarzer, R. (2005). The general self-efficacy scale: multicultural validation studies. Journal of Psychology, 139(5), 439-457. doi:10.3200/JRLP.139.5.439-457

Marcia, J. E. (1980). Identity in adolescence. Handbook of adolescent psychology. Red: J. Adelson. New York, NY, Wiley-Interscience.

Martinez, I., \& Garcia, J. F. (2007). Impact of parenting styles on adolescents'self-esteem and internalization of values in Spain. Spanish Journal of Psychology, 10(2), 338-348.

Morse, J. M., Barrett, M., Mayan, M., Olson, K., \& Spiers, J. (2002). Verification strategies for establishing reliability and validity in qualitative research. International journal of qualitative methods, 1(2), 13-22. doi:10.1177/160940690200100202 
QSR International. (2016). Nvivo 11 Retrieved 9 March 2017 from http://www.qsinternational.com/product

Sandelowski, M. (1986). The problem of rigor in qualitative research. Advances in nursing science, $8(3), 27-37$.

Schultz, D. P., \& Schultz, S. E. (2016). Theories of personality: Cengage Learning.

Simons, L. E., Claar, R. L., \& Logan, D. L. (2008). Chronic pain in adolescence: parental responses, adolescent coping, and their impact on adolescent's pain behaviors. Journal of Pediatric Psychology, 33(8), 894-904. doi:doi:10.1093/jpepsy/jsn029

Skarstein, S., Rosvold, E. O., Helseth, S., Kvarme, L. G., Holager, T., Smastuen, M. C., \& Lagerlov, P. (2014). High-frequency use of over-the-counter analgesics among adolescents: reflections of an emerging difficult life, a cross-sectional study. Scandinavian Journal of Caring Sciences, 28(1), 49-56. doi:10.1111/scs.12039

World Medical Association. (2009). Declaration of Helsinki: Ethical principles for medical research involving human subjects. Retrieved from 9 March 2017 http://www.wma.net/en/30publications/10policies/b3/

Wu, L. T., Pilowsky, D. J., \& Patkar, A. A. (2008). Non-prescribed use of pain relievers among adolescents in the United States. Drug and Alcohol Dependence, 94(1-3), 1-11. doi:10.1016/j.drugalcdep.2007.09.023 

Appendix 1:
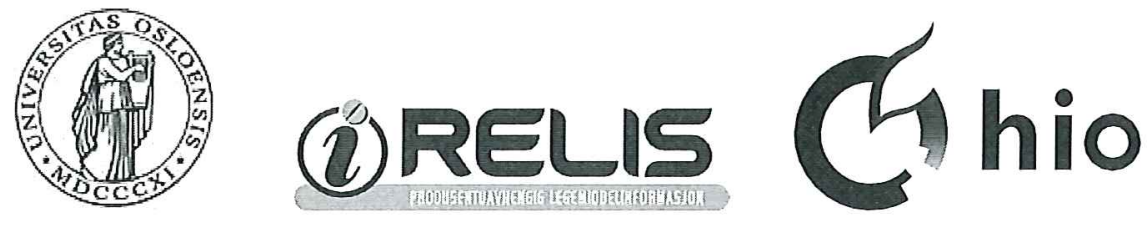

Smerte, Ungdom og Selvmedisinering

Spørreundersølkelse ved ungdomsskolene

i

Drammen 


\section{Bruk av reseptfrie smertestillende medisin}

Om deg:

0.0 Hvilken klasse på ungdomsskolen går du i? (angi tall og bokstav)

1.0 Hvilket år er du født? (angis med fire tall)

2.0 Erdu: $\square$ Gutt $\quad \square$ Jente

$\underline{\text { Smertestillende medisiner du kjenner: }}$

3.0 Hvilke av nedenfor nevnte smertestillende medisiner, se plansje med bilde av de fleste pakninger bakerst i skjema (side 16), kjenner du igjen eller har du hørt om før?

( sett ett eller flere kryss)

$\begin{array}{lll}\square \text { Aspirin } & \square \text { Dispril } & \square \text { Globoid } \\ \square \text { Fenazon-koffein } & \square \text { Antineuralgica } & \square \text { Paracet } \\ \square \text { Pamol } & \square \text { Panodil } & \square \text { Naproxen } \\ \square \text { Paracetamol } & \square \text { Pinex } & \square \text { Ledox } \\ \square \text { Ibux } & \square \text { Ibumetin } & \square \text { Otriflu } \\ \square \text { Ibuprofen } & \square \text { Fanalgin } & \square \text { Annet: }\end{array}$

Gjenkjenner ingen/husker ikke navnet på medisinen

4.0 Hvor mange ganger i løpet av de siste 3 måneder har du hatt plager der du har brukt smertestillende medisin? (sett ett kryss)
$\square$ Ingen
En gang
To til tre ganger
Fire eller flere ganger 
De neste spørsmålene handler om helsen din og bruk av smertestillende de siste 4 uker (siste måned).

\section{$\underline{\text { Smertetilstander: }}$}

5.0 Har du eller har du hatt noen av de nevnte plager i løpet av siste 4 uker? (sett ett eller flere kryss)

$\square$ Vondt i øret/øreverk

$\square$ Menstruasjonssmerter

Vondt i ryggen

Vondt i halsen

Lett hodepine

Sterk hodepine/migrene

$\square$ Tannverk

Tannreguleringssmerter

$\square$ Feber

Vondt i nakke/skuldre

$\square$ Mavesmerter/knip/krampe

Vondt i hele kroppen

$\square$ Idrettskade (forstuing o.l)

$\square$ Andre smerter, spesifiser:

$\square$ Ingen 
Bruk av smertestillende:

6.0 Bruker du eller har du brukt smertestillende medisin for noen av de nevnte plagene i løpet av siste 4 uker? (sett ett eller flere kryss)

$\square$ Vondt i фret/øreverk

$\square$ Menstruasjonssmerter

$\square$ Vondt i ryggen

Vondt i halsen

Lett til moderat hodepine

$\square$ Sterk hodepine/migrene

Tannverk

Tannreguleringssmerter

$\square$ Feber

$\square$ Vondt i nakke/skuldre

$\square$ Mavesmerter/knip/krampe

$\square$ Vondt i hele kroppen

$\square$ Idrettskade (forstuing o.l)

Andre smerter, spesifiser:

$\square$ Ingen

\section{Mengde smertestillende medisin:}

7.0 Hvis du har tatt smertestillende siste 4 uker, hvor ofte har du da tatt slik medisin? (sett bare ett kryss)

\section{Daglig}

Hver uke, men ikke daglig

Sjeldnere enn hver uke

Ikke tatt siste 4 uker 
8.0 Hvis du skulle ta smertestillende nå, hvor mange tabletter vil du ta på én gang? (sett bare ett kryss)

En halv tablett

En tablett

To tabletter

Tre tabletter eller mer

9.0 Hvis du skal ta smertestillende hvor mange ganger daglig vil du ta en slik dose? (sett bare ett kryss)

$\square$ En gang daglig

$\square$ To ganger daglig

Tre ganger daglig eller mer

10.0 Hva tror du er det viktigste som skjer hvis du tar mer smertestillende enn det som er anbefalt? (sett bare ett kryss)

Får bedre effekt

Får dårligere effekt/ blir "immun".

$\square$ Får bivirkninger

11.0 Hvor mange tabletter smertestillende medisin tatt på en gang tror du vil gi alvorlig forgifting? (angi antall tabletter)

tabletter 
Videre bruk av smertestillende

12.0 Vil du/kan du tenke deg å bruke smertestillende ved noen av nedenfor nevnte tilstander eller plager? (sett ett eller flere kryss)

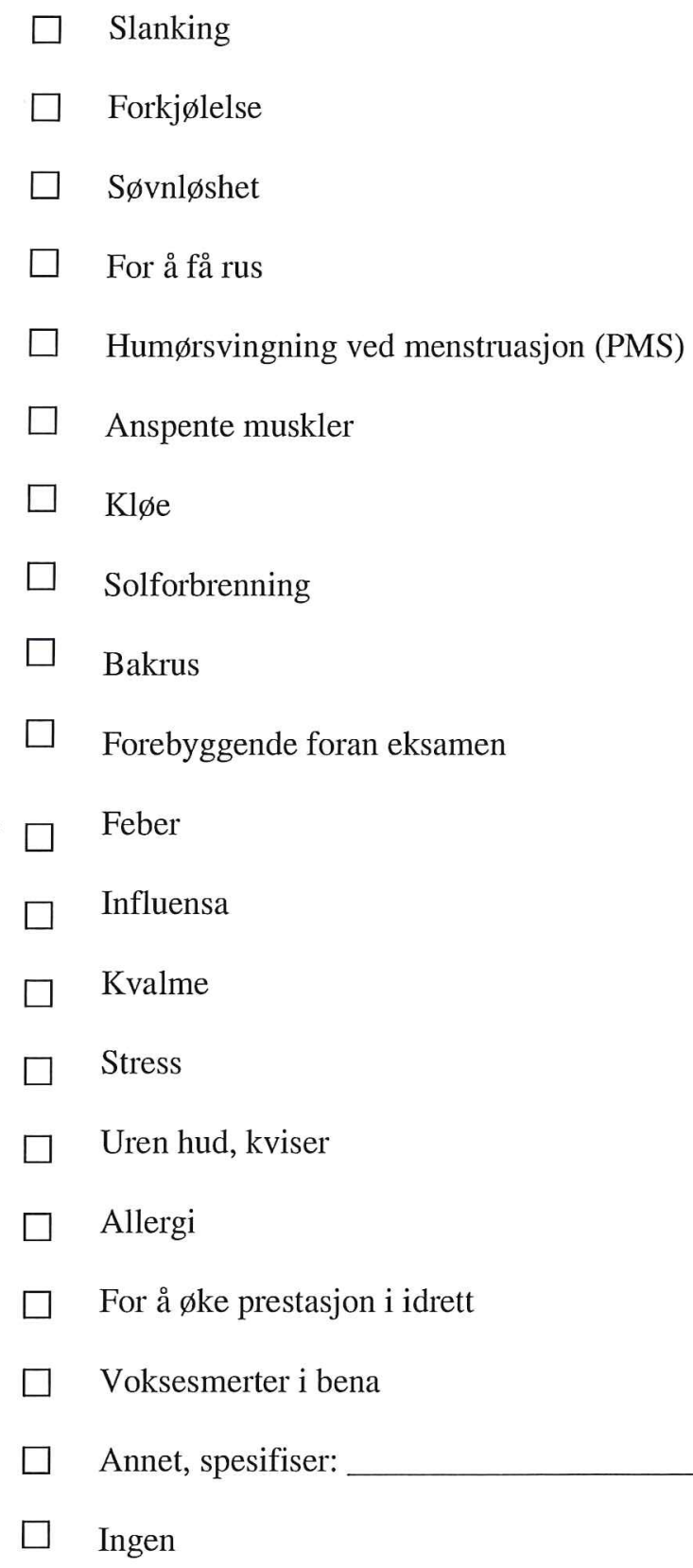


Har du ofte fått smerte/plage på grunn av nedenfor nevnte forhold? (sett ett eller flere kryss)

$\square \quad$ Lang tid ved PC eller foran TV

$\square \quad$ Lang skoledag eller dobbeltime

$\square \quad$ Lite drikke i løpet av skoledagen

$\square \quad$ Spiser uregelmessig

$\square \quad$ Mye støy i klasserommet

$\square \quad$ Lang skolevei

$\square \quad$ Tung skolesekk

$\square \quad$ Lang tid med høy musikk på MP3-spiller / iPod

$\square \quad$ Frost på grunn av lite klær

Tett program i uken med venner, trening, jobb

$\square \quad$ Mye bruk av mobiltelefon

$\square$ Annet, spesifiser:

$\square \quad$ Ingen 
14.0 Hvor godt tåler du smerte? Angi på skala (streken) nedenfor din smerteterskel for en kjent smerte, for eksempel $\varnothing$ reverk.

Lav terskel

Tåler litt smerte i kort tid
Høy terskel

Tåler mye smerte lenge

15.0 Hvor mange timer tror du det bør det gå mellom hver gang du tar smertestillende? (sett bare ett kryss)

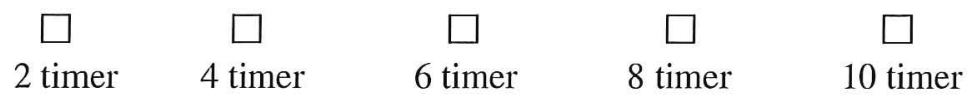

16.0 Hvis du skal sammenlikne bruk av reseptfrie smertestillende medisin med bruk av andre midler, hva kommer da nærmest: (sett bare ett kryss)

Bruk av vitaminer/kosttilskudd

Bruk av legemidler på resept

Bruk av helsekost/naturmidler

Tilgang på smertestillende og informasjon

17.0 Tilgang på reseptfri smertestillende medisin: (sett ingen, ett eller flere kryss)

$\square$ Jeg har smertestillende hjemme som jeg kan ta selv

$\square$ Jeg får smertestillende hjemme hvis jeg spør en av de voksne

$\square$ Vi har ikke smertestillende hjemme

$\square$ Jeg har fått smertestillende av en venn eller venninne

$\square$ Jeg har fătt smertestillende av idrettstrener

Jeg har kjøpt smertestillende til meg selv på apotek

Jeg har kjøpt smertestillende til meg selv på bensinstasjon, i matbutikken

Jeg passer påå ha smertestillende med meg (i lommebok, veske, skolesekk) 
18.0 Hvor har du fått informasjon om bruk av smertestillende? (sett ett eller flere kryss)

Av mor, far eller annen voksen hjemme

Av søsken

$\square$ Av apotekpersonalet

$\square$ Ved å lese pakningsvedlegget

Av venner/venninner

$\square$ Ved informasjonsprogram på TV

$\square$ Ved reklame på TV eller i blader

$\square$ Av lærer

Av helsesøster

Av lege

$\square$ Av idrettstrener

Annet, spesifiser:

Ingen informasjon 
19.0 Hvis du forteller hjemme at du har vondt i hodet, hva får du oftest beskjed om? (sett bare ett kryss)

$\AA$ A ta smertestillende med en gang

Å vente og se om det går over av seg selv før du tar smertestillende

$\AA ̊$ gjøre noe annet istedenfor å ta smertestillende

20.0 Hvis du har vondt i hodet og skal ta smertestillende, hvor mye vil du at andre skal vite om at du gjør det? (sett bare ett kryss)

Skjuler det så andre ikke vet at jeg tar smertestillende

Forteller det kun til de nærmeste så de kan vise hensyn

Bryr meg ikke om andre får vite det, tar det åpenlyst

21.0 Hvis du har vrikket foten og skal stille til kamp i lagidrett (håndball, fotball), hva vil treneren din foreta seg? (sett bare ett kryss)

Gir deg smertestillende og forventer at du deltar

Gir deg smertestillende og ber deg stå over kampen

Ber deg stå over kampen uten smertestillende

Ikke aktuelt spørsmål for meg

22.0 Hva er ditt syn på reseptfri smertestillende medisin? (sett bare ett kryss)

Et middel som stort sett ikke skal brukes

Et middel til å komme igjennom en vanskelig situasjon

Et middel som kan brukes hver gang jeg har vondt

23.0 Hva mener vennene dine om bruk av smertestillende?

(sett bare ett kryss)

De mener som oftest at man skal tåle smerte en stund før man bruker smertestillende

De mener som oftest at dersom en har vondt så trenges smertestillende Jeg vet ikke 


\section{Spørsmål om egen helse}

24.0 Hvordan er helsen din nå?

$\square$ Dårlig $\quad \square$ Ikke helt god $\quad \square$ God $\quad \square$ Svært god

25.0 Har du i løpet av de siste 12 månedene flere ganger vært plaget med smerter i (sett ett kryss for hver linje)?

$\begin{array}{lcc}\text { Hodet (hodepine, migrene e.l.) } & \text { Ja } & \text { Nei } \\ \text { Nakke/skuldre } & \square & \square \\ \text { Arm/ben/knær } & \square & \square \\ \text { Mage } & \square & \square \\ \text { Rygg } & \square & \square\end{array}$

Hvis du har svart nei på alle spørsmålene i spørsmål 25.0, gå rett til spørsmål 26.0

25.1 Har disse smertene ført til at du har vært hjemme fra skolen i løpet av de siste 12 månedene?(sett bare ett kryss)
Nei Ja, 1-2 dager Ja, 3-5 dager
Ja, 6-10 dager
Ja, mer enn 10 dager

25.2 Har smertene ført til redusert aktivitet i fritiden?

$\square \quad \mathrm{Ja} \quad \square$ Nei

25.3 Tror du disse smertene mest skyldes forhold på skolen?

$\square \quad$ Ja $\quad \square$ Nei

26.0 Bruker du briller eller kontaktlinser?

$\square$ Ja $\quad \square$ Nei

27.0 Fast tannregulering (sett bare ett kryss)

Bruker jeg nå $\square$ Brukte jeg før $\quad \square$ Har jeg ikke hatt


28.0 Røyker du daglig?

$\square \mathrm{Ja} \quad \square$ Nei

29.0 Bruker du snus daglig?

$\square$ Ja $\quad \square$ Nei

30.0 Har du noen ganger drukket så mye alkohol at du har vært beruset?(full) (sett bare ett kryss)

Nei Ja, én gang Ja, 2-3 ganger Ja, 4-10 ganger Ja, mer enn 10 ganger

\section{Fritidsaktivitet}

31.0 Hvor mange ganger i uken driver du med idrett/mosjon slik at du blir andpusten eller svett?

gang/ganger per uke

32.0 Omtrent hvor mange timer per uke bruker du på dette? (sett bare ett kryss)

0 timer $\quad 1-2$ timer $\quad 3-4$ timer $\quad 5-7$ timer $\quad 8-10$ timer $\quad 11$ timer eller mer

33.0 Driver du med konkurranseidrett (lag eller individuelt)?

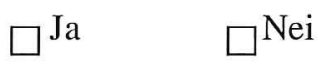

34.0 Hvor ofte er du sammen med voksne i fritiden? (sett bare ett kryss)

$\square$ Aldri $\square$ Sjelden $\quad \square$ Av og til $\quad \square$ Ofte

\section{Mat og søvn}

35.0 Hvor ofte spiser du frokost før du går på skolen? (sett bare ett kryss)

Aldri/sjelden 1 dag/uke 2-3 dager/uke Oftest daglig/alltid

36.0 Hvor ofte spiser du middag sammen med familien/voksne/foresatte per uke? (sett bare ett kryss)
Aldri
1/uke
2-3/uke
Ofte-alltid 
37.0 Hvor mange måltider spiser du i gjennomsnitt per dag?

$$
\text { _ }
$$

38.0 Hvor mye væske drikker du per dag?

(en liter er 2 flasker Cola eller 5 glass vann)

liter/dag

39.0 Tar du vitaminer eller kosttilskudd daglig?

$\mathrm{Ja} \quad \square$ Nei

40.0 Hvor mange timer sover du i gjennomsnitt per natt?

Timer/natt

41.0 Gir dette tilstrekkelig søvn så du føler deg uthvilt? (sett bare ett kryss)
$\mathrm{Ja}$
$\square$ Delvis
Nei

42.0 Når pleier du å sovne:

På hverdager: kl

I helgene: $\quad \mathrm{kl}$

43.0 Hvor mange kopper kaffe/te drikker du i gjennomsnitt per dag? (angi 0 for ingen) per dag

44.0 Drikker du daglig andre koffeinholdige drikker (Cola, Battery)?
$\square \mathrm{Ja}$
$\square$ Nei 
Synet på meg selv

$\underline{\text { Hva synes du om følgende påstander? (sett ett kryss per linje) }}$

45.1 Jeg klarer alltid å løse problemer dersom jeg prøver hardt nok Ikke riktig $\quad \square$ Litt riktig $\quad \square_{\text {Nokså riktig }} \quad \square_{\text {Helt riktig }}$

45.2 Hvis noen motarbeider meg, finner jeg en måte å oppnå det jeg vil på
Ikke riktig $\square_{\text {Litt riktig }}$

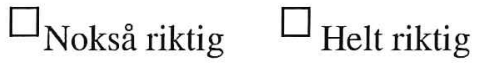

45.3 Jeg er sikker på at jeg kan mestre uventede hendelser

$\square$ Ikke riktig $\quad \square_{\text {Litt riktig }} \quad \square_{\text {Nokså riktig }} \quad \square_{\text {Helt riktig }}$

45.4 Jeg er rolig når jeg møter vanskeligheter, fordi jeg stoler på min evne til å klare meg
Ikke riktig
$\square$ Litt riktig
$\square_{\text {Nokså riktig }}$
$\square$ Helt riktig

45.5 Dersom jeg er i knipe, finner jeg vanligvis en løsning

$\square$ Ikke riktig $\quad \square_{\text {Litt riktig }} \quad \square_{\text {Nokså riktig }} \quad \square_{\text {Helt riktig }}$

Hvor enig er du i følgende påstander? (sett ett kryss per linje)

$46.1 \quad$ Jeg har en positiv holdning til meg selv
Svært enig $\quad \square_{\text {Enig }}$
$\square$ Uenig
$\square$ Svært uenig

46.2 Jeg føler meg virkelig ubrukelig til tider
Svært enig
$\square$ Enig
$\square$ Uenig
$\square$ Svært uenig

46.3 Jeg føler at jeg ikke har mye å være stolt av
Svært enig
$\square$ Enig
Uenig
$\square$ Svært uenig

46.4 Jeg føler at jeg er en verdifull person, $i$ alle fall på lik linje med andre
Svært enig
$\square$ Enig
Uenig
$\square$ Svært uenig

Hvordan synes du selv at du har det for tiden?

47.0 Vil du si at du har det (sett ett kryss)

Svært bra Bra Litt opp og ned Dårlig Svært dårlig




\section{Familie, venner og fremtid}

48.0 Hvor er du og dine foreldre født?

$\begin{array}{lccl}\text { Jeg er født i } & \text { Norge } & \text { Annet land } & \text { Hvilket land: } \\ \text { Far er født i } & \square & \square & \\ \text { Mor er født i } & \square & \square & \end{array}$

49.0 Hvem bor du sammen med nå (søsken og halvsøsken ikke medregnet)? (sett bare ett kryss)

Mor og far som bor sammen

Enten mor eller far

Omtrent like mye hos mor og far

Andre

50.0 Jeg tror vår familie, sett i forhold til andre i Norge, har (sett bare ett kryss)

Dårlig råd

Middels råd

God råd

\section{Svært god råd}

51.0 Har du jobb utenfor hjemmet?

$\mathrm{Ja}$, timer per uke

52.0 Hvor mange venner har du som du er fortrolig med eller kan snakke med om ulike problemer? (angi ofor ingen)

53.0 Hvor mange venner har du som du er sammen med relativt regelmessig, men som du $\underline{\mathrm{ikke}}$ er fortrolig med eller kan snakke med om ulike problemer? (angi 0 for ingen) 
54.0 Hva er den høyeste utdanning du har tenkt å ta? (sett bare ett kryss)

$\square$ Videregående opplæring, yrkesfaglig utdanningsprogram

$\square$ Videregående opplæring, studieforberedende utdanningsprogram

$\square$ Universitet eller høgskole

Annet

$\square$ Har ikke bestemt meg

Takk for at du svarte på alle spфrsmålene 
Plansje med bilde av de fleste pakninger reseptfri smertestillende medisin

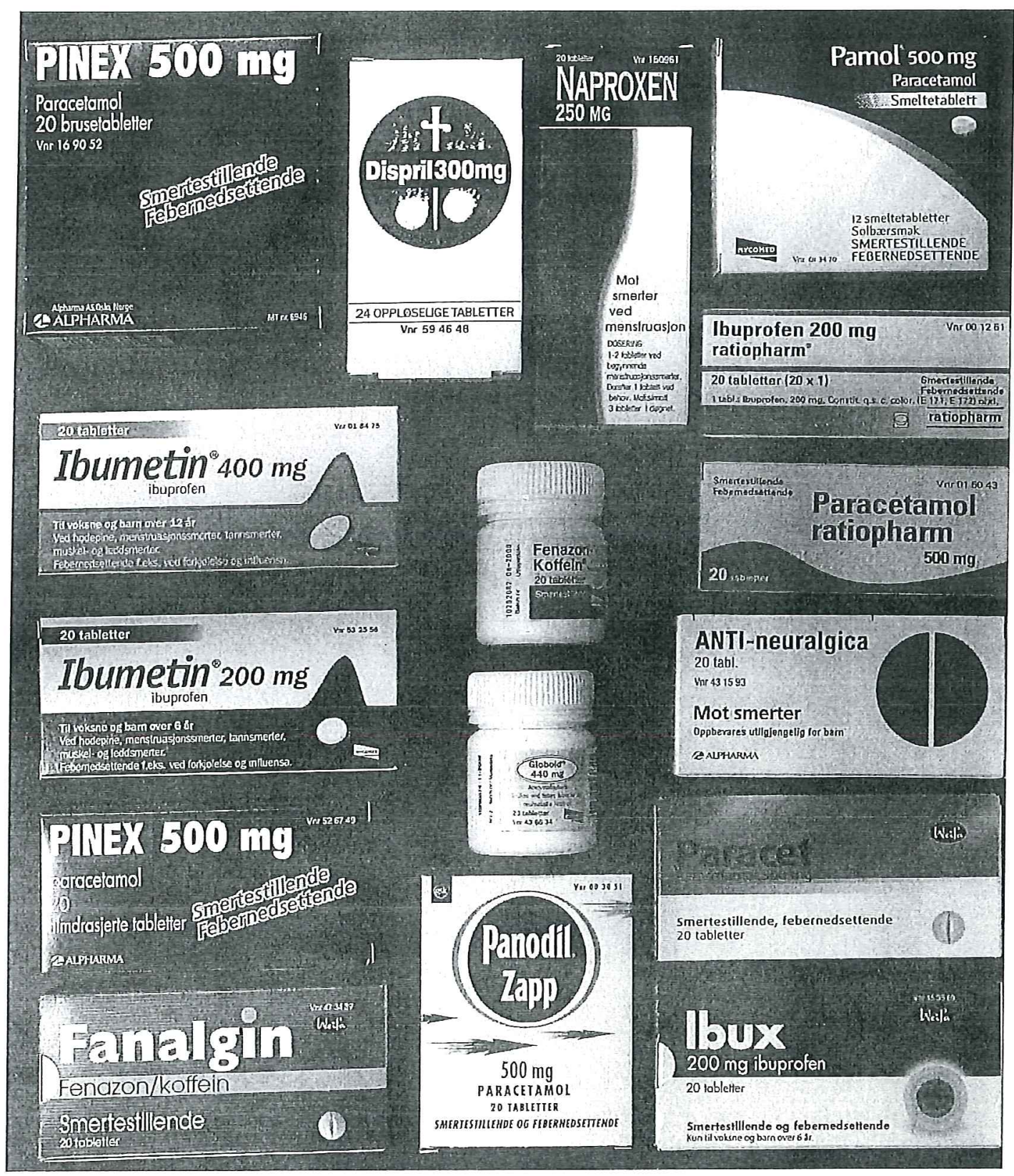





\section{Appendix 2}

\section{Ungdom: smerte og bruk av reseptfrie smertestillende medisiner Intervjuguide for ungdom:}

Intervjuene vil gjennomføres som samtaler, der den intervjuedes refleksjoner om tematikken fokuseres. Påfølgende intervjuguide er kun et redskap for å stimulere til refleksjon og gi retning for samtalene.

\subsection{Generelle spørsmål}

Kan du fortelle om livet ditt (relasjoner, familie, venner, skole, aktiviteter, matvaner, søvn, konflikter, rusmidler, røyking, fremtidsplaner, smerte, )?

På en skala fra 1 til 10 hvor 10 er veldig bra, hvordan vil du si at du har hatt det i livet? Evt. hva kunne vært annerledes for at du skulle skåret høyere?

Hvilke utfordringer vil du fremheve?

Hvis du kunne endre på noe i livet ditt, hva ville du da gjort?

\subsection{Spørsmål relatert til smerte}

Kan du fortelle meg om din opplevelse av smerte (når, hvor, hvor ofte, i hvilke situasjoner)?

Hvordan påvirker smertene deg i dagliglivet?

Hva gjør du for å mestre smerte?

Kan du gi meg noen eksempler på hva du gjør når en vanlig dag kjenner at du kan få vondt? 
Hva tror du smertene kan skyldes?

Hvem kjenner til at du har smerter?

Har du noen hjulpet deg med smerteplagene (når, hvem, hva førte det til)?

\subsection{Spørsmål relatert til bruk av reseptfrie smertestillende medikamenter}

Kan du fortelle meg om din bruk av smertestillende medikamenter (type, når, hvor ofte, i hvilke situasjoner, når startet du, hvem har lært deg hvordan du skal bruke medikamentene, kjenner du til virkninger og bivirkninger, har du erfaringer med bivirkninger - beskriv? Hvem kjenner til medikamentbruken og når du startet med smertestillende medisiner? Hvordan får du tak i smertestillende. Har du brukt reseptbelagte smertestillende medisiner?

Hvilke betydning har medikamenter i din hverdag?

Har du erfaring med andre måter å mestre smerte på, enn å bruke smertestillende medikamenter?

$>$ Hva ville du gjøre dersom det ikke fantes smertestillende medikamenter?

\subsection{Spørsmål relatert til mestring}

Hva tenker du om å møte nye utfordringer, problemer og nye mennesker?

Kan du fortelle om sist du følte du mestret en utfordrende situasjon på en svært god måte? Hva føler du når du lykkes i noe som er viktig for deg?

Kan du beskrive noen situasjoner / sammenhenger / aktiviteter der du føler du lykkes, evt også ser at andre lykkes?

Hvordan vil du beskrive deg selv i forhold til å møte store utfordringer? 


\subsection{Spørsmål relatert til livskvalitet?}

Er det noe annet enn det vi har snakket om som plager deg og som gir deg en redusert

livskvalitet?

Hvordan er humøret ditt vanligvis?

Er det noe du gjerne ville forandre ved deg selv?

Dersom det som plaget deg mest var borte, hva ville du da gjøre?

Kjenner du til selvskading. Kjenner du noen som driver med selvskading. Har du anker om dette $\mathrm{i}$ forhold til deg selv?

Har du noen tenkt at du ikke orker leve. Evt har du tenkt på selvmord / evt gjort selvmordsforsøk?

\subsection{Avsluttende spørsmål}

Er det noe viktig som ikke er nevnt?

Hvordan har samtalen vært for deg?

Dersom du var intervjuer, hva ville du da eventuelt ha gjort annerledes? 



\section{Appendix 3}

\section{Ungdom: smerte og bruk av reseptfrie smertestillende medisiner}

\section{Intervjuguide for foreldre:}

Intervjuene vil gjennomføres som samtaler, der den intervjuede i størst mulig grad får komme frem med egne refleksjoner. Påfølgende intervjuguide er et redskap for å stimulere til refleksjon og gi retning for samtalen.

\subsection{Generelle spørsmål}

Du/dere har tilbudt dere å delta i denne studien på bakgrunn av at barnet ditt bruker reseptfrie smertestillende medikamenter. Jeg vil gjerne høre om de refleksjonene du hadde i forkant og som gjorde at du ønsket å bidra. Har du gjort deg noen tanker om hva som er særlig sentralt å formidle til oss.

Er det utfordringer og/eller viktige hendelser du vil fremheve som kan påvirke livskvaliteten til barnet ditt? (familie, venner, skole, aktiviteter, matvaner, søvn, konflikter, fremtidsplaner)

\subsection{Spørsmål/tema relatert til smerte}

Kan du beskrive utviklingen av smerteplagene til barnet ditt? (Når startet det, hvordan artet det seg)?

Hva tror du om smertene i forhold til barnet ditt sin utvikling og dagligliv? 
Har du tanker om hva som kan forårsake og utløse smertene?

Har dere fått hjelp for smerteplagene (hvem, når, hvilke type hjelp, effekt)

Har du eller andre i familien eller slekten som har hatt lignende plager? Har du gjort deg noen refleksjoner om dette?

\subsection{Spørsmål relatert til bruk av reseptfrie smertestillende medikamenter}

Kan du fortelle meg om ditt barns bruk av reseptfrie smertestillende medikamenter (når, hvor ofte, i hvilke situasjoner)?

Hva gjør du/dere når barnet har vondt?

Kjenner du til om andre i nærmeste familie også bruker smertestillende ofte og kan du i så fall dele din kjennskap om dette?

Hvilke refleksjoner har du gjort deg om hva som gir eller kunne ført til redusert bruk av smertestillende medikamenter hos barnet?

\subsection{Spørsmål relatert til mestring}

Hvordan opplever du at barnet ditt takler nye utfordringer, nye situasjoner, sosiale settinger og /eller problemer.

Hvordan reagerer barnet ditt i vanskelige situasjoner?

Hvordan reagerer barnet ditt når det lykkes med en utfordrende oppgave?

Deltar barnet i aktiviteter der det selv lykkes og opplever at andre jevnaldrende lykkes? 


\subsection{Avsluttende spørsmål}

Er det noe annet vedrørende barnets livskvalitet som er viktig å formidle?

Er det noe annet som burde vært tatt opp i intervjuet?

Hvordan har intervjuet vært for deg, eventuelt hva kunne vært annerledes? 



\section{Appendix 4}

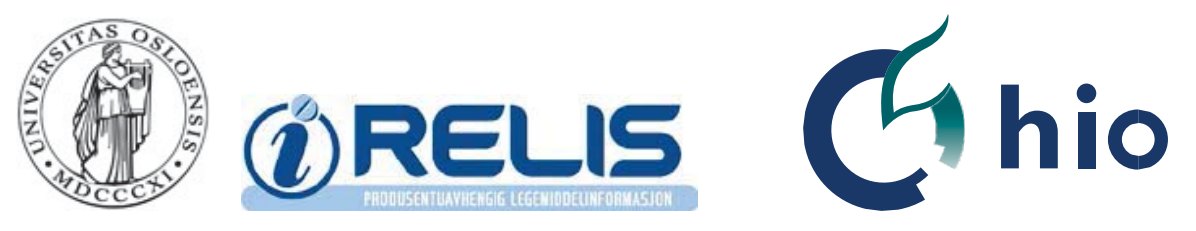

\section{TIL ELEVENE}

\section{Deltakelse i undersøkelsen "Smerte, Ungdom og selvmedisinering (SUS)"}

Hva vil vi?

Salgstall for reseptfrie smertestillende legemidler viser at forbruket $\varnothing \mathrm{ker}$. Vi mener det er viktig å få vite om dette er medisiner dere bruker og i tilfelle hvorfor, og hvilken kunnskap dere har om dem. For bedre å forstå hvorfor noen av dere bruker smertestillende, $\varnothing$ nsker vi å vite mer om ungdommers hverdagsliv og utfordringene ved å være tenåring.

Hva ber vi deg om?

Vi ber deg besvare et spørreskjema som vil bli delt ut i en skoletime. I undersøkelsen spør vi om hvor ofte du bruker smertestillende, grunnene til dette, din holdning til bruk av slike midler, opplevelse av egen helse, fritidsaktiviteter og vanlige forhold som søvn, mat og drikke.

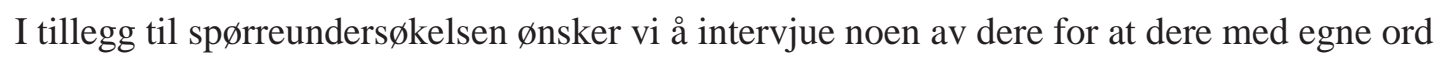
kan fortelle om ungdom og smerte. Vi vil snakke med omtrent like mange gutter som jenter med både norsk og ikke-norsk bakgrunn. Dersom du kan tenke deg å delta ber vi deg om å oppgi ditt mobilnummer. Vi vil da kunne kontakte deg på et senere tidspunkt for intervju. Intervjuet skjer på skolen, i skoletiden og vil ta ca en time. Du kan når som helst trekke seg fra å bli intervjuet.

\section{Hvem er vi?}

Vi er lege, helsesøster og farmasøyt av bakgrunn. Vi jobber innen offentlig helsevesen og med utdanning av helsepersonell. Fokus i dette prosjektet er ungdom, og hvilket forhold dere har til bruk av reseptfrie smertestillende medisiner. Studien utgår fra Universitetet i Oslo, Institutt for allmenn- og samfunnsmedisin, Regionalt Legemiddelinformasjonssenter på Rikshospitalet og Høgskolen i Oslo, Avdeling for sykepleierutdanning. Stiftelsen til fremme av norsk apotekfarmasi dekker noe av utgiftene til studien.

Får du vare anonym?

Etter retningslinjer for forskning er vi pålagt å be om skriftlig samtykke fra dere som vil delta. Din underskrift vil ikke knyttes til unders $\emptyset$ kelsen som foregår anonymt. På spørreskjema og ved eventuelt intervju skal du ikke oppgi navnet ditt. Intervjuet vil bli tatt opp på lydbånd. Etter at intervjuet er avsluttet vil vi ved å høre på opptaket skrive det ut som tekst, for så å gjennomgå hva som ble sagt. Når arbeidet er avsluttet vil opptakene slettes. 
Det er frivillig å delta.

Det er selvfølgelig frivillig å delta i undersøkelsen. Dersom du ikke ønsker å delta vil det ikke få konsekvenser for deg eller for forholdet ditt til skolen, lærerne eller karakterer, og den oppfølging du som elev får fra skolen eller skolehelsetjenesten.

Dersom det er noe du lurer på eller har behov for mer informasjon kan du ta kontakt med oss.

Per Lagerløv, prosjektleder/førsteamanuensis ved Universitetet i Oslo. Mobil 93421141

\section{TIL FORELDRE / FORESATTE}

\section{Spørsmål om samtykke til at ditt barn kan delta i en spørreundersøkelse om "Smerte, ungdom og selvmedisinering (SUS)"}

Vi er en gruppe bestående av lege, helsesøster og farmasøyt som arbeider innen offentlig helsevesen og med utdanning av helsepersonell. Riktig bruk av legemidler og tilpasset informasjon til befolkningen er nøkkelord for våre arbeidsfelt. Vi har i en tidligere studie unders $\emptyset \mathrm{kt}$ bruk av smertestillende legemiddel (paracetamol) til førskolebarn. Nå ønsker vi å rette fokus mot ungdomsskoleelever og hvilket forhold de har til bruk av reseptfrie smertestillende medisiner. Studien utgår fra Universitetet i Oslo, Institutt for allmenn- og samfunnsmedisin, Regionalt Legemiddelinformasjonssenter på Rikshospitalet og Høgskolen i Oslo, Avdeling for sykepleierutdanning. Stiftelsen til fremme av norsk apotekfarmasi dekker noe av utgiftene til studien.

Salgstall for smertestillende legemidler viser at forbruket $\emptyset$ ker. En ny unders $\varnothing$ kelse har vist at annenhver jente og hver fjerde gutt i alderen 15 - 16 år har brukt slik medisin i løpet av en måned. Men fortsatt vet vi lite om hvorfor og hvordan ungdom bruker smertestillende. Derfor vil vi kartlegge forhold rundt tenåringers bruk av reseptfrie smertestillende medisin.

Vi skal gjennomføre en spørreundersøkelse på skolen der din sønn/datter er elev. I undersøkelsen blir det spurt om hvor ofte eleven har brukt smertestillende, hva som var grunnen til dette, elevens holdning til bruk av slike midler, opplevelse av egen helse, fritidsaktiviteter og vanlige forhold som søvn, mat og drikke.

Undersøkelsen foregår anonymt. Det vil si at sønnen/datteren din ikke skal oppgi navn. Opplysningene som gis på spørreskjema vil ikke kunne spores tilbake til eleven.

I tillegg til spørreundersøkelsen ønsker vi å intervjue et lite utvalg av elever for å komme nærmere inn på deres oppfatninger om smerte. I dette utvalget bør det være like mange gutter som jenter med både norsk og ikke-norsk bakgrunn. De elever som kan tenke seg å delta blir bedt om å oppgi mobiltelefonnummer. Vi vil da kunne kontakte eleven på et senere tidspunkt for intervju. Eleven kan når som helst trekke seg fra å bli intervjuet. 
Deltakelse i undersøkelsen er selvsagt frivillig, og ungdommene vil få skriftlig og muntlig informasjon om prosjektet før de tar stilling til om de vil delta. Dersom du ikke $\emptyset$ nsker at din sønn/datter skal delta vil ikke det få noen konsekvenser for karakterer, forhold til lærere eller den oppfølging han/hun får fra skolen eller skolehelsetjenesten.

Dersom du synes det er greit at din sønn/datter deltar i undersøkelsen om ungdoms bruk av reseptfrie smertestillende legemidler, ber vi deg fylle ut nedenstående slipp og sende den med eleven på skolen.

Per Lagerløv (prosjektleder) førsteamanuensis i allmennmedisin, dr. med.

Universitetet i Oslo Tlf: 22850660 (mobil 934211 41).per.lagerlov@ medisin.uio.no

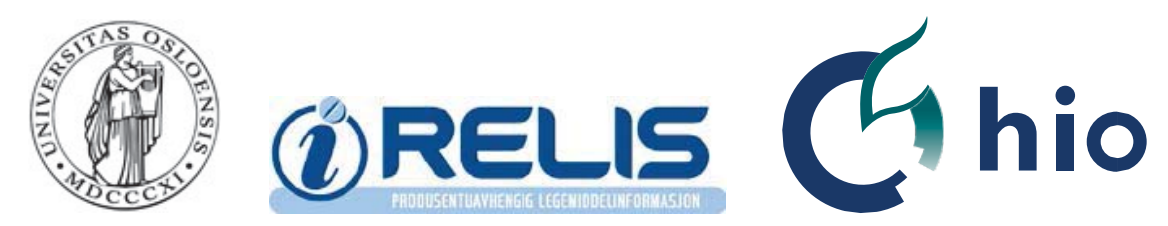

\section{Samtykkeerklæring}

\section{FOR ELEVEN}

Jeg vil delta på spørreunders $\emptyset$ kelsen for prosjektet

"Smerte, Ungdom og selvmedisinering (SUS)".

Jeg har fått informasjon om hva undersøkelsen går ut på, og kjenner mine rettigheter knyttet til frivillighet.

\section{ELEVENS NAVN}

KLASSE SKOLE

Jeg er villig til også å delta på intervju, og kan kontaktes på følgende mobilnummer:

Mobiltelefon

Jeg er

Foreldres morsmål er norsk
Gutt Jente

norsk / utenlandsk $\square$ utenlandsk 


\section{FOR FORELDRE / FORESATTE}

Jeg gir med dette samtykke til at min sønn/datter kan delta i undersøkelsen i forbindelse med prosjektet "Smerte, ungdom og selvmedisinering (SUS)"

Jeg er kjent med hva prosjektet går ut på og vet at dersom jeg ikke gir min sønn/datter samtykke til å delta påvirker det ikke på noen måte forholdet til skolen. 


\section{Appendix 5}

\section{Forespørsel om og samtykke på deltakelse i forskningsprosjektet:}

\section{Ungdom - smerte og bruk av reseptfrie smertestillende medisiner}

Vi vet at mange ungdommer sliter med smerteplager. Årsaker og sammenhenger synes å være sammensatte og det er fortsatt mye vi ikke vet om dette. For å få mer kunnskap slik at vi kan utvikle tiltak for å hjelpe ungdommer i lignende situasjoner, spør vi deg som ungdom og dere som foreldre om å delta denne forskningsstudien.

Målet med studien er å få økt kunnskap om hvordan ungdom i alderen 14 - 16 år opplever utfordringer i dagliglivet, smerteplager og sammenhenger knyttet til bruk av reseptfrie smertestillende medisiner, slik at hjelpetiltak kan utvikles.

Vi ønsker å snakke med ungdom som har erfaring med bruk av reseptfrie smertestillende medisiner med et daglig eller ukentlig forbruk i en lengre periode, dvs mer enn 4 uker sammenhengende. Ungdommen skal ikke ha en kjent lidelse, diagnose eller akutt skade som er under profesjonell medisinsk smertebehandling.

Studien er et samarbeid mellom forskere ved Avdeling for Sykepleierutdanning ved Høgskolen i Oslo og Akershus og Avdeling for allmenn- og samfunnsmedisin ved Universitet i Oslo.

Studien vil basere seg på intervjuer med ungdom og foreldre. Intervjuene vil ha form av samtaler der forskeren følger en huskeliste med stikkord. Dette skal sikre at vi får snakket om sentrale temaer. Forsker vil snakke med ungdom og foreldre hver for seg. I intervjuene er kun den som intervjues og forskeren til stede. Intervjuene vil anslagsvis ta mellom 30 og 60 minutter. Tid og sted avtales med den enkelte deltager.

En fordel ved å delta i studien er at den som deltar får fortelle om sine opplevelser og erfaringer knyttet til utfordringer i hverdagen, smerter og bruk av reseptfrie smertestillende. Ved å dele 
erfaringene deres med oss, så kan dette bidra til at andre unge kan få mer tilrettelagt hjelp. En mulig ulempe ved deltagelse er at det må avsette tid til intervjuet.

\section{Frivillig deltakelse}

Det er frivillig å delta i studien. Deltagerne kan når som helst og uten å oppgi grunn trekke sitt samtykke til å delta i studien. Dersom dere ønsker å delta, undertegner dere samtykkeerklæringen på siste side og leverer denne til forsker. Samtykke innebærer at dere også godkjenner å kontakte helsesøster dersom det kommer frem at det er alvorlig fare for liv og helse. Dere får en kopi av den signerte erklæringen.

\section{Anonymisering}

Informasjonen som registreres om deltakerne skal kun brukes slik som beskrevet $\mathrm{i}$ hensikten med studien. Alle opplysningene vil bli behandlet uten navn og fødselsnummer eller andre direkte gjenkjennende opplysninger. En kode knytter deltakeren til sine opplysninger gjennom en navneliste. Det er kun prosjektleder og en prosjektmedarbeider som har adgang til navnelisten og som kan finne tilbake til deltakeren. Alle lydfiler avidentifiseres og dette betyr at det ikke vil være navn på lydopptakene som lagres. Opptakene lagres på en ekstern harddisk, innelåst $\mathrm{i}$ en safe. Kun vi forskere vil ha adgang til lydfilene. Lydfilene slettes ved avslutning av prosjektet, senest fire år etter at siste intervju er gjennomført. Det vil ikke være mulig å identifisere deltagere i studien når resultatene publiseres.

\section{Rett til innsyn og sletting av opplysninger}

Hvis dere sier ja til å delta i studien, har dere rett til å få innsyn i hvilke opplysninger som er registrert om dere. Dere har videre rett til å få korrigert eventuelle feil i de opplysningene vi har registrert. Dersom dere senere i løpet av studien skulle ønske å trekke dere, kan dere kreve å få slettet opplysninger, med mindre disse allerede er inngått $i$ analyser eller brukt $i$ vitenskapelige publikasjoner.

\section{Økonomi}

Studien finansieres i sin helhet av Høgskolen i Oslo. Deltagelsen er kostnadsfri. 


\section{Kontaktpersoner}

Dersom dere har spørsmål til studien eller senere ønsker å trekke dere, kan skolehelsesøster eller en av disse kontaktes:

Professor Sølvi Helseth: tlf: 224537 73, mail: solvi.helseth@hioa.no

Doktorgradskandidat, høgskolelektor: Siv Skarstein: tlf: 48179218, mail siv.skarstein@hioa.no

\section{Samtykke til deltakelse i studien: Ungdom - smerte og bruk av reseptfrie} smertestillende medikamenter

\section{Signert samtykke fra ungdommen til egen deltagelse i studien}

Jeg ønsker å delta i studien

(Signert av ungdom, dato, sted)

\section{Foreldre/foresatte sitt samtykke til ungdommens deltagelse i studien}

Vi samtykke til at vår ungdom kan delta i studien (gjelder ungdom under 16 år):

\begin{tabular}{|l|l|}
\hline JA & NEI \\
\hline
\end{tabular}

(Signert av forelder eller foresatt, sted, dato)

\section{Samtykke til egen deltagelse i studien fra forelde/foresatte}

Jeg/vi ønsker å delta i studien:

\begin{tabular}{|l|l|}
\hline JA & NEI \\
\hline
\end{tabular}

(Signert av foreldre eller foresatt, sted, dato) 